\title{
Moving to Greater Exchange Rate Flexibility Operational Aspects Based on Lessons from Detailed Country Experiences
}

Inci Ötker-Robe and David Vávra, and a team of economists
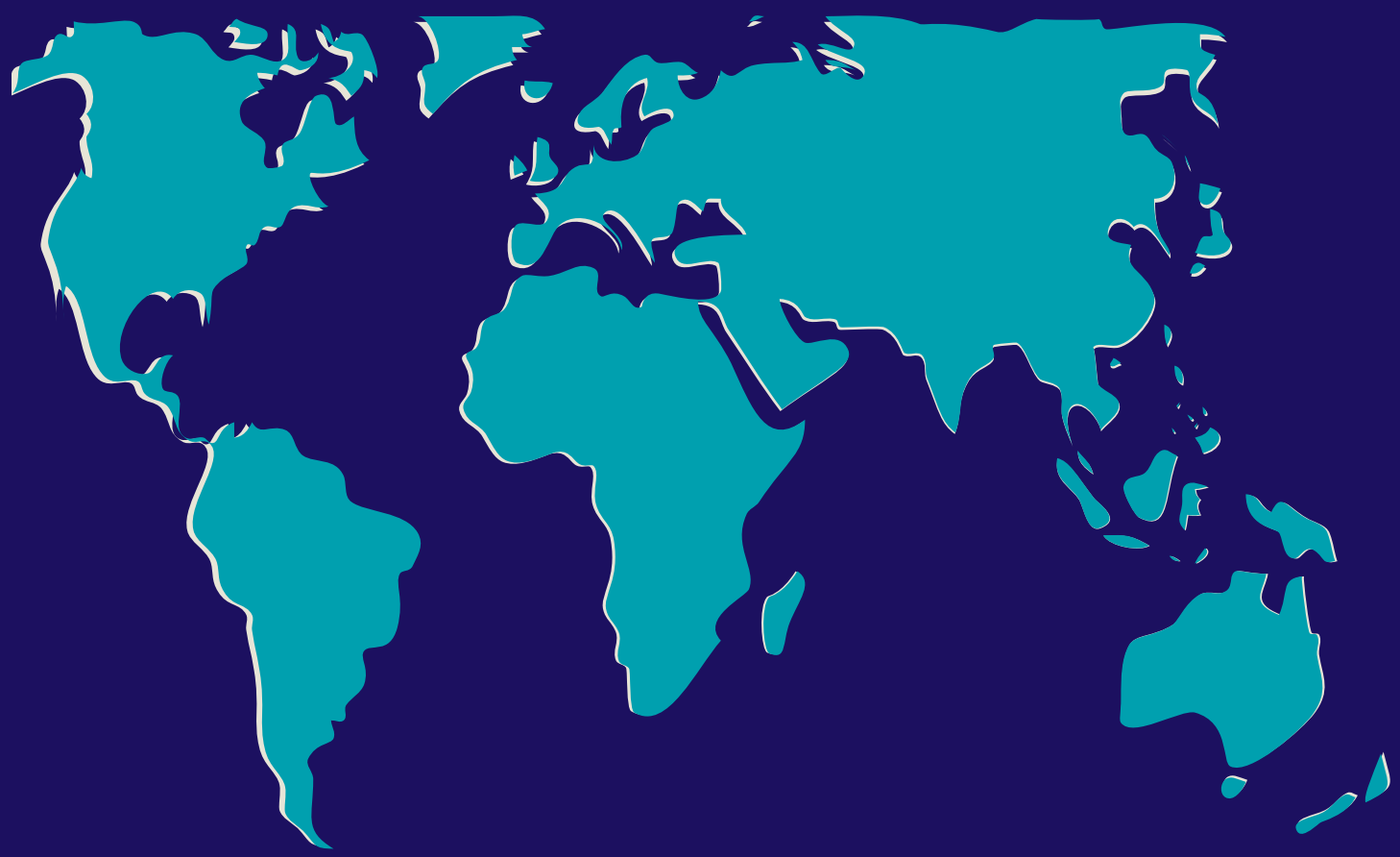

INTERNATIONAL MONETARY FUND 


\section{Moving to Greater Exchange Rate Flexibility Operational Aspects Based on Lessons from Detailed Country Experiences}

Inci Ötker-Robe and David Vávra, and a team of economists 
(C) 2007 International Monetary Fund

Production: IMF Multimedia Services Division

Typesetting: Alicia Etchebarne-Bourdin

Figures: Bob Lunsford

Ötker, Inci.

Moving to greater exchange rate flexibility : operational aspects based on lessons from detailed country experiences / Inci Ötker-Robe and David Vávra, and a team consisting of Luis Ahumada ... [et al.]. - Washington, DC : International Monetary Fund, 2007.

p. cm. - (Occasional paper ; 256)

Includes bibliographical references.

ISBN 978-1-58906-624-3

1. Foreign exchange administration - Case studies. 2. Foreign exchange rates - Case studies. 3. Monetary policy - Case studies. I. Vávra, David, 1972- II. International Monetary Fund. III. Occasional paper (International Monetary Fund) ; no. 256 HG3851 .0854 2007

Price: US $\$ 30.00$

(US\$28.00 to full-time faculty members and students at universities and colleges)

Please send orders to:

International Monetary Fund, Publication Services 700 19th Street, N.W., Washington, D.C. 20431, U.S.A.

Tel.: (202) 623-7430 Telefax: (202) 623-7201

E-mail: publications@imf.org

Internet: http://www.imf.org 


\section{Contents}

Preface

Abbreviations

Part I. The Overall Framework and Synthesis of Country Experiences

I. Overview

II. Country Experiences with Transition to Greater Flexibility: Operational Aspects Underpinning Durable Exits

The Nature and Pace of the Exits

Factors that Triggered the Move to Greater Flexibility

Coordination of Transitions with the Supporting Elements of a Floating Regime

Challenges Faced in the Transition to Greater Flexibility

Conclusions and Lessons from the Country Experiences

\section{Part 2. Detailed Country Experiences}

III. Orderly Transitions

Chile (1984-99)

Israel (1985-2005)

Poland (1990-2000)

IV. Disorderly Transitions

Brazil (1999)

Czech Republic (1996-97)

Uruguay (2002)

\section{Appendixes}

I. From Fixed to Float: Operational Ingredients of Durable Exits to Flexible Exchange Rates

II. Experiences with Short-Lived Exits to Greater Flexibility

III. Ukraine: An Example of Ongoing Cautious Steps toward Greater Exchange Rate Flexibility

IV. Foreign Exchange Hedging, Complementary Markets, and the Role of the Central Bank

\section{Boxes}

1. Fixed to Float: Operational Ingredients of Durable Exits to Flexible Exchange Rates 
2. Czech Republic: The Condition of the Financial System

\section{Tables}

1. Country Experiences with Transition from Pegged to Flexible Regimes: Nature of the Exits

2. Country Experiences with Transition from Pegged to Flexible Regimes:

Motivation and Triggers of Exit

3. Extent of Preparedness for Transitioning to Greater Flexibility: Before the Full Float

4. Country Experiences with Transition from Pegged to Flexible Regimes:

Sequencing with Supporting Elements

5. Extent of Preparedness for Transitioning to Greater Flexibility: Before

Moving to a More Flexible Peg

6. Evolution of Chile's Exchange Rate Regime since 1984

7. Evolution of Israel's Exchange Rate Regimes, 1985-2005

8. Evolution of Poland's Exchange Rate Regime since 1990

9. Evolution of Uruguay's Exchange Rate Regime, 1990-2005

\section{Figures}

1. Addressing the Fear of Floating

2a. Exchange Rate Regime Evolutions: Gradual Orderly Exits

2b. Exchange Rate Regime Evolutions: Fast Disorderly Exits

3. Sequencing of Transitions with Supporting Elements: Gradual Orderly Exits

4. Sequencing of Transitions with Supporting Elements: Fast Disorderly Exits

\section{Appendix Box}

A1. The Bank of Israel's Role in Developing Foreign Exchange and Complementary Markets

\section{Appendix Figure}

A1. Preparing for an Orderly Exit from a Peg

The following conventions are used in this publication:

- In tables, a blank cell indicates "not applicable," ellipsis points ( . . ) indicate "not available," and 0 or 0.0 indicates "zero" or "negligible." Minor discrepancies between sums of constituent figures and totals are due to rounding.

- An en dash (-) between years or months (for example, 2005-06 or January-June) indicates the years or months covered, including the beginning and ending years or months; a slash or virgule (/) between years or months (for example, 2005/06) indicates a fiscal or financial year, as does the abbreviation FY (for example, FY2006).

- "Billion" means a thousand million; "trillion" means a thousand billion.

- "Basis points" refer to hundredths of 1 percentage point (for example, 25 basis points are equivalent to $1 / 4$ of 1 percentage point).

As used in this publication, the term "country" does not in all cases refer to a territorial entity that is a state as understood by international law and practice. As used here, the term also covers some territorial entities that are not states but for which statistical data are maintained on a separate and independent basis. 


\section{Preface}

Many countries moved toward more flexible exchange rate regimes over the past decade, which reflects in part the belief that more flexible exchange rates provide a greater degree of monetary policy autonomy and flexibility in responding to external shocks, including large and volatile capital flows. There has often been a reluctance to let go of pegged exchange rates despite the benefits of flexible rates. The extensive institutional and operational requirements needed to support a floating exchange rate as well as difficulties in assessing the right time and manner to exit tend to be additional factors in this reluctance. This paper presents the concrete steps taken by certain countries in transitioning to greater exchange rate flexibility, with a view to elaborating on the operational ingredients that proved helpful in promoting successful and durable transitions. It attempts to provide a better understanding of how these various operational ingredients were established and coordinated with the exits, how their implementation interacted with macro and other conditions, and how they contributed to the smoothness of the exits.

The material in this paper was originally prepared in connection with a workshop on moving to greater exchange rate flexibility conducted in Ukraine in April 2005. The detailed case studies prepared subsequently also aimed at providing a follow-up to a discussion by the International Monetary Fund's (IMF) Executive Board in December 2004 on "From Fixed to Float: Operational Aspects of Moving Toward Exchange Rate Flexibility" (IMF, 2004b). In concluding the discussion, Directors asked for more guidance on the sequencing and order of importance of the operational elements, backed by analysis of more specific country experiences and cross-country studies.

The detailed country case studies and their syntheses were prepared by a team of experts under the guidance and direction of İnci Ötker-Robe, former Technical Assistance Wing, Europe, of the Monetary and Capital Markets Department (MCM). The experts, Luis Ahumada, Fernando Barrán, André Minella, Zbigniew Polański, Piotr Szpunar, Barry Topf, and David Vávra, are on the staff of the central banks of a number of countries that moved from various forms of pegged exchange rate regimes to floating exchange rates. The team collaborated closely with the former Exchange Regimes and Exchange Regime and Debt and Reserve Management Division (ER) of MCM, where the "Fixed to Float" paper (IMF, 2004a) had been prepared, in particular with Udaibir Das, Christian Mulder, and Eva Petrova. Neil Saker and Jahanara Zaman of ER contributed to two of the appendixes of this paper. Graham Colin-Jones provided editorial support and Maria Delia M. Araneta provided secretarial support. Sean Culhane of the External Relations Department edited the manuscript and coordinated the production of the publication.

The paper has benefited from comments of colleagues in MCM and in other departments of the IMF, and of Eduardo Loyo, Executive Director for Brazil. The views expressed in this paper are those of the IMF staff and do not necessarily reflect the views of national authorities or IMF Executive Directors.

Jaime Caruana

Director

Monetary and Capital Markets Department 



\section{Abbreviations}

$\begin{array}{ll}\text { ACI } & \text { Financial Markets Association } \\ \text { BCU } & \text { Central Bank of Uruguay } \\ \text { BoI } & \text { Bank of Israel } \\ \text { CBB } & \text { Central Bank of Brazil } \\ \text { CBC } & \text { Central Bank of Chile } \\ \text { CFA } & \text { certified financial analyst } \\ \text { CNB } & \text { Czech National Bank } \\ \text { Copom } & \text { Monetary Policy Committee (Brazil) } \\ \text { CPI } & \text { consumer price index } \\ \text { EU } & \text { European Union } \\ \text { FX } & \text { foreign exchange } \\ \text { ISDA } & \text { International Swap Dealers Association } \\ \text { IT } & \text { inflation targeting } \\ \text { LTCM } & \text { Long-Term Capital Management } \\ \text { MPC } & \text { Monetary Policy Council (Poland) } \\ \text { NBP } & \text { National Bank of Poland } \\ \text { NBU } & \text { National Bank of Ukraine } \\ \text { NDF } & \text { nondeliverable forward } \\ \text { NIS } & \text { New Israel sheqel } \\ \text { OTC } & \text { over the counter } \\ \text { PPP } & \text { purchasing power parity } \\ \text { TA } & \text { technical assistance }\end{array}$





\section{Part I \\ The Overall Framework and Synthesis of Country Experiences}





\section{Overview}

M any countries moved toward more flexible exchange rate regimes over the past decade. 1 Among the factors underlying the move to greater flexibility has been the belief that more flexible exchange rates provide a greater degree of monetary policy autonomy and flexibility in responding to external shocks, including large and volatile capital flows. Flexible exchange rates have been expected to (1) reduce one-way bets against currencies, thereby discouraging short-term capital inflows that can be easily reversed; (2) discourage a buildup of large unhedged foreign currency positions by reducing the implicit exchange rate guarantees implied by pegged and tightly managed exchange rates; and hence (3) stimulate prudent risk management and foreign exchange (FX) market development as market participants seek to hedge against potentially greater exchange rate risks.

\footnotetext{
${ }^{1}$ See Eichengreen and others (1998), Fischer (2001), and literature cited therein.
}

There is often a reluctance to let go of pegged exchange rates despite these benefits (the so-called fear of floating). Policymakers tend to keep the pegs, reflecting, in general, the perceived costs of exchange rate volatility related to (1) concerns about losing policy credibility; (2) adverse effects of a potential appreciation of the domestic currency on external balances; (3) higher inflation from exchange rate pass-through (given the limited technical and institutional capacity to implement alternative monetary policy frameworks such as inflation targeting (IT), and underdeveloped financial markets characterized by larger exchange rate fluctuations); and (4) potential losses from currency mismatches, in particular when markets and instruments to hedge against risks are limited. The difficulties in assessing the right time to exit and in determining the alternative regime to adopt tend to be additional factors in this reluctance.

Such concerns about floating hence affect the pace and manner in which countries move to greater flex-

Figure I. Addressing the "Fear of Floating"

Factors that lead to fear of floating

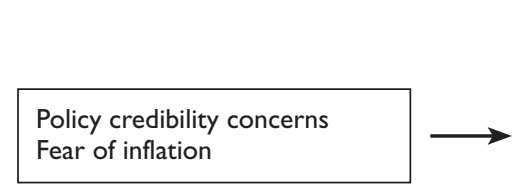

Fear of appreciation of the domestic currency and adverse impact on external balance

Fear of exchange rate losses from currency mismatches
Measures that could mitigate the factors that give rise to fear of floating

Stronger monetary policy framework with a transparent, alternative monetary anchor; operational independence of the central bank; prudent monetary and fiscal policies; reasonably well-developed, deep foreign exchange (FX) markets and appropriate intervention policies to reduce excessive exchange rate volatility

Fiscal retrenchment; structural reforms that would improve external competitiveness

Strong financial sector policies with an adequate prudential and supervisory system for FX risk management; reasonably well-developed FX and money markets to hedge risks 


\section{Box I. Fixed to Float: Operational Ingredients of Durable Exits to Flexible Exchange Rates}

This box provides a brief summary of the main points of the IMF's operational framework for moving toward exchange rate flexibility. ${ }^{1}$ This framework provides handson guidance on the institutional, operational, and technical aspects of moving toward exchange rate flexibility, presenting in turn a context for the country experiences in Part 1: Section II and Part 2.

Although the timing and priority accorded to each of these areas may vary from country to country depending on initial conditions and economic structure, the successful ingredients for floating include (1) developing a deep and liquid FX market, (2) formulating intervention policies consistent with the new exchange rate regime, (3) establishing an alternative nominal anchor in the context of a new monetary policy framework and developing supportive markets, and (4) reviewing exchange rate exposures and building the capacity of market participants to manage exchange rate risks and of the supervisory authorities to regulate and monitor them. ${ }^{2}$

Operating a flexible exchange rate regime works well only when there is a sufficiently liquid and efficient FX market for price discovery. A well-functioning FX market allows the exchange rate to respond to market forces, helps minimize disruptive day-to-day fluctuations in the exchange rate, and facilitates exchange rate

${ }^{1}$ Appendix I provides a more detailed summary, drawing on IMF (2004a and 2004b). The fixed-to-float framework was endorsed by the IMF's Executive Board in 2004, which reiterated that no single exchange rate regime is appropriate for all countries at all times (also see Eichengreen and others, 1998; and Mussa and others, 2000, on exchange rate issues).

${ }^{2}$ These are in addition to the role of sound macroeconomic and structural policies-including fiscal discipline, monetary policy credibility, and a sound financial sector-which are essential to maintaining any type of regime, fixed or floating. risk management. Developing (spot and forward) FX markets requires eliminating market-inhibiting regulations, improving the market microstructure (for example, by allowing risk-hedging instruments, simplifying FX legislation, or putting in place adequate payment and settlement systems), and increasing information flows in the market, while reducing the central bank's marketmaker role. Allowing some exchange rate flexibility is a key step in limiting what is, to some extent, an unavoidable chicken-and-egg problem: Exchange rate flexibility requires a deep market and better risk management, but a deep market and prudent risk management require flexibility. Providing for a two-way risk is also important, in fostering better management of risks and minimizing destabilizing trading strategies (and, thereby, the risk of disorderly exits).

Private sector FX risk exposure can have an important bearing on the pace of the exit, the type of flexible exchange rate regime adopted, and intervention policies, requiring a careful management of the transfer of FX risk back to the private sector and systems to monitor and manage the private sector's exposures. In managing the FX risk, the market participants need to develop analytical and information systems to monitor and measure risks in addition to internal risk management and prudential procedures. Adequate prudential and supervisory arrangements and enforcement capacity also need to be in place so that banks' direct and indirect FX exposures and related risks can be monitored. Although early investment in these elements is typically beneficial by itself, it can also help mitigate the risk of disorderly exits; having an effective FX-risk-related supervisory and prudential framework can limit contagion of financial crises. Careful development of derivatives markets for foreign exchange with appropriate safeguards is an essential element in building capacity to manage FX risks, while limiting their potential misuse for speculative activity. ibility. Some countries that put significant emphasis on preparedness for floating chose a cautious and gradual approach to greater flexibility while working on establishing the necessary supportive elements of floating rates. In other countries, authorities experienced difficulty in managing the exits that occurred under market pressure when flexible exchange rates were adopted with little preparation devoted to addressing the fears of floating. Country experiences suggest that those that work on mitigating risks associated with floating (Figure 1) can achieve a smoother exit from their pegged regimes, even when the elements supporting greater flexibility are not fully in place before the move to greater flexibility.

An earlier IMF study described the institutional, operational, and technical aspects of moving toward flexibility that are important for a successful transition (referred to henceforth as the fixed-to-float framework). The framework (provided in Duttagupta, Fernandez, and Karacadag, 2004, and subsequently endorsed by the IMF Executive Board in December 2004) concluded that for a successful transition to a floating regime, the following four "ingredients" were generally needed: (1) developing a deep and liquid FX market, (2) setting up adequate systems to review and manage exchange rate risks, (3) formulating coherent intervention policies consistent with the new regime, and (4) establishing an appropriate alternative nominal anchor in the context of the new monetary policy framework (IMF, 2004a and 2004b). This framework is summarized in Box 1.

This paper presents the concrete steps a selected number of countries took in transitioning to greater exchange rate flexibility, elaborating on the operational 
Transition to flexible exchange rates creates the need to develop a coherent intervention strategy that has specific policies on objectives of intervention. Intervention strategy becomes discretionary under a flexible exchange rate regime, so it is essential to set up well-specified intervention principles to enhance the credibility of the new regime. Whether the objective is to correct misalignments, calm disorderly markets, meet reserve targets, or supply publicly acquired foreign exchange, care needs to be taken to signal commitment to a market-determined rate and avoid excessive smoothing of short-term fluctuations. Avoiding excessive smoothing is crucial so as not to suppress the nascent markets and useful market signals and to avoid sending confusing messages about policy intentions. Transparency of intervention policies is important in building confidence in the new regime, especially after forced exits. A public commitment to the objectives and principles of intervention enables market scrutiny and accountability for FX operations.

Moving to flexible exchange rates also creates the need to replace the exchange rate with another credible nominal anchor and to redesign the monetary policy framework around the new anchor. Having a credible alternative framework is essential in stabilizing market expectations and maintaining or regaining credibility and monetary stability in the aftermath of exiting a peg or a disorderly exit. Many countries moving to flexibility in recent years have favored IT frameworks over money-targeting ones, as the effectiveness of the latter has been limited by the weak relationship between monetary aggregates and inflation. A credible alternative such as IT, however, requires extensive preparation, with substantial amount of capacity building and credibility building, and thus planning ahead for the transition is critical to achieving an orderly exit. A lengthy transition period reflects, in part, the time required to fulfill the necessary institutional requirements and macroeconomic conditions (see Eichengreen and others, 1999; IMF, 2000a and 2000b; Mishkin, 2000; Carare and others, 2002; and Fraga, Goldfajn, and Minella, 2003).

Countries planning to move to a floating regime face important questions on the pace of the exit and its sequencing with other policies, including capital account liberalization. Often, these questions involve difficult trade-offs, and considerations (including the degree of preparedness, the openness of the capital account, the macroeconomic situation, and conditions in domestic and international markets) that are often country-specific. If taken from a position of macroeconomic strength, a faster exit is beneficial in signaling determination and enhancing the credibility of monetary policy, but the speed at which relevant institutions can be built is often a main determinant of the pace at which an orderly exit can proceed. In general, early preparation for float is essential in bolstering the chances of success of the exit - gradual or rapid, with the elements taking the longest time to build (for example, capacity to operate under an alternative framework and markets) put in place first.

Clear trade-offs are involved in the sequencing of exchange rate flexibility with capital account liberalization. There are risks to opening the capital account before adopting a flexible exchange rate; many countries were forced off pegs after sudden reversals of capital flows, whereas others faced heavy inflows and appreciation pressures on their pegs. On the other hand, liberalizing the capital account can help offset transitory current account shocks, expand the instruments for risk management, and deepen the FX market, all of which are important for operating a flexible exchange rate. The transition to flexibility can in general be facilitated by removing or strengthening existing asymmetries in the openness of the capital account to support an orderly correction of misalignments (for example, by liberalizing outflows to reduce pressures from inflows and/or liberalizing long-term inflows before short-term ones). attributes that proved helpful in promoting successful transitions. It does so in the context of actual country studies, covering three countries with exits under market pressure (Brazil, Czech Republic, and Uruguay), and three countries with gradual and orderly transitions (Chile, Israel, and Poland). The particular issues addressed are how the various operational ingredients for floating identified in the fixed-to-float framework were established and coordinated with the exit, how their implementation interacted with macro and other conditions, and how these ingredients contributed to the smoothness of the exit.

The case studies cover only durable exits, to identify the factors that contributed to the durability of the transitions in the sense that the move to flexibility has not been subsequently reversed. To supplement this, Appendix II summarizes the experience of three countries with short-lived exits (Ecuador, Pakistan, and Uzbekistan), and Appendix III presents an example of an ongoing transition to a flexible regime (Ukraine). The examples in Appendix II highlight the factors undermining durable exits, and the example in Appendix III illustrates the many challenges faced in the transition process.

The paper is organized as follows: Section II in Part 1 provides a synthesis of the six country experiences in the context of the fixed-to-float framework and identifies the operational attributes that proved particularly helpful in promoting smooth and durable exits to floating regimes. Sections III and IV in Part 2 present the detailed case studies for orderly and disorderly transitions, respectively. 


\section{Country Experiences with Transition to Greater Flexibility: Operational Aspects Underpinning Durable Exits}

\begin{abstract}
$\mathrm{T}$ his section brings together the experiences of six countries to extract the common elements in moving to greater flexibility. It reviews the nature and pace of the exits and the factors underlying them, the extent to which the regime transitions were coordinated and sequenced with the supporting elements of flexible regimes, and whether and how differences in preparation affected the smoothness and durability of the exits, including whether they were gradual or fast. The case studies, presented in Sections III and IV of Part 2, illustrate in detail the particular steps and combination of operational measures the authorities took to achieve durable exits and the lessons they learned in the process.
\end{abstract}

\section{The Nature and Pace of the Exits}

Three of the six exits studied were gradual and orderly; the other three were fast and under market pressure, involving a collapse of the pegged regime. The fast exits involved a one-step move from different types of pegs-a de facto crawling peg in Brazil (1999), a horizontal band in the Czech Republic (1997), and a crawling band in Uruguay (2002) - within a period of at most six months following market pressures. Gradual exits involved a step-by-step move to a full float through increasingly more flexible pegs (Table 1 and Figure 2). The countries involved ultimately exited to a free float with explicit inflation targets (Brazil, Chile, Czech Republic, Israel, and Poland) or monetary targets (Uruguay, with a plan to adopt IT). In all gradual exits, the transition to full-fledged IT was also gradual through an initial step that involved a simultaneous pursuit of exchange rate and inflation targets. The countries with disorderly exits (except Uruguay) adopted full-fledged IT faster.

All six exits were durable, whether orderly or disorderly, in that there were no major reversals in the process of introducing exchange rate flexibility. The gradually exiting countries continued their move to a floating regime through increasingly more flexible arrangements, and the exits under pressure were not followed up with a return to pegged exchange rates. A few reversals were observed but were temporary: Chile temporarily reduced the width of the crawling band against the downward pressure on the peso in 1998, and Israel started re-intervening in 1996 in response to large capital inflows. The interventions in Brazil in 2001-02 and 2005-06 were to correct disorderly market conditions and to rebuild reserves, respectively, consistent with the stated objectives of intervention.

The gradual exits were lengthy, even though the benefits of greater flexibility had been generally recognized at an early stage. The transition to a full float took about 15 years in Chile, 20 years in Israel, and 10 years in Poland. Several adjustments to the regime parameters ${ }^{1}$ likely helped avoid disorderly exits while giving the authorities time to prepare for an orderly exit when most important supporting elements of a flexible regime had been put in place.

The slow transition process reflected, in general, the time it took to establish the elements that would mitigate the concerns about floating. Such concerns included undermining policy credibility or loss of competitiveness from potential appreciations (in all three countries), as well as pass-through to inflation and potential balance sheet effects (Chile and, in the earlier stages of the transition, Israel). As discussed in more detail below, gradual increases in exchange rate flexibility also helped the FX markets to deepen, contributing to the efforts to establish the pillars of greater flexibility.

In the countries that exited involuntarily, the benefits of floating compared with the potential complications following an exit were generally not recognized. General concerns about a return of inflation associated with the loss of a credible nominal anchor, as well as those about a loss of competitiveness (Czech Republic) and currency mismatches in a largely dollarized banking system (Uruguay), played a role in delaying the exits.

The fast disorderly exits did not enjoy a credibility benefit because they took place not from a position of macroeconomic or financial strength but in the absence of some of the crucial institutional underpinnings of a floating regime. An alternative anchor had to be found in a crisis environment, which complicated the task

${ }^{1}$ Including, for example, adjustments in the central rate, band width, and rates of crawl. 


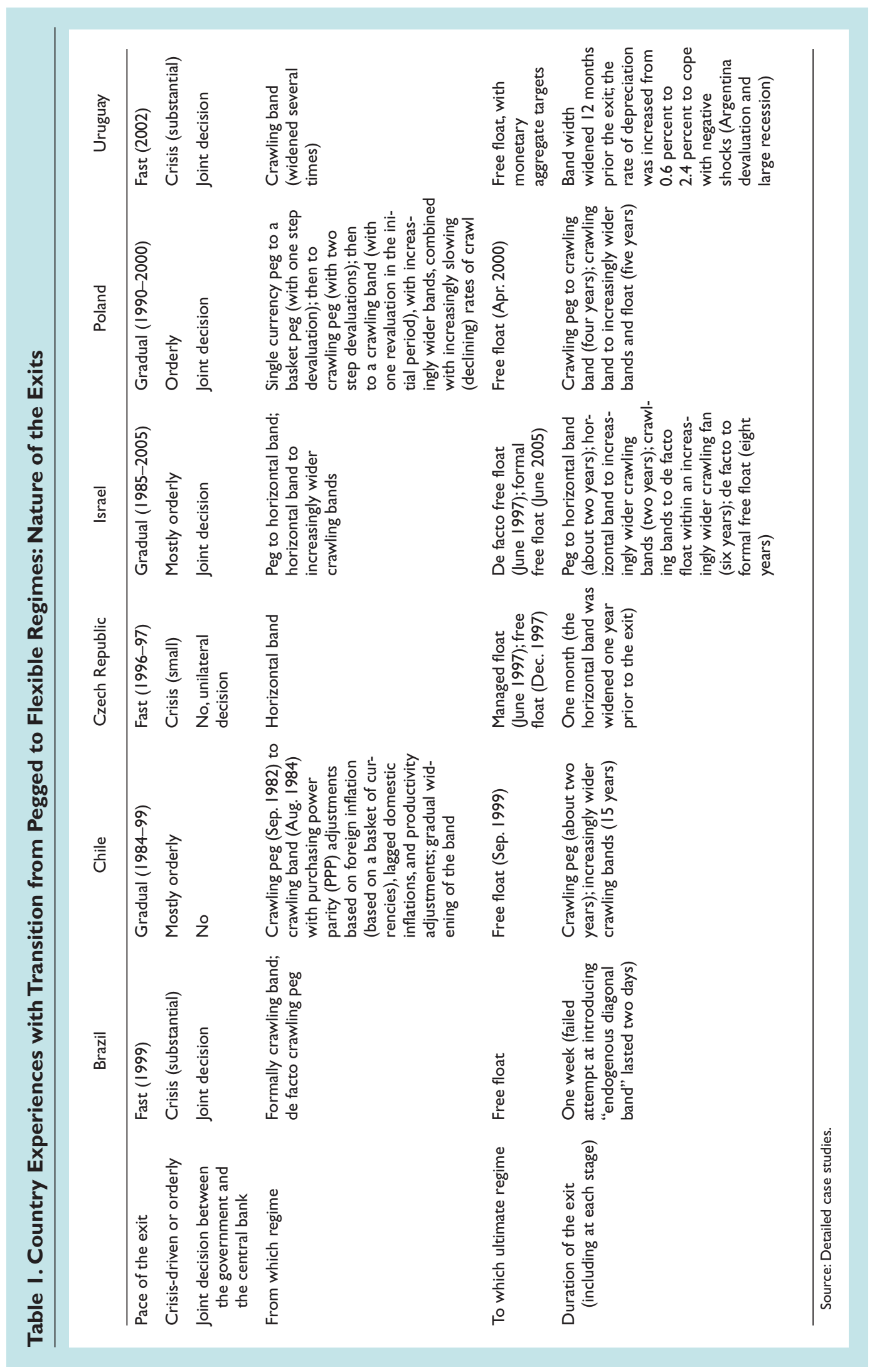




\section{COUNTRY EXPERIENCES WITH TRANSITION TO GREATER FLEXIBILITY}

Figure 2a. Exchange Rate Regime Evolutions: Gradual Orderly Exits

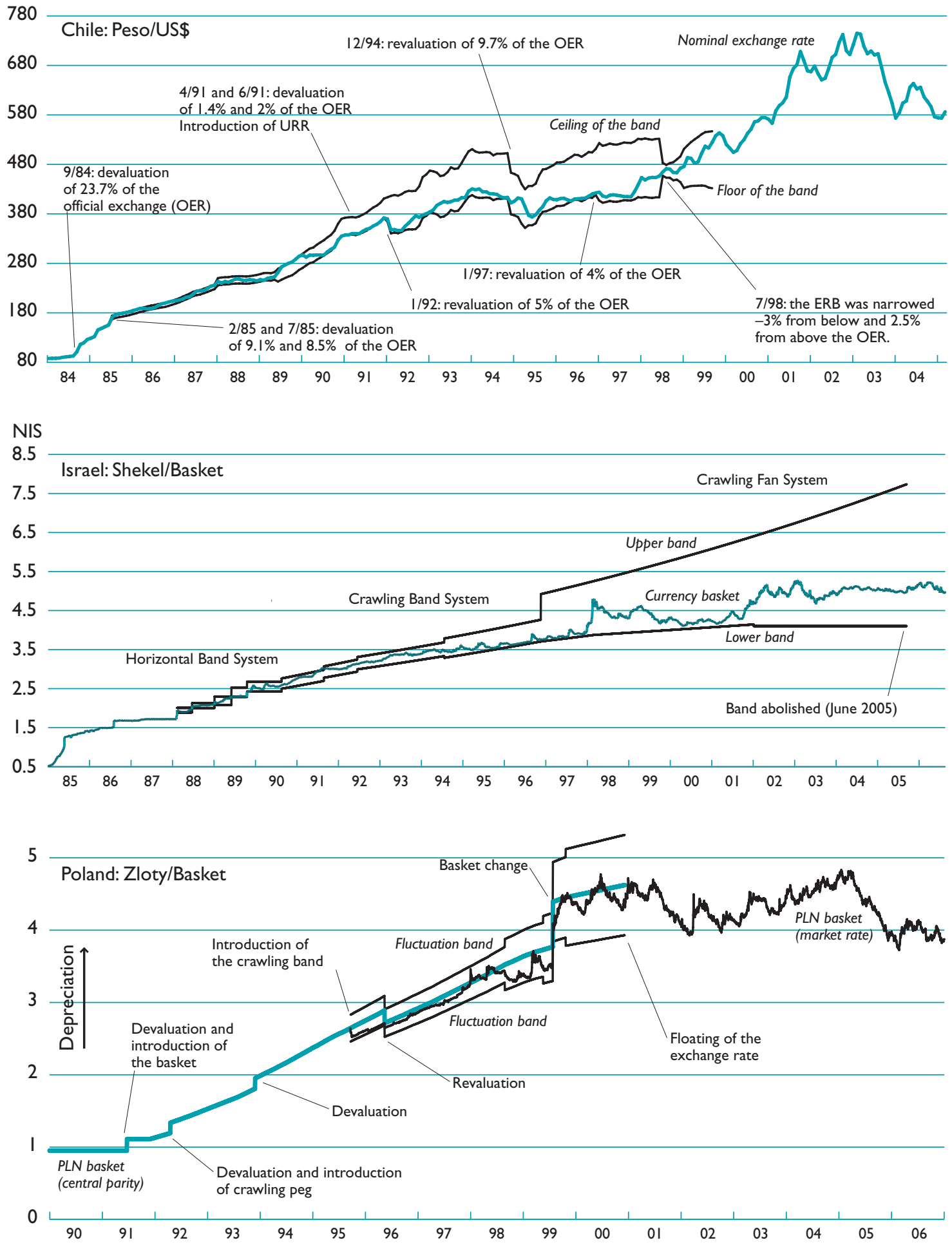

Sources: National central banks. 
Figure 2b. Exchange Rate Regime Evolutions: Fast Disorderly Exits
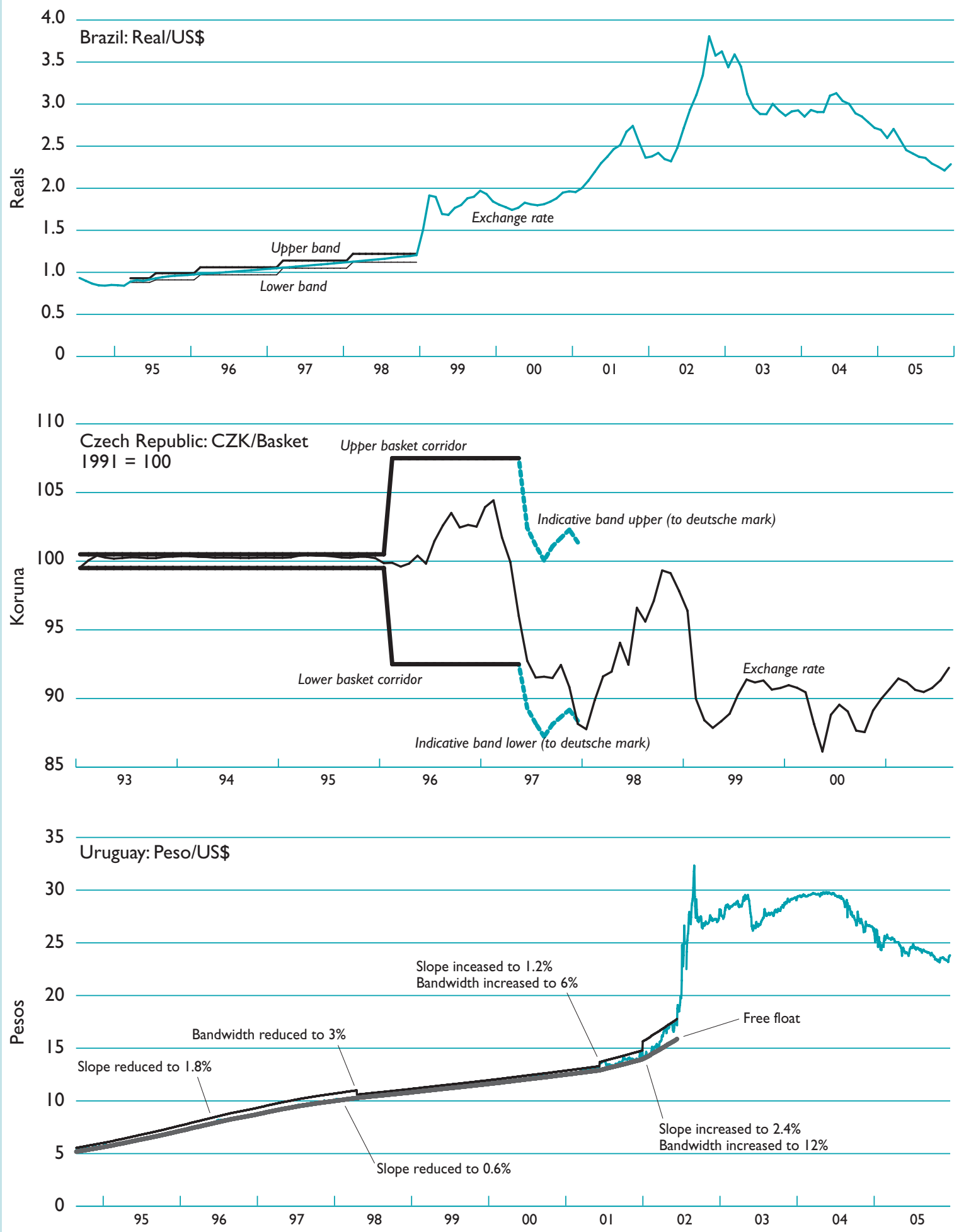

Sources: National central banks. 


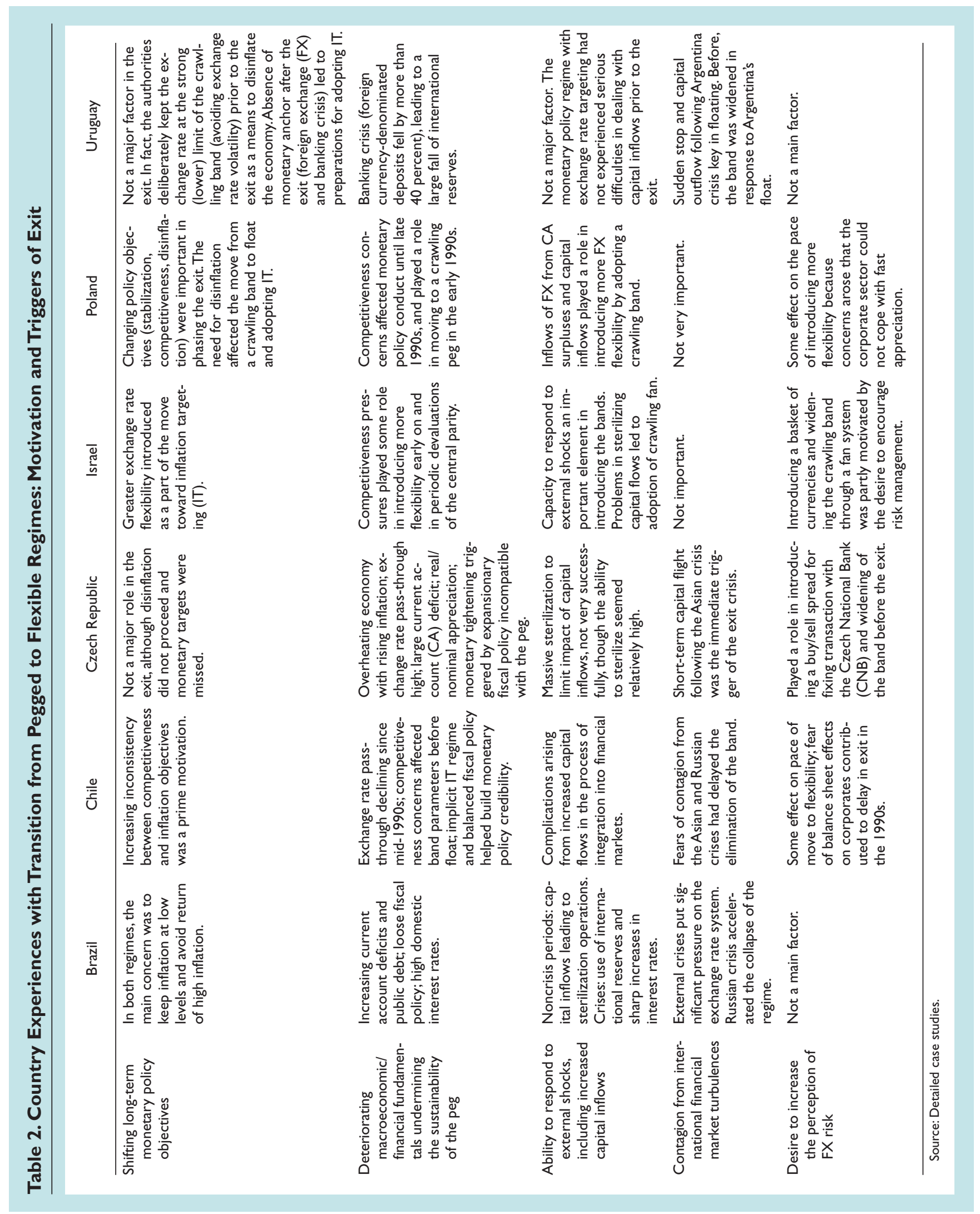


of establishing credibility. Nevertheless, the existence of some of the supporting factors (see below) helped limit the period of instability after the float (Brazil and Czech Republic).

\section{Factors that Triggered the Move to Greater Flexibility}

Greater flexibility was introduced in general when multiple monetary policy objectives became increasingly more incompatible (Table 2 ). A growing emphasis on reducing inflation as compared with other goals (for example, competitiveness) was the main incentive for the gradual exits. At the initial stages of the transition, a desire to strike a balance between the goals of reducing inflation and safeguarding competitiveness led in general to the adoption of preannounced crawling pegs. The need for greater flexibility grew as countries opened capital accounts and received inflows that complicated monetary management: Efforts to maintain inflation and exchange rate targets simultaneously required large-scale sterilizations that eventually became costly or even counterproductive by stimulating further inflows. Flexible exchange rates helped absorb the impact of the inflows and let the authorities set interest rates at levels consistent with inflation targets. Reduced implicit exchange rate guarantees helped limit incentives for speculative inflows.

The forced exits were triggered by contagion from international financial crises that revealed the countries' domestic macroeconomic or financial vulnerabilities and policy inconsistencies. All three countries experienced downward pressure on their currencies from the ongoing market turbulence in other emerging markets (the Russian crisis for Brazil, the Asian crisis for the Czech Republic, and the Argentine crisis for Uruguay), which led to an eventual collapse of the pegged regimes. Tight domestic monetary policies had attracted significant short-term capital inflows, with those inflows leading to, in the context of exchange-rate-based stabilizations and absence of fiscal policy support, rising external deficits and overheating pressures; the overheating pressures in turn put pressure on the sustainability of the pegs (Brazil and Czech Republic). In Uruguay, financial vulnerabilities in the highly dollarized public and private sectors, when combined with external shocks that amplified the external imbalances, undermined market confidence and played a role in the collapse of the crawling band.

In some cases, desire to encourage better risk management provided an additional motivation for moving to greater flexibility. In Israel, for example, the move to a crawling fan regime in mid-1997 was aimed at increasing the perception of two-way risk in the exchange rate:
By allowing an asymmetric widening of the crawling band on the weaker limit of the band, the authorities raised the potential scope for depreciation, while in fact the stronger (more appreciated) limit of the band was under pressure. This regime shift, combined with the nonintervention policy of the Bank of Israel (BoI), in effect helped the private sector realize that it had to cope with FX uncertainty, which encouraged, in turn, the development of FX hedging tools. In other words, greater exchange rate flexibility provided a means for mitigating some of the risks associated with flexible exchange rates, thereby reinforcing itself.

\section{Coordination of Transitions with the Supporting Elements of a Floating Regime}

Country experiences summarized below support the fixed-to-float framework by showing that advance preparation pays off in attaining a smooth and durable transition to flexible regimes. Having the main ingredients of flexibility fully in place before the switch to a full float (Table 3 ) provided a coherent transition process and contributed to the orderly nature of the exits in the gradually exiting countries. In particular, agreement on the principles of the transition process and characteristics of the regime to be exited helped provide a framework for the process. Establishing the individual supporting elements was also mutually reinforcing, in that introducing some flexibility allowed some capacity building for floating, which in turn permitted more exchange rate flexibility. Advance preparation was crucial in avoiding costly crisis exits from pegs, as well as in moderating the severity of exits under market pressure.

The importance of the appropriate degree of preparedness is also underscored by the experiences of those countries that either reversed or experienced delays in their transition to greater flexibility. The experiences of those that reversed their initial decision to move to greater flexibility point to a number of operational weaknesses (Appendix II), including an underdeveloped and illiquid foreign exchange market (Uzbekistan), a limited capacity to manage exchange rate risk (Ecuador, Uzbekistan, and Pakistan), a lack of appropriate intervention policy (Uzbekistan and Pakistan), and a limited institutional and technical capacity to adopt a credible alternative nominal anchor (Uzbekistan and Pakistan). Likewise, Ukraine's ongoing experience with moving to a flexible regime underscores the importance of quickly establishing the necessary ingredients of a floating regime (Appendix III); intensive efforts to do so could limit the risks of policy reversals and help ensure that the absence of the essential ingredients does not slow the transition process. 
Table 3. Extent of Preparedness for Transitioning to Greater Flexibility: Before the Full Float ${ }^{1}$

\begin{tabular}{|c|c|c|c|c|c|c|}
\hline & \multicolumn{3}{|c|}{ Orderly Exits } & \multicolumn{3}{|c|}{ Exits under Pressure } \\
\hline & $\begin{array}{l}\text { Chile } \\
\text { (1984-99) }\end{array}$ & $\begin{array}{c}\text { Israel } \\
(1985-2005)\end{array}$ & $\begin{array}{c}\text { Poland } \\
(1990-2000)\end{array}$ & $\begin{array}{l}\text { Brazil } \\
(1999)\end{array}$ & $\begin{array}{l}\text { Czech Rep. } \\
\text { (1996-97) }\end{array}$ & $\begin{array}{l}\text { Uruguay } \\
(2002)\end{array}$ \\
\hline \multicolumn{7}{|l|}{ Ingredients of a Floating Regime } \\
\hline \multicolumn{7}{|l|}{ (I) FX market development } \\
\hline Spot markets & $\sqrt{ }$ & $\sqrt{ }$ & $\sqrt{ }$ & $\sqrt{ }$ & $\sqrt{ }$ & $\sqrt{ }$ \\
\hline \multirow{2}{*}{\multicolumn{6}{|c|}{ Complementary markets }} & $x$ \\
\hline & & & & & & $\mathrm{x}$ \\
\hline Securities market & $\sqrt{ }$ & $\sqrt{3}$ & $\sqrt{ }$ & $\sqrt{ }$ & $\sqrt{ }$ & $\widehat{\sqrt{4}}$ \\
\hline (2) FX risk management capacity & $\sqrt{ }$ & $\sqrt{ }$ & $\sqrt{ }$ & $X^{5}$ & $\sqrt{ }$ & $x$ \\
\hline (3) Alternative monetary policy framework & $\sqrt{ }$ & $\sqrt{ }$ & $\sqrt{ }$ & $x$ & $x$ & $x$ \\
\hline Monetary policy implementation capacity & $\sqrt{ }$ & $\sqrt{ }$ & $\sqrt{ }$ & $\sqrt{ }$ & $\sqrt{ }$ & $x$ \\
\hline (4) Intervention strategy for a floating regime & $\begin{array}{l}\text { With the } \\
\text { float }\end{array}$ & $\sqrt{ }$ & $\begin{array}{l}\text { With the } \\
\text { float }\end{array}$ & $\begin{array}{l}\text { With the } \\
\text { float }\end{array}$ & $\sqrt{ }$ & $\begin{array}{l}\text { With the } \\
\text { float }\end{array}$ \\
\hline Overall preparedness & $\begin{array}{c}\text { Well } \\
\text { prepared }\end{array}$ & $\begin{array}{c}\text { Well } \\
\text { prepared }\end{array}$ & $\begin{array}{c}\text { Well } \\
\text { prepared }\end{array}$ & $\begin{array}{l}\text { Reasonably } \\
\text { well } \\
\text { prepared }\end{array}$ & $\begin{array}{l}\text { Reasonably } \\
\text { well } \\
\text { prepared }\end{array}$ & $\begin{array}{l}\text { Not } \\
\text { well } \\
\text { prepared }\end{array}$ \\
\hline \multicolumn{7}{|l|}{ Memo: Capital Account Liberalization } \\
\hline Short-term capital inflows liberalized & $\sqrt{6}$ & $\sqrt{ }$ & $\sqrt{ } 7$ & $\sqrt{6}$ & $\sqrt{ } 7$ & $\sqrt{ }$ \\
\hline Capital outflows liberalized & $\sqrt{6}$ & $\sqrt{ }$ & $\sqrt{7}$ & $\sqrt{ }$ & $\sqrt{7}$ & $\sqrt{ }$ \\
\hline Derivative transactions liberalized & $\sqrt{ }$ & $\sqrt{ }$ & $\sqrt{ } 7$ & $\sqrt{ }$ & $\sqrt{ } 7$ & $\sqrt{ }$ \\
\hline \multicolumn{7}{|l|}{ Source: Detailed case studies. } \\
\hline \multicolumn{7}{|l|}{ Note: $F X=$ foreign exchange. } \\
\hline \multicolumn{7}{|c|}{ IThe years in parentheses refer to the period of transition to a full float. } \\
\hline \multicolumn{7}{|c|}{ 2Major boom one year before the float. } \\
\hline \multicolumn{7}{|c|}{ ${ }^{2}$ Lagged behind compared to the foreign exchange markets. } \\
\hline \multicolumn{7}{|c|}{${ }^{4}$ For maturities less than 270 days. } \\
\hline \multirow{3}{*}{\multicolumn{7}{|c|}{$\begin{array}{l}{ }^{5} \text { The prudential framework was not in place to control the overall risk exposure of banks, with identified shortcomings mainly regarding the prudential } \\
\text { regulation of banks' exposure to FX risk. Corporates in general (and banks) were making active use of the futures markets to hedge their exposures } \\
\text { or to take speculative positions. Market participants were not accustomed to assessing, as a matter of routine, the FX risks posed by regular market } \\
\text { volatility. }\end{array}$}} \\
\hline & & & & & & \\
\hline & & & & & & \\
\hline \multirow{2}{*}{\multicolumn{7}{|c|}{$\begin{array}{l}{ }^{6} \text { For Chile, all controls were removed shortly before or with the float. For Brazil, controls were liberalized gradually during the 1990s (inflow controls } \\
\text { of 1993-96 liberalized by 1999), with further liberalization for nonresident investments after the float. }\end{array}$}} \\
\hline & & & & & & \\
\hline \multicolumn{7}{|c|}{7 In the Czech Republic, most inflows and outflows had been liberalized by 1997, but certain inflow transactions (including financial derivatives) were } \\
\hline \multicolumn{7}{|c|}{ liberalized in early 1999, following a transition period to phase out the remaining controls under the agreement with the Organization for Economic } \\
\hline \multicolumn{7}{|c|}{$\begin{array}{l}\text { Cooperation and Development (OECD), with full liberalization taking place in } 2002 \text {. Similarly in Poland, full liberalization of all capital account transactions } \\
\text { took place in 2002, until which time certain transactions (including selective derivatives operations and short-term portfolio and deposit transactions) } \\
\text { had remained controlled. }\end{array}$} \\
\hline
\end{tabular}

\section{A Deep and Liquid FX Market}

In the case of gradual exits, the FX market was illiquid and undeveloped at the beginning of the transition process, often dominated by the central bank as the sole market maker. The central bank's role through its fixing mechanism was gradually reduced as markets developed; fixing formally ended in Israel in 1990 and Poland in 1999. In most cases, market development began only after some exchange rate flexibility was introduced: in Israel, when the exchange rate was allowed to vary within a \pm 5 percent band; in Chile, after widening of the band to \pm 5 percent; and in Poland, following the adoption of a crawling band with a \pm 7.0 percent width. In the Czech Republic, too, where some flexibility had been introduced in 1996 shortly before the disorderly exit, the market developed more rapidly after the band was widened from \pm 0.5 percent to \pm 7.5 percent. In most cases, the market mechanism began as a direct interbank market (in Israel, it began with an intermediate stage of a multilateral auction in 1990-94 when a continuous interbank market was introduced).

In all cases, the spot FX market was the first to develop, followed by derivatives (forward, swap, options, and futures) markets (Table 4 and Figures 3 and 4). The spot markets had been well developed in all six 
countries at the time of exit, but derivatives markets for FX were introduced only gradually: Well-developed derivatives markets existed in only a few countries when the move to flexibility commenced. In Uruguay, only the spot market was well developed before the float, whereas derivatives markets were virtually nonexistent; efforts to promote their development started after the float in 2002. In Brazil and Chile, FX spot and derivatives markets developed steadily from the mid-1990s until the float in 1999. In many of the countries (Chile, Czech Republic, Israel, and Poland), the FX derivatives market developed in tandem with greater exchange rate flexibility.

The process of establishing spot markets started at fairly early stages in the move to greater flexibility. The central banks played a significant role in this process by creating infrastructure and institutions conducive to market activity and by removing obstacles to it. ${ }^{2}$ In particular, they stimulated market development by (1) allowing some flexibility through widening of trading bands; (2) reducing their market role by ceasing to be a single market maker and ending fixing interventions (Czech Republic, Israel, Poland) or by discontinuing narrower inner bands or undeclared target levels (Israel, Poland, Uruguay); and (3) removing obstacles to market activity by permitting arbitrage operations between banks and eliminating limits to market access (Chile), liberalizing the bank-client market (Czech Republic), and encouraging trading through the interbank market (Czech Republic, Uruguay). ${ }^{3}$ The central banks also added to market development by upgrading infrastructure (for example, sophisticated trading mechanisms and over-the-counter continuous trading in Israel).

Most central banks had also been actively promoting development of the FX derivatives markets. Gradually increasing the exchange rate flexibility contributed to a growing recognition of FX risks and helped stimulate activity in the derivatives markets in Chile, the Czech Republic, Israel, and Poland. In fact, the major leap in derivatives market development occurred after the exchange rate bands were significantly widened prior to floating. ${ }^{4}$ The authorities promoted the markets also by gradually removing the impediments to forwards, swaps, and other derivative transactions (Chile, Czech

\footnotetext{
${ }^{2}$ See Appendix IV for the role of the central bank in promoting spot and hedging markets in foreign exchange and complementary supporting markets.

3In the Czech Republic, a fee was introduced on FX transactions with the central bank to encourage banks to participate in the interbank FX market. In Uruguay, the government began trading its FX receipts mainly with the interbank FX market, rather than with the central bank.

${ }^{4}$ In the Czech Republic, a major boom occurred in 1996 before the float in 1997; in Israel, there was a significant pickup after the crawling fan in 1997; and in Poland market development started in 1998, with a major boom in 1999 preceding the float.
}

Republic, Poland $)^{5}$ and by allowing growing nonresident exposure in domestic markets (for example, the zloty-denominated bond market in Poland). In a number of countries, the central bank created or stimulated market activity by actively participating in derivative transactions: the BoI issued instruments to kick-start markets in new instruments (Appendix IV). In Uruguay, the Central Bank of Uruguay (BCU) took steps in this direction only after the float, actively participating in derivative transactions.

The presence of other supportive (complementary) financial markets was also an important factor in the creation of deep, liquid derivatives markets for hedging. Among these, liquid and efficient short-term interbank money and government securities markets had the closest link to spot and derivatives FX markets, because the interest rates established in these markets were vital for interest rate parity to function and for pricing swaps, forwards, and other hedging instruments (Appendix IV). Such markets were essential for the development of spot, forward, and swap markets in Israel and Poland; in Uruguay the absence of domestic currency securities hindered derivatives market development. After the float, the BCU took prompt measures to support domestic currency bill markets. In Poland, the NBP actively contributed to the development of complementary markets by creating infrastructure and institutions, being involved in setting standards, setting up benchmark reference rates, and creating incentives.

Although authorities appreciated the importance of such markets in coping with potentially greater exchange rate volatility, they also recognized that derivatives transactions could facilitate speculation. There were fears that forward transactions could allow speculative attacks and would be harder to control (for example, Israel and Poland). ${ }^{6}$ In most cases, however, the pressures were created by discrepancies between economic fundamentals and the policy regime; the latter was adjusted to reduce these discrepancies. It was also recognized that it would be hard to stop the development of derivatives once the markets for underlying instruments (for example, treasury bills and treasury bonds) were liberalized. In fact, maintaining restrictions on derivative transactions was considered to be potentially counterproductive, leading to an even faster development of derivatives offshore in an attempt to circumvent onshore restrictions (for example, the nondeliverable forwards market for the zloty in London).

\footnotetext{
5In Poland, for example, a deep FX swap market developed quickly, squeezing out the vibrant offshore nondeliverable forwards market for zlotys in London, when FX swaps were excluded from the National Bank of Poland (NBP) permit requirement in 1998. Other FX market segments developed henceforth.

${ }^{6}$ In Israel, for example, forward transactions played a major role in many speculative attacks. In Poland, use of derivatives augmented the appreciation pressure on the zloty in 1998 .
} 


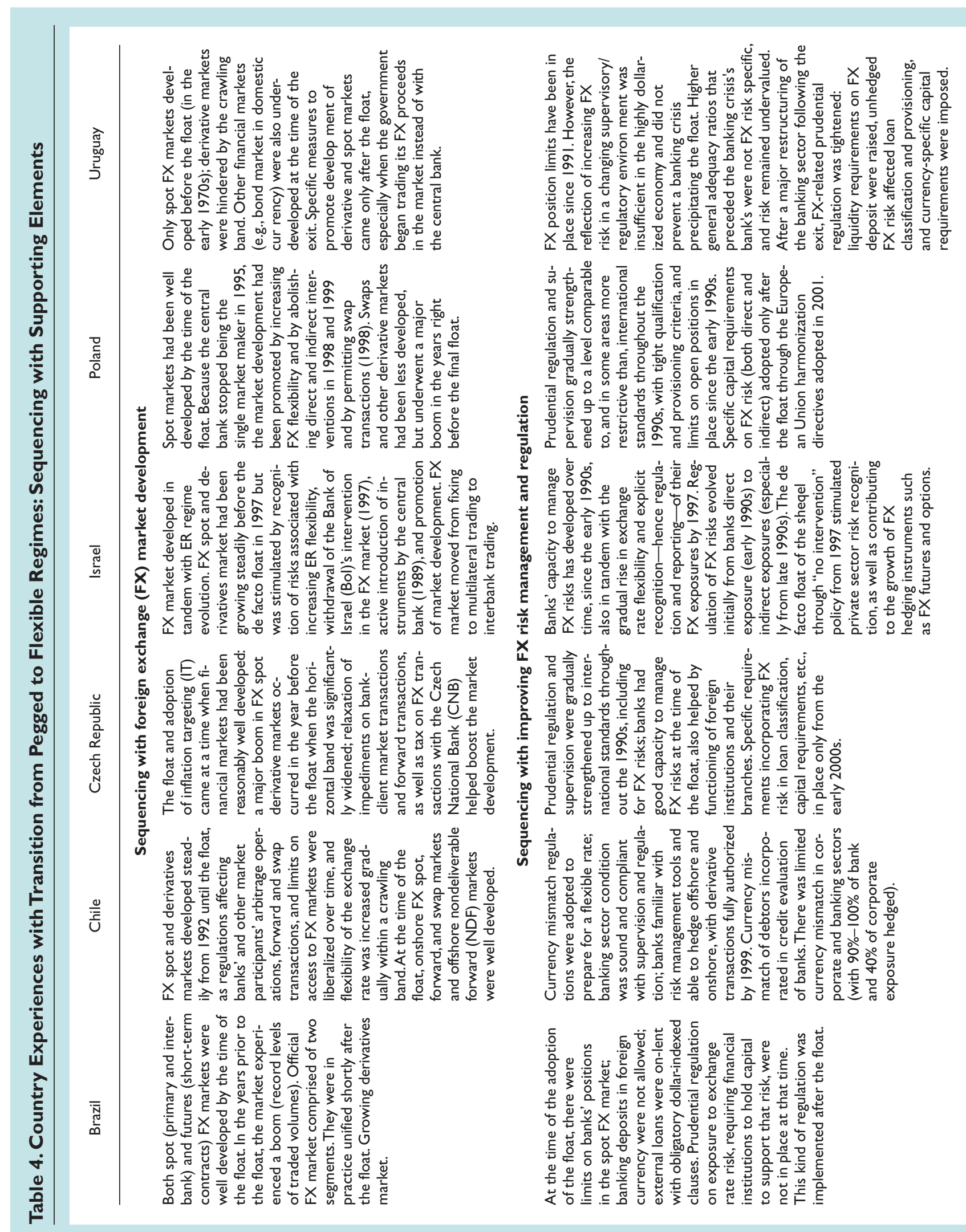




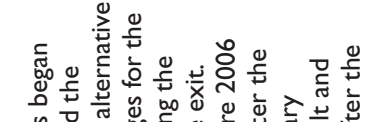

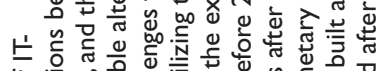

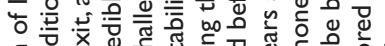

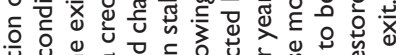

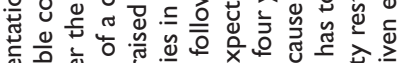

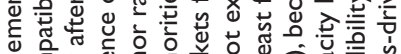

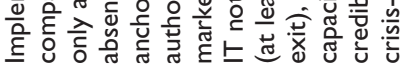

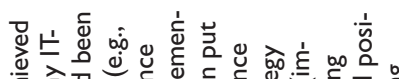

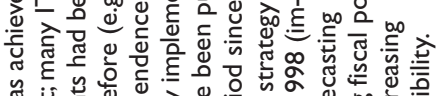

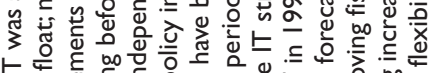
든흔 5.

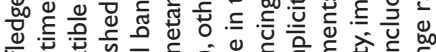

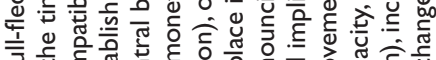

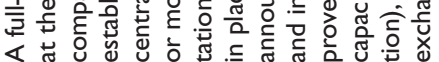

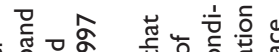

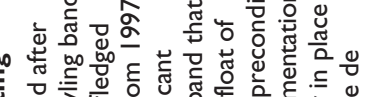

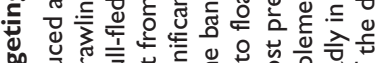

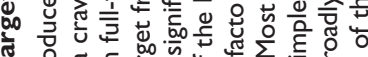
× ○

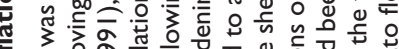

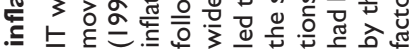

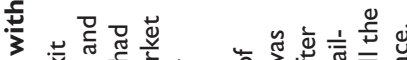
of

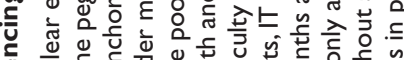
告 50

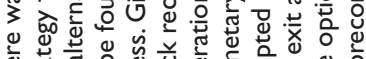

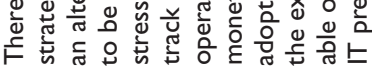

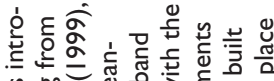

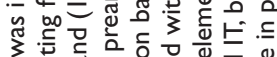
Ex s, bo

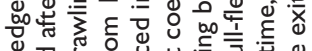

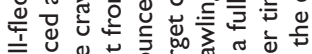

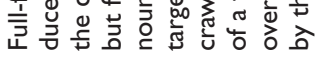

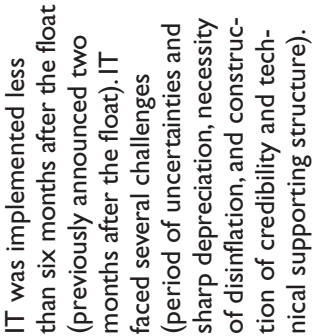

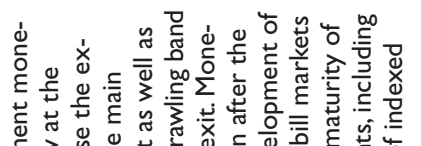

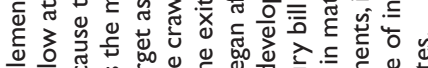

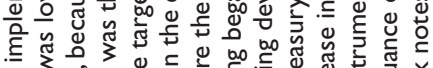

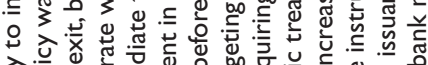

产高等

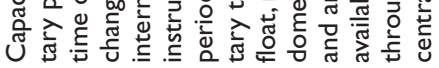

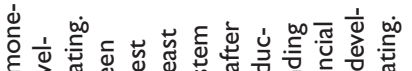

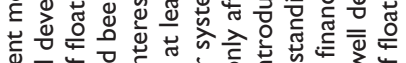

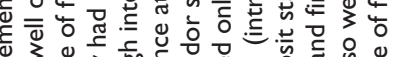

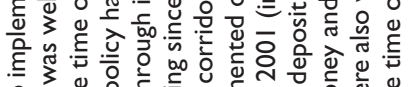

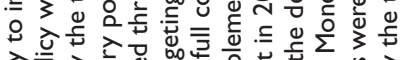

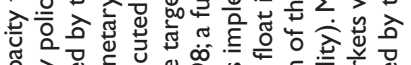

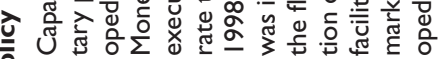

\section{年}

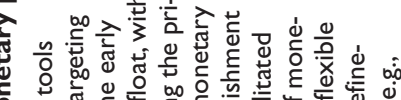

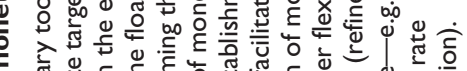

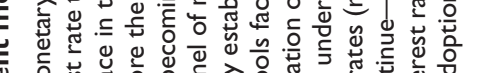

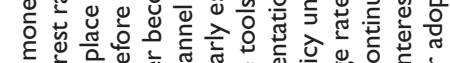

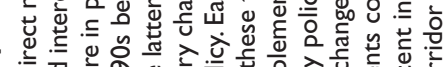

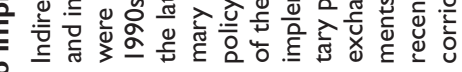

ㅎํ ह่

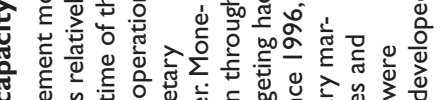

等

生

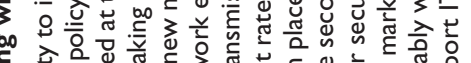

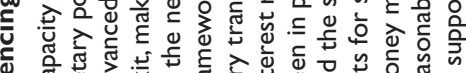

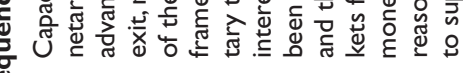

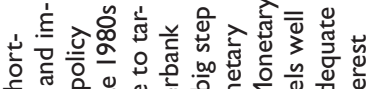

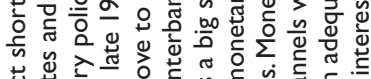

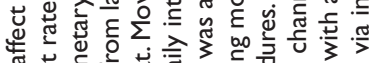

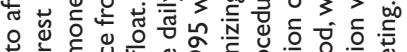

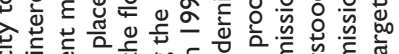

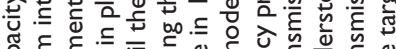

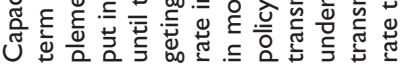

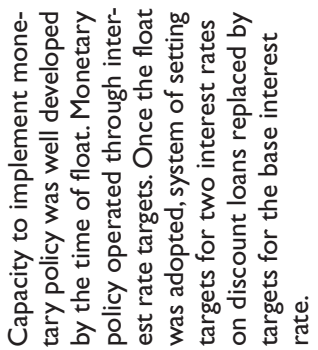

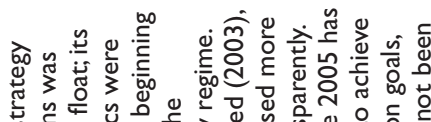

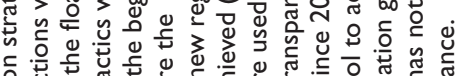

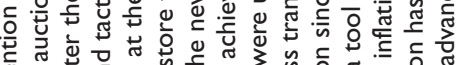

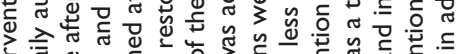

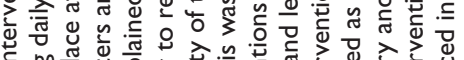

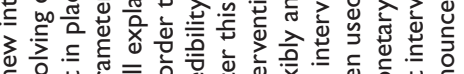

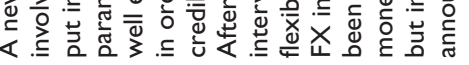

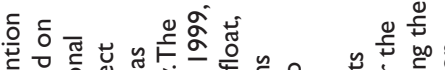

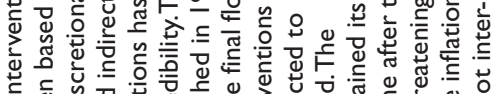

它

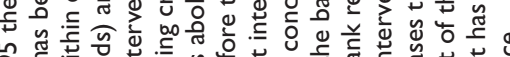

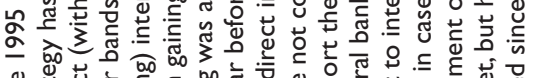

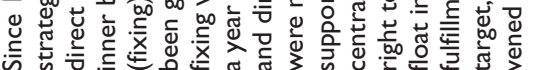

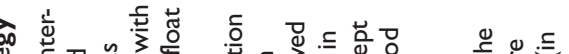

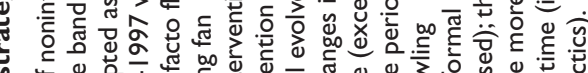

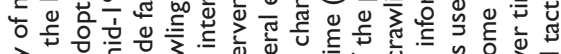

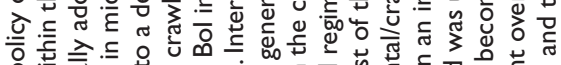

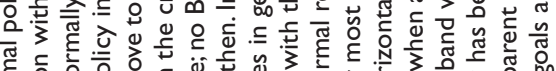

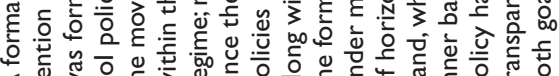

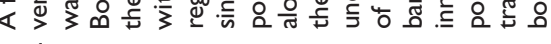

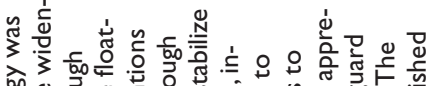

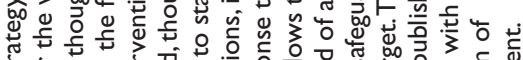

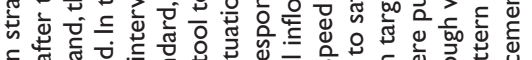

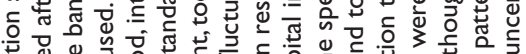

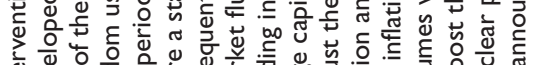

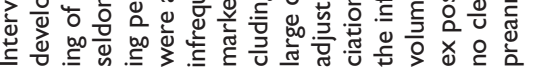

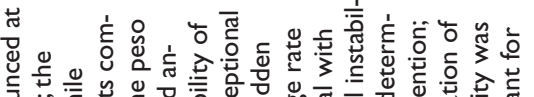

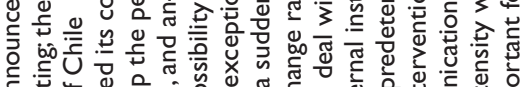

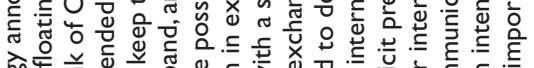

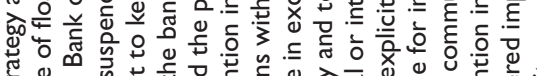

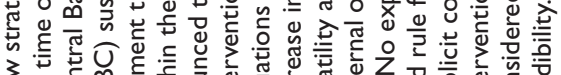

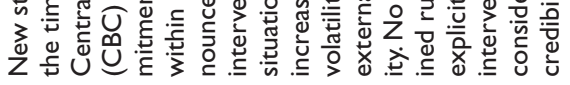

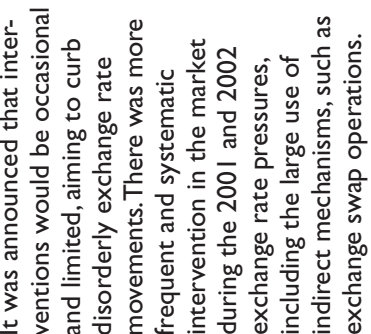




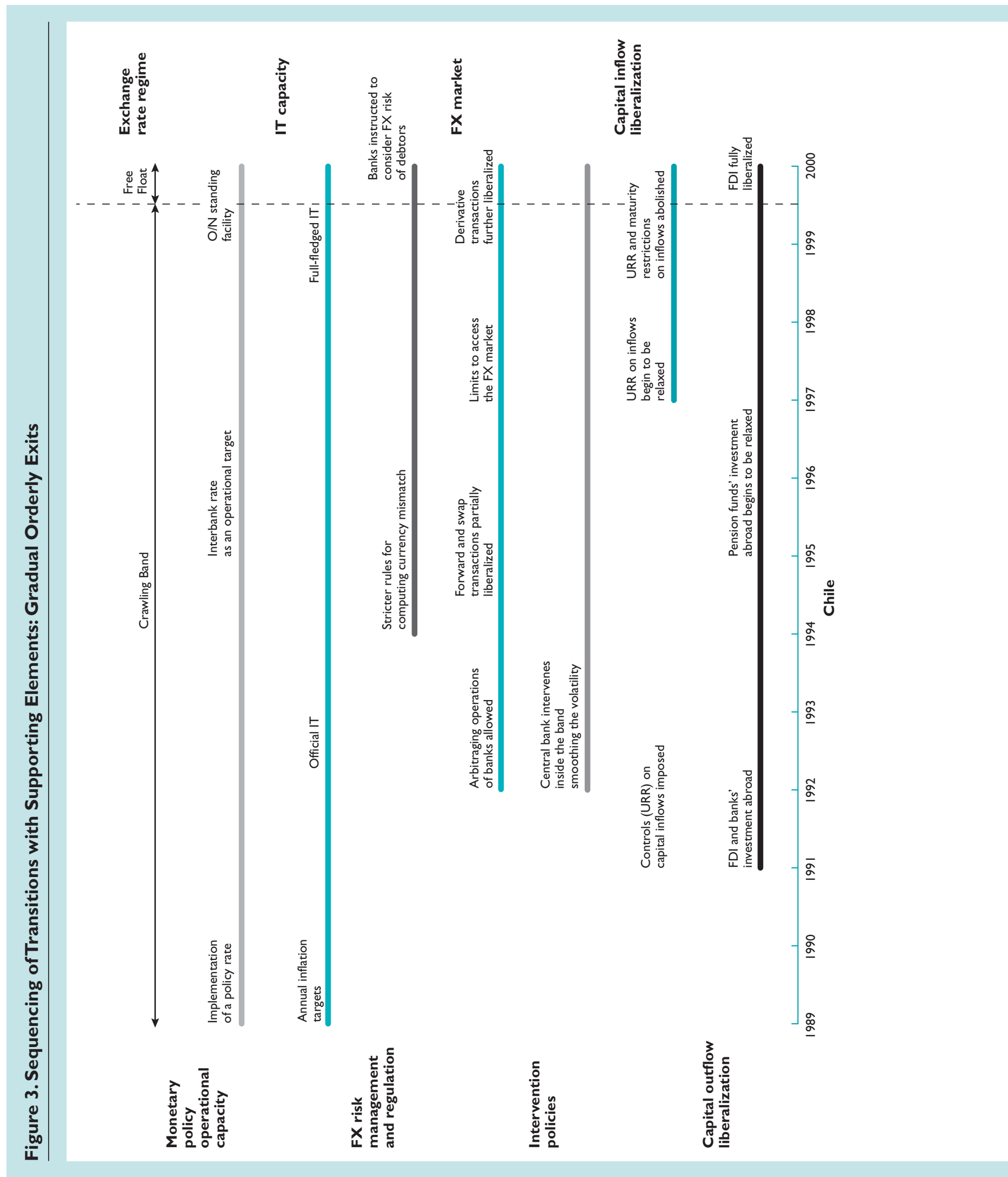




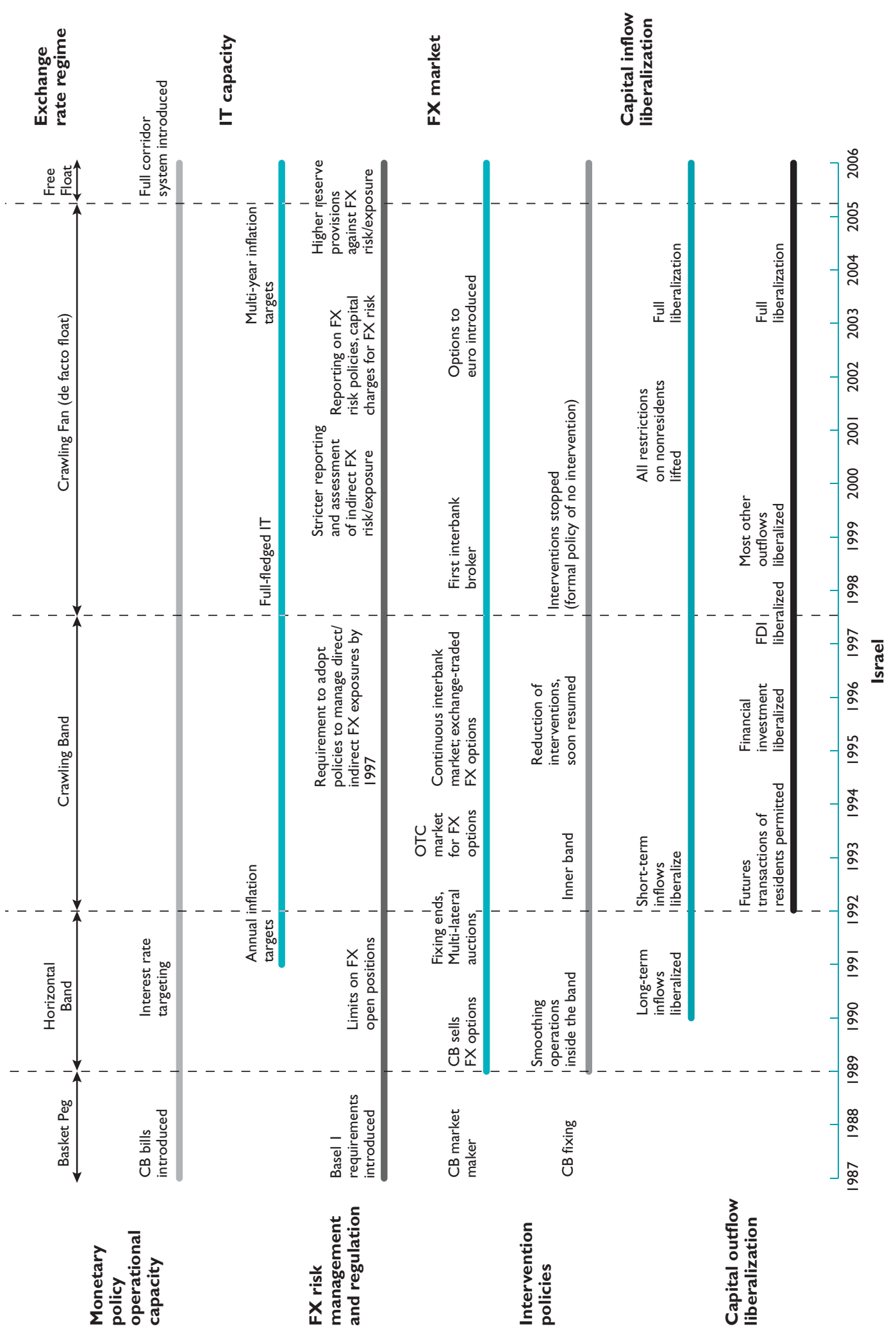




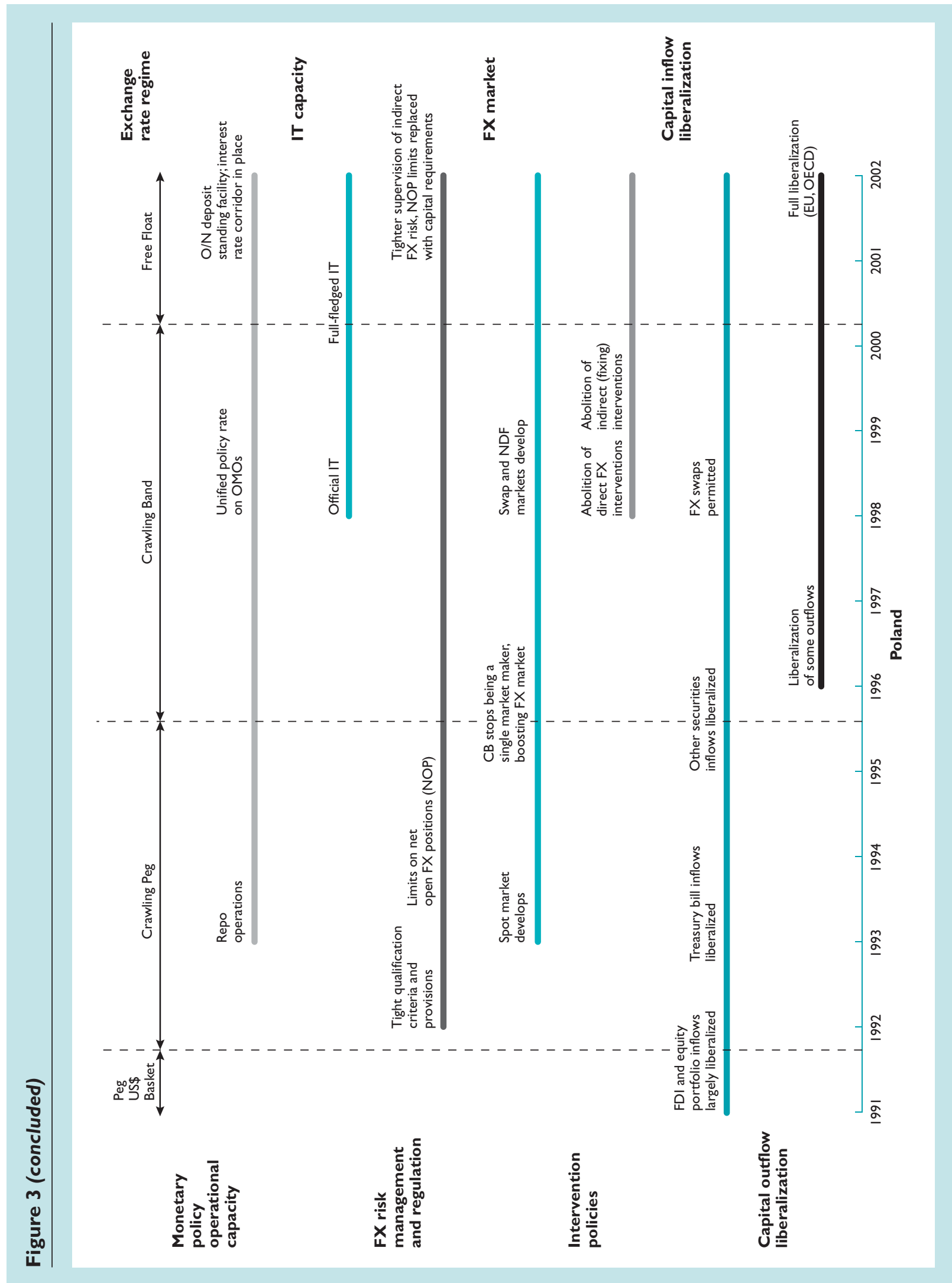


When liberalizing derivative transactions, the authorities established some precautions to limit such risks (for example, documentation requirements to prove the legitimacy of the underlying transactions so as to limit speculative activity, and prudential and supervisory rules to mitigate excessive risk taking linked with the use of derivatives). In Chile, FX operations and derivatives transactions were initially permitted only to support trade activities or investments abroad. The authorization requirement to engage in derivatives transactions with external counterparties was eliminated at the time of the float. In Israel, documentation requirements were used for underlying transactions for a considerable period. Forward transactions were permitted in stages by tenor (for example, first forwards up to one month, then three months, then six months, and then one year, at which point all restrictions were lifted). Although the use of options was not considered an avenue for speculation and options market development was promoted actively, documentation requirements were maintained to indicate that options were used for hedging purposes. Banks' direct and indirect exposures to FX risks associated with derivative transactions were also incorporated in prudential systems (for example, forward exposures in open FX positions and in capital requirements (Israel, Poland)).

\section{Systems to Assess and Manage FX Risks}

In most countries studied, the private sector had a reasonable capacity to manage FX risk exposure at the time of the float (Table 4). This capacity developed along with a strengthening of the prudential and supervisory framework in the Czech Republic and Poland, though without specific consideration for FX risks (except for limits on open positions); explicit incorporation of indirect FX risks (for example, in capital or loan classification requirements) came only after the float in the context of harmonizing prudential systems according to European Union directives. In Chile and Israel, building the FX risk management capacity went hand in hand with an explicit recognition, regulation, and reporting of banks' FX exposures. ${ }^{7}$ In all four countries, it was also supported by a gradual liberalization of swap and forward transactions throughout the transition process, which facilitated hedging. In the Czech Republic, the ability to manage FX risks in turn assisted the transition to

\footnotetext{
${ }^{7}$ The regulation and reporting of FX risks included, for example, net open FX position limits (in Chile and Israel); inclusion of debtors' currency mismatches in assessing repayment capacity and minimum credit rating requirements for external borrowing by corporations (in Chile); and the requirement to incorporate FX exposures in capital and reporting requirements and FX credits in provisioning requirements, use of stress tests for indirect FX exposures, reporting of FX risk management policies by banks, and maintenance of FX liquidity requirements (in Israel).
}

flexibility and limited a potential spillover of currency pressures into a financial crisis.

Commercial banks' capacity to manage FX risks was also supported by the gradual increase in exchange rate flexibility and discontinuation of central bank intervention within the crawling bands. In all four countries, reduced implicit exchange rate guarantees implied by greater flexibility stimulated risk recognition of market participants, enabled them to learn early on to work with exchange risks, and contributed to the development of derivative instruments to hedge such risks. In Chile, for example, greater room for exchange rate changes within a widening band encouraged hedging onshore or offshore. The currency mismatches in the banking and corporate sectors were limited, and about 90 to 100 percent of bank and 40 percent of corporate exposures were hedged. In Israel, the nonintervention policy of the BoI from mid-1997 made FX risks explicit, and responsibility to manage the risk was imposed on those incurring the risk (banks and nonfinancial businesses); this in turn led to a fall in net FX liabilities and stimulated the growth of hedging instruments.

In Brazil and Uruguay, there was room for improvement in FX risk management at the time of the exit. In Uruguay, the supervisory and regulatory environment, although being strengthened to increase banks' resilience, had not specifically addressed the rising FX risk in a highly dollarized economy. FX-related prudential rules were tightened after a major bank restructuring following the float. ${ }^{8}$ In Brazil, there were no limits on global FX risk exposures of financial institutions in terms of capital, but there were more direct restrictions that would affect FX activity. ${ }^{9}$ Nevertheless, the private sector's unhedged FX risk exposure was rather limited through natural hedging, issuance of dollar-indexed public debt, and derivatives transactions. Specific regulations were put in place after the float, and banks were asked to use stress testing for such risks. Although building this capacity during a crisis was difficult, efforts in this direction helped boost market confidence while also reducing the risk of future problems and potential costs of exchange rate fluctuations under flexible rates.

The experiences suggest that a relatively stable financial system with little FX exposure was important in achieving a smooth exit. In Brazil and the Czech Republic, banks had no significant FX exposure, which likely helped limit contagion from the currency crises

${ }^{8}$ Liquidity requirements on FX deposits were raised, unhedged FX risks were incorporated in loan classification and provisioning requirements, and currency-specific capital requirements were imposed.

${ }^{9}$ There were restrictions on foreign currency positions in bank balance sheets: No bank deposits in foreign currency were allowed, and external loans were on-lent with obligatory dollar-indexed clauses to avoid currency mismatch problems. There were also specific limits on long positions and a limit on short positions contingent on banks' adjusted net worth, both in the spot market. 


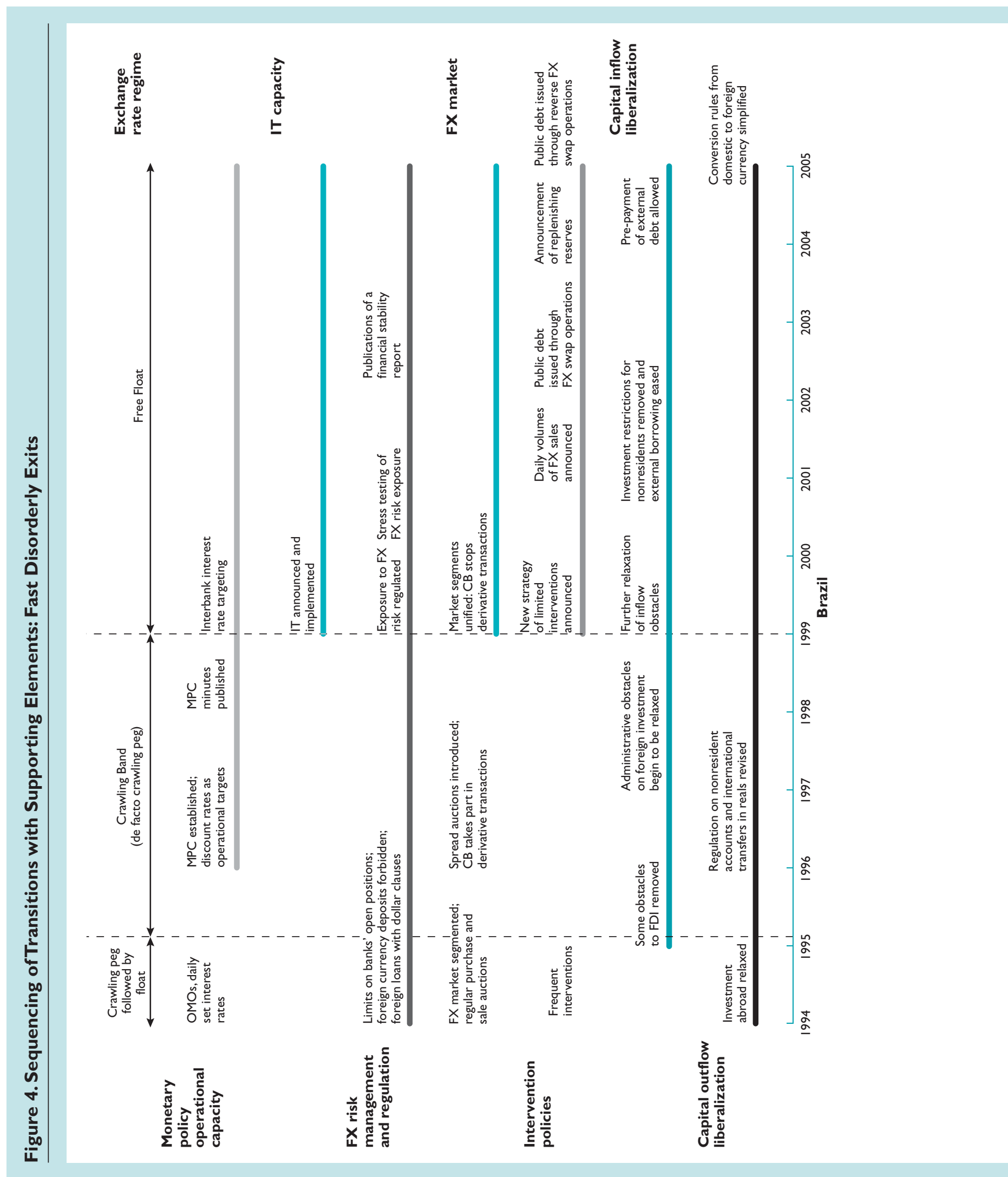




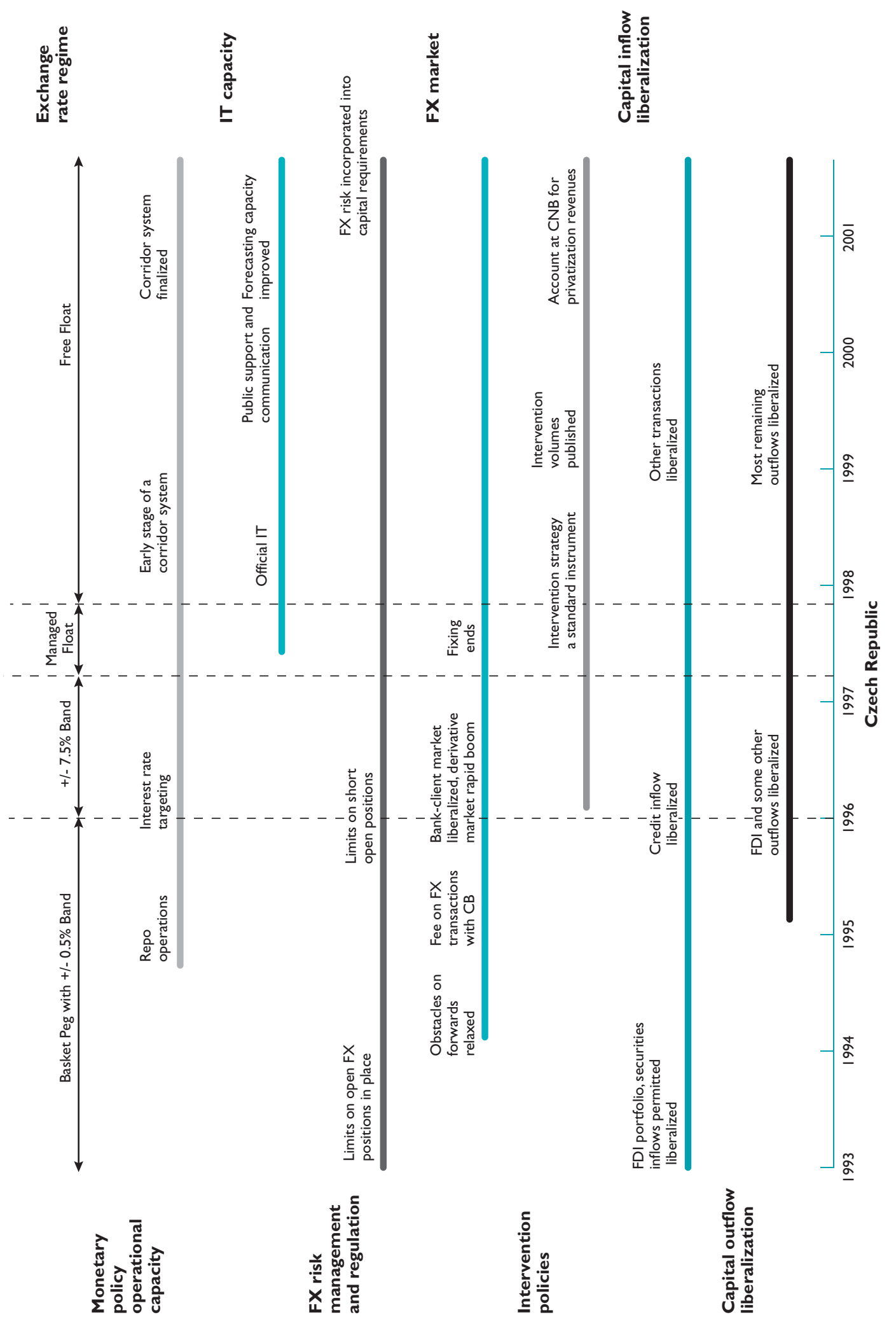




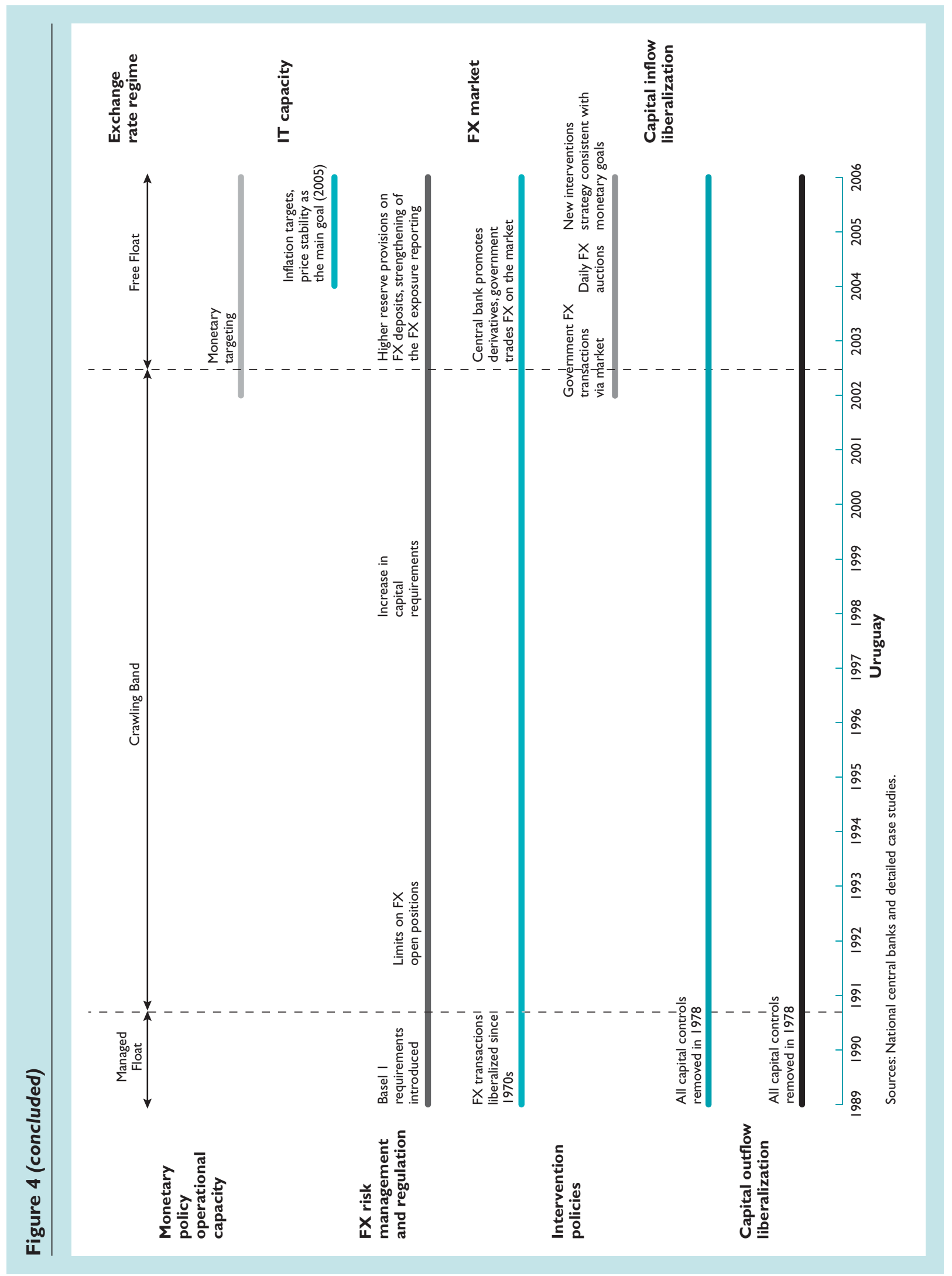


to the banks. In Uruguay, the highly dollarized balance sheets with large FX exposure, combined with weak FX risk management capacity, made the exit challenging, with large losses resulting from the sharp depreciation. In Chile, banks were well capitalized, with a strong regulatory and supervisory framework built after the banking crisis in the 1980s. Indirect FX exposure was small and well hedged. The prudential and supervisory system was also strengthened in Israel after the 1983 banking crisis, and banks had tools for direct and indirect FX risks. In Poland, tight prudential regulations with market risk management techniques, offsite and onsite supervision, and foreign bank presence led to a system resilient to exchange rate fluctuations.

\section{FX Intervention Policies}

Transition to a flexible exchange rate regime created the need to develop a coherent intervention strategy, including policies on the objectives, timing, and amounts of interventions in both orderly and disorderly exits. Such a strategy was needed to credibly signal the commitment to a market-determined rate and build confidence in the new regime, while also avoiding excessive smoothing of short-term fluctuations. Most countries have been gradually adapting their intervention mechanisms along with the introduction of greater exchange rate flexibility. In addition to central bank fixings, direct market interventions were used with the bands on the margin to smooth out exchange rate volatility. Intramarginal interventions were also used to support unannounced inner bands or undeclared exchange rate targets. ${ }^{10} \mathrm{In}$ the case of orderly exits, such interventions were gradually abandoned to enhance credibility under a more flexible regime, supported by infrequent interventions used more transparently. Interventions through fixing mechanisms were abolished at the time of the exit (Czech Republic) or before the exit (Israel, before moving to the crawling band; Poland, before the float).

The intervention strategies under a more flexible regime did not require much advance preparation and were generally adopted at the time of the exit (orderly or disorderly). In some cases the new strategy was announced explicitly, by suspending the commitment to an exchange rate target and setting the broad conditions under which interventions would take place (for example, when excessive exchange rate changes, particularly

\footnotetext{
${ }^{10}$ In Brazil, the Central Bank of Brazil (CBB) established significantly narrower inner bands under a system of horizontal bands; the size of the inner band and its frequent adjustments in practice translated into a de facto crawling peg with a steady devaluation of the real. In Uruguay, the crawling band system in theory allowed for greater flexibility, but the system looked like a de facto crawling peg, with interventions supporting the stronger limit of the band. In Israel and Poland, flexibility permitted within the bands was initially limited by the narrower informal bands.
}

those that would pose a threat to inflation targets-as in Chile, the Czech Republic, and Poland-threaten external or internal stability). In Israel, a formal policy of no intervention within the band was adopted as the Bol's policy at the time of the switch to a crawling fan, whose design was meant to minimize the need for interventions. In Uruguay, FX interventions since the float aimed at achieving monetary and inflation goals. In Brazil, interventions have become less frequent under the float; they are used mainly to curb disorderly conditions in the market, but some indirect mechanisms were also used to ease pressures on the currency (for example, issuance of domestic dollar-linked debt or participation in the derivatives market).

Transparency of intervention policies was important in establishing the credibility of the new regimes, especially following the forced exits. There was, in general, greater transparency about the strategy than about the tactics. ${ }^{11}$ The CNB used a similar strategy that had been developed after the widening of the band to safeguard the inflation target in the floating period. Intervention volumes have been published ex post, with no clear pattern of preannouncement. Similarly, in Brazil, the general principles of intervention were announced publicly after the float and reiterated on several occasions; there was no commitment to a precise rule as to amounts and timing of intervention. In Uruguay, both the strategy and tactics were announced at the time of the exit as a means of restoring credibility; since credibility was attained, interventions have been no longer preannounced but are used more flexibly and somewhat less transparently. In Chile, no predetermined intervention rule was declared, but the goals and intensity of the interventions have been explicitly communicated for purposes of credibility. In Israel and Poland, transparency and credibility have improved over time, with commitment to no intervention even at times of market tensions.

\section{Availability of an Alternative Nominal Anchor and Monetary Policy Framework}

Adopting a new credible anchor and redesigning the monetary policy framework around it required significant capacity building and credibility building. Although all six countries ultimately chose to adopt an IT framework as the alternative monetary policy regime, the level of preparedness for this regime affected the smoothness of the transitions; in other words, planning ahead was critical to achieving a smooth exit.

\footnotetext{
${ }^{11}$ Strategy in general refers to the objectives of intervention and the specification of the circumstances that would warrant intervention, whereas tactics cover more operational details, including methods and modalities of intervention, agents used, and specific timing and amounts of interventions.
} 
In the countries with gradual exits, the adoption of a full-fledged IT framework followed a lengthy transition period-10 years in Chile and 8 years in Israel from the point when the first annual inflation targets were declared. In Poland, a partial form of IT was introduced relatively quickly, but it took close to two years for a full-fledged IT to be introduced with the floating of the currency. The length of the transitions reflected in part the difficulty of putting together the extensive institutional requirements for a successful implementation of this framework. The countries thus abandoned the anchor role of the exchange rate only gradually, through the adoption of partial IT at an earlier stage, with the latter involving an interim period of inflation and exchange rate targets pursued simultaneously. Thanks to the lengthy transition periods, gradually exiting countries satisfied most of the preconditions of a full-fledged IT at the time of exit from their pegs.

On the contrary, in the case of fast exits, the process of adopting IT started after the floats, requiring intensive efforts for capacity building. Brazil and the Czech Republic introduced IT after an intensive preparation period (three and six months, respectively), having had in place some but not all of the essential elements for its implementation. In Brazil, there was a need to further improve the institutional framework and fiscal policy, as well as to build modeling and forecasting capacity. The Czech Republic did not have a clear mandate to pursue price stability (which was formally adopted after several years) and attained a sufficient understanding of the monetary transmission mechanism and modeling and forecasting capacity only several years after the IT adoption. Uruguay took on a step-wise approach: Monetary targeting was adopted in the absence of many of the IT conditions and a credible alternative and in light of the need to reestablish credibility and stability, as efforts to set up the institutional, technical, and policy environment conducive to IT were speeded up. ${ }^{12}$

The adoption of IT without all the supporting elements caused difficulties in establishing credibility. Brazil and the Czech Republic adopted IT to quickly regain credibility in the absence of a better option, choosing to establish the remaining elements subsequently. With IT adopted in a period of uncertainty and weak currency in Brazil, and with no adequate forecasting capacity, restoring and maintaining credibility had to be supported by even tighter financial policies, although the crisis-driven economic slowdown turned out to be milder if compared to the crises in other emerging market economies. In the Czech

\footnotetext{
${ }^{12}$ The BCU has had a mandate to pursue price stability since 1995 , but with no accountability. A strong commitment to price stability was signaled after the float. The BCU is in the process of strengthening its instrument independence, upgrading modeling and forecasting capacity, and establishing greater accountability.
}

Republic, the limited knowledge of the policy transmission mechanism complicated decisions about the appropriate degree of policy tightening needed for the inflation target, contributing to an initial undershooting of the targets combined with a protracted recession; the protracted recession raised questions about CNB independence in the absence of sufficient public familiarity with the new regime. Despite these difficulties, a relatively rapid introduction of IT helped the country overcome the crisis quickly, and the credibility of the IT regime has remained strong since then.

\section{Effective Capacity for Monetary Policy Implementation}

The monetary operations capacity to affect shortterm interest rates was generally well advanced at the time of the exit. Establishing this capacity was important, with the burden of liquidity management falling on effective monetary instruments under flexibility. Efforts to establish this capacity typically began well before the introduction of flexibility, though they were by no means complete before the float. A clear policy rate existed (Brazil, Israel, and Poland) or was being established (Chile and Czech Republic) at the time of the regime shift. An interest rate corridor was put in place to support interest rate targeting in Chile before the float; the system was under way in the Czech Republic but was set up after the float in Israel and Poland. Reasonably well-developed financial markets supported the interest rate channel of monetary transmission. In Uruguay, no attempt had been made to develop a market for peso-denominated instruments in a highly dollarized economy, which in turn undermined monetary operations capacity in the post-crisis period.

Adequate capacity to conduct monetary policy facilitated the implementation of the new monetary policy framework. Having these tools in place facilitated a quick adoption (Brazil and Czech Republic) and implementation (Chile, Israel, and Poland) of a full-fledged IT regime as the alternative monetary framework, which helped preserve monetary policy credibility under flexible exchange rates. Particularly in the Czech Republic and Brazil, adequate capacity to conduct monetary policy played a crucial role in reestablishing monetary stability following the exits under market pressure. By contrast, in Uruguay, in the absence of such capacity, attaining monetary control was a key challenge in the aftermath of the crisis exit, with uncertainty over the exchange rate destabilizing inflation expectations. To regain monetary control and support the monetary targeting regime, the authorities had to quickly develop a peso market for short-term treasury bills and introduce additional instruments.

Most central banks took measures relatively early in the transition process to improve monetary man- 
agement, which, in light of the extensive capacitybuilding needs, took time to develop. Efforts in this regard focused on establishing well-functioning, liquid securities and interbank money markets that would enhance banks' ability to manage liquidity and, through an effective transmission mechanism, help affect key interest rates in the economy. The central banks fostered the development of such markets by reducing the issuance of nonmarketable securities; using central bank bills and other marketable securities for monetary operations; creating an appropriate infrastructure; ${ }^{13}$ setting standards (for example, for repurchase (repo) contracts, reference rates); creating incentives for market participants to engage in market operations (for example, by ending the central bank's single market-maker role); and deregulating markets (for example, by removing credit ceilings and liberalizing deposit-loan rates).

\section{Coordination with the Liberalization of the Capital Account}

In the countries that exited under market pressure, capital account transactions had been mostly liberalized before the exits, highlighting the risks of liberalization before moving to flexibility. In Uruguay, the capital account had been open almost 30 years prior to the exit. In Brazil, the transition to floating took place in the context of a relatively open capital account; though some direct and market-based controls were imposed on short-term inflows during 1993-96, they were not very effective in reducing the inflows or in affecting their composition, and were liberalized by the time of the float. In the Czech Republic, inflows (including foreign direct investment (FDI), portfolio, securities, and credit inflows) had been liberalized earlier and more extensively than had outflows, with significant capital inflows leading to the adoption of a wider band shortly before the float. As in Poland, the liberalization in the Czech Republic in the early 1990s was part of both the overall economic transition process and the preparations for OECD membership.

In the case of gradual transitions, capital account liberalization was better coordinated with greater exchange rate flexibility. Long-term inflows were liberalized usually before short-term ones, and liberalization of the latter took place in tandem with a gradual rise in flexibility. Short-term inflows, when liberalized before outflows, created appreciation pressures, complicating macroeconomic management. Introducing some exchange rate flexibility helped absorb the impact of the inflows and focus monetary

\footnotetext{
${ }^{13}$ This infrastructure includes, for example, efficient payment systems, book entry systems for securities, unified bank accounts crucial for money markets, and money market and primary dealer systems.
}

policy on achieving inflation goals, while also discouraging speculative inflows that are more easily reversed. In Poland, for example, most inflow controls (first long-term, then most short-term) had been liberalized before the crawling band, which was then widened in steps in response to persistent inflows. In Israel, inflows were liberalized before outflows, and long-term inflows before short-term ones; short-term inflows were liberalized shortly after a move to the crawling band. In Chile, the liberalization moved parallel to exchange rate flexibility and involved the use of market-based inflow controls to reduce the inflows' short-term component. ${ }^{14}$

Some countries made an effort to eliminate or reduce the asymmetries in the openness of the capital account. For example, in Chile, Israel, and Poland, the authorities started liberalizing some outflow transactions that could help reduce the appreciation pressure generated by heavy inflows. Full liberalization of the capital account followed the float in all three countries. It is important to note that in these countries, the controls on forward and other derivative transactions were liberalized gradually before the full float, facilitating risk management, hedging, and market development, all essential for the smooth functioning of a floating regime. In some cases (for example, Israel), speculation in the FX market gradually became a stabilizing force as different sectors were able to operate freely. As discussed earlier, the authorities established appropriate prudential tools and strengthened their supervisory systems to ensure that banks measured and managed their direct and indirect exposures to FX risks.

\section{Challenges Faced in the Transition to Greater Flexibility}

Whether the transition toward greater exchange rate flexibility was gradual or forced by the markets, the authorities had to cope with several important challenges in the process. These included difficulties in assessing the extent of preparedness and appropriate timing of the move, restoring and maintaining credibility of monetary policy and finding a new nominal anchor, determining the appropriate market role of the central bank during and after the move to greater flexibility, and determining the proper role of transparency and communication in monetary and exchange rate policy implementation.

\footnotetext{
${ }^{14}$ These controls were effectively lifted shortly before the float, but were formally eliminated well after (in 2001). Such controls were also considered (and were technically available) in the Czech Republic, Israel, and Poland but were not adopted to avoid the risk of undermining the credibility of the liberalization strategies.
} 


\section{Assessing Preparedness and Timeliness for Further Increases in Flexibility}

In countries that had an abrupt exit from the pegs, the absence of some of the important ingredients for flexibility complicated the management of the exit, highlighting the benefit of advance preparation. In Uruguay, the absence of derivative markets for hedging and the lack of adequate instruments for monetary policy caused challenges in dealing with exchange rate volatility and constrained the immediate option of adopting IT as the alternative anchor. Similarly, in Brazil and the Czech Republic, the IT framework was adopted without all the supporting elements in place, causing initial challenges in effectively implementing the new framework and establishing its credibility.

All gradually exiting countries put significant emphasis on the presence of supportive elements, but assessing the state of preparedness and the right time to move was a challenge. Although the extent to which the prevailing multiple monetary objectives became incompatible was in general the trigger for moving to a float, the pace of the exits was also affected by the desire to avoid policy U-turns once moving to flexibility had been decided and by the authorities' comfort level about the preparedness of the economies. In Chile, for example, in the absence of timely data, the fears of losses from currency mismatches in the corporate sector contributed to delaying the exit by several years; the mismatches turned out to be less substantial and the availability of hedging better than had been assumed. Similarly overestimated was the degree of exchange rate pass-through, which had actually been falling in the 1990s. Israel's approach-a maximum gradualism-owed much to the adverse hasty liberalization experience of the 1970s.

\section{Restoring Credibility and Finding a New Nominal Anchor}

Reinstating monetary policy credibility to prevent a return of high inflation proved to be a major challenge for all crisis exits. The sharp exchange rate depreciation, the absence of an inflation anchor, and the memories of high-inflation periods fueled fears of a return to hyperinflation, particularly in Brazil and Uruguay. The crisis environment made this task particularly challenging, 15 and in some cases played a role in the adoption of possibly less than ideal transitory solutions (for example, the adoption of monetary targeting in Uruguay, despite the difficulty of implementing it under crisis conditions, and a temporary period of managed

\footnotetext{
${ }^{15}$ The task was arguably more challenging for Uruguay, where instruments to implement monetary policy had to be developed from scratch to attain monetary control in a full-blown financial crisis.
}

floating with indicative bands in the Czech Republic until IT was introduced).

Each country took a different approach to coping with this challenge, in part reflecting the different levels of preparedness for the new anchor. In Brazil and the Czech Republic, the authorities considered the speed of finding an alternative framework crucial in restoring credibility, and hence adopted IT soon after the exit, while intensifying efforts to improve the remaining elements. In Brazil, a determined approach to implement IT, intensive communication efforts, heavy investment in research and forecasting capacity, and learning from other IT experiences were helpful. Uruguay chose to restore credibility initially through higher interest rates, and later through monetary targeting, while signaling a commitment to price stability and plans to adopt IT. This gradual process allowed Uruguay to progress in establishing the IT preconditions before moving to this regime. The authorities put emphasis also on greater transparency and communication after the float to enhance credibility.

Coping with the absence of IT preconditions was a challenge also for the gradually exiting countries, though less so than in the crisis countries. As in the Czech Republic, the absence of a good understanding of the monetary transmission mechanism and forecasting capacity complicated monetary policy management in Poland in the early years of IT implementation. This challenge did not undermine the credibility of the new regime in Poland, but in the Czech Republic the initial credibility of the new regime was affected by the absence of other supportive elements (for example, wider public consensus and a clear mandate for price stability).

\section{Central Bank Involvement in the FX Market}

A common challenge in transitioning to greater flexibility was to determine the extent of central bank involvement in the FX market during and after the exits. In the case of disorderly exits, the difficulty was to determine the extent to which the central bank should limit exchange rate volatility and its pass-through to inflation while avoiding market perceptions of a return to maintaining an exchange rate target level or range. For the countries that pursued gradual transitions, the challenge was to determine how to reduce the central bank's market involvement without jeopardizing the prevailing exchange rate target.

For the exits under pressure, the authorities remained engaged in the FX market until market pressures subsided. The Czech authorities declared a managed float with an indicative nonbinding exchange rate band. The markets stabilized after the announcement, although the CNB continued to intervene frequently on both sides in the following period. In Uruguay, the regime switch took place under more severe market pres- 
sures; interventions were limited to calming disorderly markets within the bounds set for net domestic assets and international reserves. The markets settled only after monetary and fiscal policies were tightened and extensive measures for bank restructuring were taken. Explicit communication of the goals, amounts, and procedures of FX interventions was aimed at enhancing exchange rate and monetary policy credibility. In Brazil, the frequency and size of interventions fell after the float but CBB involvement continued through indirect interventions to ease market pressures.

For the gradual exits, the central banks typically intervened within the bands at the initial stages, but abolished these practices over time. These interventions were intended either to smooth exchange rate volatility to defend some informal inner bands or to achieve other goals (when conducted asymmetrically), including further disinflation (Israel) or competitiveness (Poland). The authorities abandoned such practices because of their lack of transparency and incompatibility with the goal of greater exchange rate flexibility. The central banks also reduced their market role by ceasing to be the sole market maker. Greater transparency associated with intervention at the margins and two-way risks brought by gradually widening bands likely contributed to reducing intervention volumes (Israel and Poland). In Israel, for instance, the introduction of an asymmetric crawling band (the fan) was successful in eliminating the need for intervention by raising the perception of depreciation risk when there was in fact persistent appreciation pressure.

\section{Appropriate Level of Transparency and Communication}

Determining the appropriate level of transparency in communicating the exchange rate strategy was an important challenge during the transition process. In general, countries chose to be more transparent in communicating the strategies (for both the overall intervention strategy and preparation for greater exchange rate flexibility) when faced with credibility problems. Experience with this approach has been generally favorable. Also, abandoning undisclosed inner bands increased the transparency and credibility of monetary policy and intervention strategies. In Poland, advance communication of gradual increases in exchange rate flexibility supported the transition: By announcing the intention to change the system, the authorities provided market participants with time to prepare for the new regime.

Similar considerations applied to communicating operational decisions and tactics of exchange rate strategies. In Israel and Poland, the authorities refrained from disclosing intervention tactics or the precise timing of changes in exchange rate arrangements, with a view to limiting the possibility of speculation against the domestic currency. In other countries, a transparent approach was used with respect to operational details as well, though temporarily. In Uruguay, for example, disclosure of the intervention tactics and objectives played a positive role in restoring credibility in the aftermath of the currency crisis. Intervention became more discretionary once credibility in conducting monetary policy was restored and the practice of preannounced daily interventions was abandoned.

\section{Conclusions and Lessons from the Country Experiences}

The experiences of the six countries broadly support the fixed-to-float framework. They also provide some additional lessons on the operational elements that can contribute to successful and durable exits. These lessons stress the importance of an effective coordination of the exit strategy with the various ingredients of the fixed-to-float framework, setting up complementary markets and capacity to conduct effective monetary operations at an early stage to support these ingredients, and an effective communication strategy in the process of transition. The following conclusions can be drawn from the experiences:

1. Gradual transitions to exchange rate flexibility through increasingly more flexible forms of intermediate regimes in the interim period offer time to prepare for an orderly exit, thereby reducing the scope for policy reversals. During the gradual exits of the three countries, avoiding moral hazard (or implicit exchange rate guarantees) was essential in the transition process, with two-way risks helping to reduce both one-way bets and the scope for destabilizing market strategies.

2. It is important to strike the right balance between caution and taking advantage of the mutually reinforcing relationship between flexibility and capacity building. A premature introduction of exchange rate flexibility can be damaging; advance preparation is essential in ensuring a smooth and successful regime change. However, too much emphasis on meeting all preconditions may unduly prolong the move to a float and even increase the risk of being forced out by the markets at the wrong time. Timely and reliable information is crucial in assessing preparedness.

3 . The experiences with disorderly exits underscore the high premium assigned by markets to a consistent mix of macroeconomic and financial policies under increased capital mobility. Capital mobility exposes inconsistencies in the macroeconomic policy mix (for example, a combination of expansive fiscal and restrictive monetary policies 
under a pegged exchange rate) and financial sector vulnerabilities, making the transition process more vulnerable to external pressures. Supportive fiscal policies were indeed helpful in reducing the burden on monetary policy during gradual exits, as well as in restoring monetary stability and credibility following crisis exits. A strong financial system with low FX exposure helped limit the risk of crisis exits as well as a spillover of a currency crisis to the financial sector.

4. In this connection, the experiences also emphasize that coordinating the exit strategy with capital account liberalization may reduce the pressure on macroeconomic policies and help avoid disorderly exits. In many cases, establishing some flexibility prior to capital account liberalization was beneficial, and transitions to flexibility could be supported by removing existing asymmetries in the capital account (for example, by liberalizing capital outflows to reduce the appreciation pressure on the currencies from heavy inflows).

5. The experiences demonstrate that putting in place the recommended building blocks of greater exchange rate flexibility at an early stage indeed greatly facilitates the transition to a floating regime, helps address fears of floating, and bolsters the chances of a successful exit, gradual or rapid. This process takes time and requires substantial capacity-building efforts. All four ingredients of moving to exchange rate flexibility played key roles in preparing the economies and smoothing the regime transitions.

6. In addition, a transparent and effective communication strategy on monetary and exchange rate policies was essential in preparing the economies for greater flexibility as well as contributed to the credibility of the floating regimes, in the context of both orderly and disorderly exits. Moreover, building an effective capacity for monetary policy operations and deepening the complementary markets, such as interbank money and securities markets, supported the establishment and effective implementation of the four ingredients of floating.

7. Although there was no unique path to greater flexibility in terms of its sequencing with the supporting elements, some basic elements were put in place at fairly early stages of the overall process and continued until the float, consistent with the suggested path in the fixed-to-float framework: laying the groundwork for an alternative monetary framework, establishing FX markets, and building FX risk management systems (see Figure A1 in Appendix I). Intervention policies did not involve much advance preparation, and a general strategy was adopted and announced at the time of the exit. Even when the exact path and sequencing could not be determined in advance, agreement on the principles of the transition and the characteristics of the eventual regime was helpful in establishing guidelines and a framework for the process.

8. As argued in the fixed-to-float framework, establishing the individual supporting elements can be mutually reinforcing. Introducing some exchange rate flexibility both allowed and spurred capacity buildup in the case of gradual transitions, permitting in turn more exchange rate flexibility; over time a virtuous cycle took shape. In particular, allowing for two-way variation in the exchange rate at an early stage (for example, by a gradual widening of exchange rate bands and limiting central bank intervention) helped stimulate FX activity and provided incentives for better risk management. In fact, in most cases market development began only after some exchange rate flexibility was introduced even though not all the ingredients of a floating regime were fully in place (Table 5). Increasing the exchange rate flexibility through more flexible forms of pegs was hence helpful in establishing the remaining ingredients (capacity for risk management and an alternative monetary framework).

9. The authorities have a crucial role in the overall process. Apart from providing a stable regulatory environment and infrastructure that encourage and facilitate market activity, the authorities took an active approach in developing FX and complementary markets. At the initial stages, the central banks played a market-maker role in illiquid markets, issued their own bills for monetary management, introduced instruments for hedging, and participated in FX derivatives markets; they ceased their market-maker role as the markets reached an appropriate level of maturity, limiting their role thereafter to being a market participant. They also played key roles in building capacity to manage FX risks: indirectly, by gradually increasing FX flexibility, as well as directly, through appropriate regulation and monitoring. Cautious liberalization of derivative activities played an important role in facilitating risk management and hedging market development, supported with appropriate sequencing and safeguarding measures to mitigate the potential misuse of derivatives instruments.

10. The experiences also highlight that the relationship between flexibility and its building blocks may not be continuous. Providing small degrees of flexibility when several of the ingredients of 


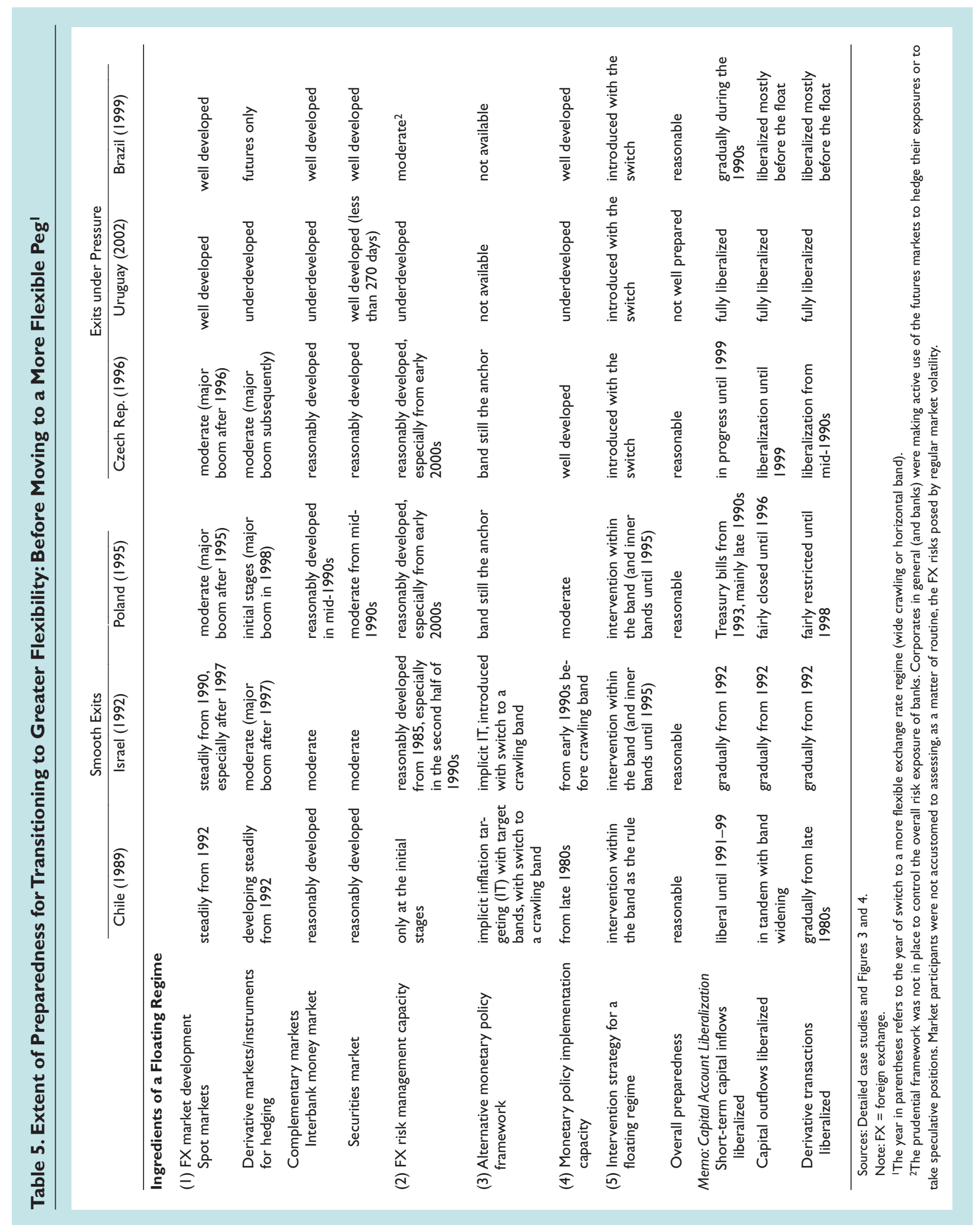


floating are lacking may be beneficial, because the former helps to build the ingredients, whereas introducing too much flexibility without many of the building blocks may be risky and make the transition more challenging.

11. In fact, in the countries exiting their pegs under market pressure, the lack of some, or most, of the ingredients supporting a floating regime prior to the exit complicated the transition to a float and the subsequent stabilization efforts (particularly in the presence of highly dollarized public and private sector balance sheets). Intensive capacitybuilding efforts were required to establish a credible nominal anchor, markets, and instruments in an unstable crisis environment.

12. The experiences also suggest, however, that disorderly exits can be durable, even in the absence of most preconditions at the time of the exit, if the lack of these elements is quickly recognized and addressed through intensive capacity-building efforts. Extensive efforts to put in place the preconditions of IT and to strengthen markets and risk management systems were essential in supporting the operation of the floating regimes, thereby contributing to the durability of the exits in the crisis countries. These efforts also helped limit the severity of the crises and achieve a relatively quick return of policy credibility.

13. Transition to flexibility usually involved testing by the markets of the authorities' commitment (in both disorderly and orderly transitions). Credibility was generally established firmly once the commitment had been tested by the markets. The experiences hence underscore the importance of having consensus and coordination among the key parties in order to make tough decisions, and of a commitment to maintaining consistent policies. 
Part 2

Detailed Country Experiences 



\section{Orderly Transitions}

\section{Chile (1984-99)।}

Chile's transition to a free float was a very gradual, and mostly orderly, process that took about 15 years from the introduction of a crawling band mechanism. The gradual regime shift was in response to changing economic conditions and policy priorities and occurred through successive adjustments to the parameters of the crawling band throughout the period and its eventual elimination in 1999. The floating regime that has been in place since then withstood well the contagion pressures from the subsequent crises in Argentina and Brazil in the early 2000s. The low level of exchange rate pass-through to inflation, limited dollarization of the banking system, the prudent attitude of the private sector to exchange rate risk, the efforts to build over time FX and financial markets, and the capacity to implement an alternative monetary policy framework under greater flexibility have facilitated a smooth operation of the floating exchange rate regime.

\section{Motivations and Factors Triggering the Exit from the Crawling Band}

The gradual switch from the crawling band to a floating exchange rate regime took place through successive adjustments in the parameters of the band during 1984-99, aimed in general at increasing the flexibility of the exchange rate. The adjustments involved a gradual step-by-step widening of the band, changes in its rate of crawl, and discrete adjustments to its central parity (three devaluations and five revaluations). The band was eliminated in September 1999 following a brief period of tightening in mid-1998 against the background of market turbulence in other emerging markets $^{2}$ (see Table 6 for a summary of the evolution of the exchange rate regime). The Central Bank of

\footnotetext{
${ }^{1}$ Prepared by Luis Ahumada (Central Bank of Chile). Camilo Carrasco and Andrea Tokman provided helpful discussions and understanding of the policy changes during the 1990s.

${ }^{2}$ The band was narrowed from \pm 12.5 percent to -3 percent $/+2.5$ percent in June 1998. However, the CBC subsequently decided to widen the band daily, a process that led to its elimination in September 1999.
}

Chile actively intervened within the band, with a view to coping with the pressure on the band exerted by massive capital inflows in the 1990s, and the intervention resulted in a significant increase in international reserves. ${ }^{3}$

Overall, the gradual exit to a floating regime was a response to changing economic conditions, with an attempt by the monetary authorities to resolve conflicts among the potentially incompatible policy objectives in an increasingly global environment. The crawling peg adopted in 1982 had aimed mainly at preserving external competitiveness rather than anchoring inflation expectations, with the central parity set to depreciate according to past inflation. During the 1980s, a band was introduced around the crawling parity, and was gradually widened to \pm 5 percent by 1989 , in part to introduce some flexibility in the FX market that a crawling peg was not able to provide (Morandé, 2001). The band was widened further and eventually abandoned as Chile became increasingly more integrated with and hence more susceptible to developments in international capital markets.

The transition toward greater flexibility was carried out in such a way as to accommodate what clearly became the authorities' ultimate goal: attaining price stability. With the announcement of an explicit inflation target in 1990, achieving price stability became a priority. As strong capital inflows during the 1990s created tensions between the inflation objective and the commitment to maintaining the exchange rate within the band, the CBC acted in favor of the former objective, allowing an increasingly more flexible exchange rate within a gradually widening crawling band. ${ }^{4}$ This prioritization in favor of the inflation target helped boost public confidence in the inflation target despite the presence of the band. From September 1998, the crawl rate was also revised to follow the expected future, rather than past, inflation rate-a shift in the policy approach to anchoring inflation expectations. The exchange rate commitment hence became increasingly

3The CBC's international reserves rose from US $\$ 2.6$ billion at the inception of the band to US\$19.2 billion in October 1997. It fell to US $\$ 14.8$ billion at the time of the band's elimination.

${ }^{4}$ See Morandé (2001) and Schmidt-Hebbel and Werner (2002). 
Table 6. Evolution of Chile's Exchange Rate Regime since 1984

$\begin{array}{ll}\text { Date } & \text { Event }\end{array}$

\section{Crawling band regime}

August 1984

September 1984

February 1985

June 1985

July 1985

January 1988

June 1989

March 1991

April 1994

June 1991

December 199|

January 1992

May 1992

July 1992

December 1994

December 1995

January 1997

July 1998

September 1998

December 1998

\section{Floating exchange rate regime}

September 3, 1999
A formal fluctuation band of $\pm 0.5 \%$ is introduced. External inflation, defined by the Central Bank of Chile Board, adjustment of 3.6\%. Domestic inflation adjustment lagged one month. Domestic basket for the value of the exchange rate is $100 \%$ U.S. dollar.

Devaluation of the nominal exchange rate of $23.7 \%$

Devaluation of the nominal exchange rate of $9.1 \%$

The band is widened to $\pm 2.0 \%$.

Devaluation of the nominal exchange rate of $8.5 \%$

The band is widened to $\pm 3.0 \%$.

The band is widened to $\pm 5.0 \%$.

Band remains at $\pm 5.0 \%$, but external inflation adjustment is set to $0 \%$.

Revaluation of the nominal exchange rate of $\mathrm{I} .4 \%$

The exchange rate is revalued $2.0 \%$ and the external inflation adjustment is set back to $3.6 \%$.

External inflation adjustment is set to $2.4 \%$.

The exchange rate is revalued $5.0 \%$, and the band is widened to $\pm 10.0 \%$.

External inflation adjustment is set to $1.6 \%$.

The band is kept at $\pm 10 \%$, but the peso is fixed to a basket of currencies: $50 \%$ U.S. dollar, $30 \%$ deutsche mark, and $20 \%$ Japanese yen. External inflation adjustment is set back to $2.4 \%$

The exchange rate is revalued $9.70 \%$, and the basket of currencies is realigned: $45 \%$ U.S. dollar, $25 \%$ Japanese yen, and $30 \%$ deutsche mark.

A Balassa-Samuelson productivity adjustment of $2 \%$ is applied to the center of the band.

The exchange rate is revalued $4.0 \%$, and the band is widened to $\pm 12.5 \%$. The basket of currencies is realigned: $85 \%$ U.S. dollar, $5 \%$ Japanese yen, and $15 \%$ deutsche mark.

The band is tightened, $3.0 \%$ from below and $2.5 \%$ from above. The productivity adjustment is eliminated.

The band is set symmetrical again to $\pm 3.5 \%$. The band is set to progressively broaden to reach $\pm 5.0 \%$ on December 3I, 1998 (marking the first steps toward a flexible exchange rate regime). The external inflation adjustment is eliminated, and the central parity is made to crawl according to a target rather than past inflation. The daily adjustment factor is set to $0.013575 \%$.

On December 24 the band is widened to $\pm 8.0 \%$ with the same factor of daily widening of the band.

Sources: Morandé and Tapia (2002); and Central Bank of Chile, Annual Reports.

secondary vis-à-vis the inflation target. ${ }^{5}$ The float, following almost a decade of implicit IT, aimed at improving the credibility of the inflation target, reflecting a recognition that successful control of inflation would not be achieved with two coexisting nominal anchors.

\footnotetext{
${ }^{5}$ See De Gregorio and Tokman (2004) and Tapia and Tokman (2004)
}

The formal inflation target has been the only nominal anchor since 1999.

External factors also played a role in Chile's move to a flexible exchange rate regime with full-fledged IT. A significant fall in GDP growth and inflation after the Asian crisis in 1997 led the monetary authorities to embark on a substantial enhancement of the macroeconomic framework, the main elements of which 
were the adoption of a floating exchange rate regime, the deepening of the FX derivatives market, and a complete opening of the capital account. The gradual abandonment of the band was also part of an international trend (Morandé and Tapia, 2002): Integration of capital markets made it difficult to manage hybrid exchange rate systems, as demonstrated most recently by the Asian crisis; the authorities, seeing that the only viable options were either to float or to adopt a currency board, chose the first option (Morandé and Schmidt-Hebbel, 2000). Finally, the period when the band was eliminated was a relatively calm one, domestically as well as internationally; the absence of pressures in the FX market in either direction, with the peso being close to the band's center, provided the authorities with an opportune time to exit (Morandé, 2001).

The floating of the currency was also facilitated by diminishing concerns typically associated with the fear of floating. A lower degree of exchange rate passthrough and the availability of hedging instruments against inflation and exchange rate risks were factors that, once reasonably measured and evaluated, facilitated the gradual widening and subsequent elimination of the band. There were initial fears of potential balance sheet effects of a large depreciation on the corporate sector, particularly during 1998. However, an increasingly more flexible exchange rate had created strong incentives for the development of a forward market (see below), which helped the private sector be more prepared to take on exchange rate risks than it had in the past. The exchange rate pass-through coefficient also proved to be much smaller than previously thought, so fluctuations in the exchange rate would have a lesser impact on inflation (Morandé, 2001). All these factors together facilitated the elimination of the band in late 1999 and the adoption of full-fledged IT in 2000 , once the CBC established that risks to financial stability from floating were not significant.

\section{Coordination of the Exit with the Supporting Elements of Float}

Evidence suggests that the Chilean economy was prepared for floating well before the regime switch in 1999. Several elements supporting a floating regime were present when the authorities eliminated the crawling band (see Figure 3a): A relatively low degree of exchange rate pass-through, a well-developed and regulated financial sector, highly developed derivatives and financial markets, and a low level of dollarization with limited exposure of the banking and corporate sectors to FX risks minimized the potential negative effects of letting the currency float and mitigated the fears of floating (De Gregorio and Tokman, 2004). The authorities had already been implementing (since 1990) an implicit IT framework and had effective instruments for conducting monetary policy under greater exchange rate flexibility.

\section{The Foreign Exchange Market}

FX spot and derivatives markets developed steadily from 1992 until the float. In the mid-1980s, the operation of a forward market was authorized in conjunction with the widening of the crawling band; banks were allowed to trade FX forwards with maturities between 15 and 180 days with market-determined forward rates, which facilitated the deepening of this forward market. Spot and forward markets continued to develop as the authorities liberalized over time the regulations affecting arbitrage operations, authorized swap transactions, eased access to the FX market, and allowed greater exchange rate flexibility within the crawling band. At the time of the float, the onshore spot, forward, and swap markets and the offshore NDF market were all well developed (Ahumada and others, 2006).

Increased exchange rate flexibility has continued to stimulate the FX market since the float. The turnover in the FX derivatives market rose from 0.06 percent of GDP in 1993 to 1.4 percent of GDP in 1998, and to 2.9 percent by 2003 . The cost of hedging also declined during this period; the spread on a forward contract fell from 26 basis points to 16 basis points between 1998 and 2003, comparable to that in the OECD countries (De Gregorio and Tokman, 2004). Overall, the activity in the Chilean spot FX market is not substantially different from that observed in more developed economies. The level of FX derivatives market activity is slightly above that in other emerging economies, but considerably lower than that in developed economies (Ahumada and others, 2006).

\section{FX Risk Management}

At the time of the peso's float, both the corporate and banking sectors had established sufficient capacity to manage FX risks. The financial sector was more exposed than the corporate sector to FX risks, before and after the elimination of the band, but 90 to 100 percent of bank net exposure was hedged, compared with 40 percent for the corporate sector (Chan-Lau, 2005).

The banks were more familiar with risk management tools and were able to hedge in offshore markets. The liberalization of the currency mismatch regulations was somewhat gradual, adopted to prepare the system for a flexible exchange rate. The regulations adopted after the 1982 banking crisis initially limited the mismatches to 20 percent of the absolute value of Tier I capital. Several operations were excluded from this limit and separately treated. In 1995, banks were required to finish daily with a long cash position 
in their trading activities. FX operations and derivatives transactions were permitted only to support trade activities or investments abroad. In August 1998, the global limit was maintained but the computation of mismatches was distinguished among currencies (Cowan and De Gregorio, 2005). In 1999, currency mismatch regulations were amended to incorporate all FX operations, and a framework for managing liquidity and interest rate risk was introduced. Futures, forwards, swaps, and combinations thereof were permitted and the authorization requirement to engage in derivatives transactions with external counterparties was eliminated by 1999. Currency mismatches of debtors were incorporated in the credit evaluation of banks only beginning in 2000 .

The corporate sector had a prudent attitude toward exchange rate changes even before the float and retained it subsequent to the elimination of the band. The firms were adequately matched in terms of currencies for the 1995-2003 period, which indicates that even in the prefloating period they were aware of the risks of currency mismatches (Cowan and De Gregorio, 2005). However, there is also some evidence that the mismatch trend was increasing until 1998, but with the depreciation of the peso that started in 1999 and the subsequent float, the FX exposure of domestic firms declined persistently (De Gregorio and Tokman, 2004). Nevertheless, during this period FX exposure was significant for only 13 percent of publicly listed firms and the exposure affected only 17 percent of all industries in the corporate sector in the late 1990s (Dominguez and Tesar, 2001; and Chan-Lau, 2005).

Moreover, effective exposure of the corporate sector to currency risk was also low. Most of the firms were naturally hedged, being located in the tradables sector. The share of firms hedging their exposures increased over time, from 8 percent in 1993 to 21 percent in 1998 , with a continued increase after the float to 33 percent in 2003. Domestic corporations reportedly use mainly the onshore market to hedge their FX exposures. The U.S. dollar-peso forward market has the active participation of medium and large firms; the access of smaller enterprises to the forward market has been limited somewhat by counterparty credit risk and lack of sophistication. The offshore market has been used mainly by leveraged foreign investors (Chan-Lau, 2005).

The private sector's FX risk management capacity has been supported by a number of factors. A tightening of prudential rules, in response to an earlier banking crisis but before the move to a floating exchange rate, supported risk management (for example, minimum credit rating requirements for domestic corporations' external borrowing in the 1990s). The gradually widening crawling band also likely provided a limited implicit guarantee to those holding unhedged foreign liabilities, thereby limiting unhedged exposures (De Gregorio and Tokman, 2004; and Cowan and De Gre- gorio, 2005). Managing FX risks has been facilitated by a well-functioning and liquid forward market.

\section{Monetary Policy and Operations}

The changes in the exchange rate regime proceeded hand in hand with the efforts to establish an alternative monetary policy framework that would replace the exchange rate anchor and to build the capacity to conduct monetary policy under a flexible regime. The adjustments to the crawling band were mostly directed at increasing the degree of exchange rate flexibility and were accompanied by efforts to reduce inflation through a gradual adoption of a full-fledged IT framework (Céspedes and Soto, 2005). From 1989, a preannounced inflation band target coexisted with the crawling band. Full-fledged IT was introduced with the elimination of the crawling band, and the inflation target, under a fully floating exchange rate, has become the sole anchor for inflation expectations.

Most of the elements of a full-fledged IT regime were already in place before the exit to the floating regime in 1999. These elements, which were built over time, included the autonomy of the CBC since 1989, well-developed and liquid financial markets, an effective capacity to conduct monetary operations, and a reasonable capacity to model and forecast inflation. Over the years, the CBC gained credibility through its success in meeting the (implicit) inflation targets and improved transparency through the publication of its regular inflation reports and the release of the minutes of its policy meetings. Efforts to build capacity to affect short-term interest rates and conduct effective monetary policy operations started in the late 1980s and continued until the float. A reasonably good understanding of the monetary transmission channel helped in implementing daily interbank rate targeting from 1995, an important step in modernizing the monetary policy procedures.

\section{FX Intervention Strategy}

Foreign exchange market interventions were a common and expected feature when the crawling band was in place. The $\mathrm{CBC}$ had the authority to intervene in the market at its discretion, even if the exchange rate was far from the band limits. Intramarginal interventions were in fact a frequent practice during the 1990s. After the elimination of the band, a free floating exchange rate system was adopted, under which a new intervention strategy had to be determined.

The authorities announced a new intervention strategy at the time of floating. Although the CBC abandoned the commitment to keep the peso within a band, it announced the possibility of intervention in exceptional situations involving a sudden increase in exchange rate volatility, with a view to dealing with external and/or 
internal instability and reducing the speed of currency depreciation. The CBC also announced that it would inform the market about such decisions. No explicit predetermined rule for intervention was established, but explicit communication of intervention intensity was considered important for credibility. So that they do not become a common practice, interventions have been made transparent and details announced in advance, including the specific period during which the CBC could intervene and the maximum amounts to be used. Interventions were aimed at providing a signal to the market that the authorities considered the evolution of the exchange rate not justified by fundamentals and the extent of the depreciation excessive (De Gregorio and Tokman, 2004). ${ }^{6}$

\section{Sequencing with Capital Account Liberalization}

Chile's capital account liberalization gradually moved parallel to its exchange rate liberalization (Le Fort-Varela, 2005). The adjustments in the regulations aimed to support the crawling band by reducing the net inflow of capital and stemming the appreciation of the peso. Following the surge in capital inflows, capital outflows were gradually liberalized along with the widening of the band. ${ }^{7}$ In addition, controls were imposed on short-term capital inflows from June 1991, aimed at retaining the possibility of managing the exchange rate with an independent monetary policy. These controls were primarily market based, in the form of an unremunerated reserve requirement, and were tightened several times to increase the rate or to broaden its scope (see Ariyoshi and others, 2000; and Le FortVarela, 2005). The inflow controls were lifted in 1998, and all remaining controls on inflows and outflows were removed in 2001, well after the regime shift. Controls on derivatives transactions were relaxed from the mid-1990s to 1999 to facilitate the handling of FX risks under more flexible exchange rates.

\footnotetext{
${ }^{6}$ The CBC has intervened in the market twice since 1999: first in August 2001, in response to the regional financial disorder caused by the crisis in Argentina, followed by the turbulence in international capital markets after the events of September 11. The CBC announced that from that date to the end of the year, it could intervene in the FX market that was operating under a free floating regime; it also announced the resources available for intervention. The second intervention took place in October 2002 and was attributed to the pressures on the Brazilian real. Both attempts to influence the exchange rate are considered to have been successful. Similar announcements were made in October 2003 for possible FX intervention (Tapia and Tokman, 2004).

${ }^{7}$ The minimum time to repatriate capital and earnings for FDI capital was reduced successively during 1991-93 from 10 years in 1985 to 1 year in 1993, and eliminated in 2000. Banks were allowed to invest abroad up to 40 percent of their funds collected as term deposits in 1991, and the amounts that pension funds were allowed to invest abroad were increased successively during 1992-99.
}

\section{Other Supporting Elements}

At the time of the move to a floating regime, the banking sector was sound and compliant with supervision and regulation. The banking sector, built over the 1990s, had a sustained large capital base and kept a low level of dollarization, accompanied by a strict regulatory and supervisory framework that limited banks' exposure to credit and currency risks. Chile also successfully created a unit of indexation to hedge inflation risk. Since the early 1980s this unit has been widely used in deposit contracts and to finance long-run real estate loans. The quality of the loan portfolio of the banks was high, with nonperforming loans reaching at most 3 percent of total loans under the worst-case scenarios before the Asian crisis. ${ }^{8}$

A well-developed domestic capital market also supported the flexible exchange rate regime. The development of the domestic capital market allowed several firms to change the composition of their debt by issuing long-term bonds denominated in Chilean pesos to reduce their FX exposures and vulnerability to large depreciations in the currency. The development of the capital market was due in part to the increasing importance of institutional investors, mainly pension funds, which made up a sizable share of the demand for debt instruments in the domestic market through the 1990s.

A prudent fiscal policy was also a key ingredient in Chile's success in disinflation and transition to a new nominal anchor (Morandé, 2001). Over this period, fiscal authorities managed to maintain a fiscal surplus, which allowed monetary authorities to implement a monetary policy that eventually lowered inflation from two-digit chronic levels to those observed in developed countries.

\section{Challenges Faced and Lessons from Chile's Transition Experience}

Chile's transition to a full float was a fairly lengthy process because of the significant emphasis the authorities placed on the presence of the supportive elements for a floating regime. The regime shift took about 15 years, even though the economy was apparently well prepared, with the essential conditions already in place well before the float. The trigger for the eventual decision seems to have been the extent to which the prevailing multiple monetary objectives became incompatible. As in the other gradually exiting countries (Israel and Poland), the monetary authorities considered that it would be hard to defend an exchange rate band that allowed for a gradual depreciation of the currency within a crawling band, while at the same time ful-

\footnotetext{
${ }^{8}$ The Basel I framework was incorporated only in 1997 along with a substantial amendment of the banking law, which broadened the scope of banking activities.
} 
filling the inflation rate target. The pace of the exit, however, seems to have been greatly affected by the authorities' comfort level about the preparedness of the economy.

The main challenge confronting the authorities was to determine whether the economy was sufficiently prepared for the floating regime. Assessing the state of preparedness for the float and hence the right time to move was difficult. In particular, the authorities had feared that the liberalization of the exchange rate and the associated volatility in the FX market could endanger the low and stable inflation goal and, therefore, the credibility of the central bank, as well as the financial stability of the economy. ${ }^{9}$ In fact, the fear of losses from currency mismatches in the corporate sector and of the potential pass-through of exchange rate changes to inflation contributed to delaying the exit by several years.

The lack of reliable and prompt information to assess these risks was the main contributor to the difficulty of assessing the level of preparedness. The degree of exchange rate pass-though, which the authorities had considered to be high, was actually decreasing over the 1990s, and hence was overestimated, especially in light of the consumer price index (CPI) inflation index. ${ }^{10}$ Similarly, the lack of reliable, prompt information about the balance sheets of the corporate and household sectors and uncertainty about the level of development of the domestic derivatives market undermined the authorities' ability to assess the potential negative consequences of a sudden exchange rate depreciation. The mismatches turned out to be less substantial and the availability of hedging better than had been assumed. The widespread use of dollar-peso forward operations introduced in 1992 and the deep market for peso-indexed bonds allowed market participants to hedge against currency risk.

The following lessons can be drawn from Chile's experience with the regime transition:

- The gradual evolution of exchange rate flexibility and capital account liberalization can support each other. A gradual increase in the flexibility of the exchange rate helped Chile obtain the benefits of a growing integration with capital markets, while lessening its risks. Gradual liberalization of capital outflows, a more cautious liberalization of the

\footnotetext{
${ }^{9}$ After many years of intervention in the FX market and a relatively predictable nominal exchange rate, the corporate sector could have developed significant exposure to FX risk and greater exchange rate volatility.

${ }^{10}$ The diminishing pass-through over the CPI could have also been the consequence of the institutional credibility gained by the central bank and the government in successfully pursuing lower inflation and a sustained policy of a balanced budget. Hence, depreciations of the exchange rate could be perceived by agents as a transitory adjustment mechanism to changes in external conditions.
}

short-term inflows, and an early liberalization of derivative transactions facilitated this integration, as market participants gained expertise and monetary authorities prepared for a move to a full float.

- Early preparation helps address fears of floating and increases the chances of a successful and smooth exit. In the case of Chile, building the capacity to manage FX risks and implement monetary operations, developing FX markets, and preparing since the early 1990s for an alternative monetary anchor toward full-fledged IT were vital in making a smooth transition to a floating regime. In addition, the CBC's transparent and effectively communicated intervention strategy also contributed to establishing the credibility of the floating regime and the IT framework.

- The availability of a timely and adequate information base is crucial in assessing the extent of preparedness. In the case of Chile, prompt information on private sector balance sheets and on dynamics between the exchange rate and inflation could have helped avoid an undue delay in moving to greater flexibility, which in turn could have been helpful in responding to external shocks that hit the domestic economy in the late 1990s.

- The Chilean experience also illustrates the mutually reinforcing relationship between greater exchange rate flexibility and market and capacity building: Introducing greater flexibility through a gradually widening crawling band encouraged better FX risk management and spot and forward FX market development, which in turn helped support the move to a fully flexible exchange rate regime in 1999.

- Finally, building a sound financial system and a deep capital market is also crucial in avoiding potentially disruptive consequences of a move to a flexible exchange rate regime. The strict supervision and regulation of the banking system, the emergence of a large institutional investor base, and the successful introduction of various financial instruments (for example, inflation-indexed bonds) were helpful in coping with greater exchange rate volatility under the floating regime.

\section{Israel (1985-2005)||}

Israel's transition from a pegged exchange rate to a floating exchange rate was extremely gradual, lasting

\footnotetext{
${ }^{11}$ Prepared by Barry Topf (Bank of Israel). The author thanks Sarah Cohen for her assistance with data, and numerous staff of the BoI for the information and experience they provided.
} 
exactly 20 years, from 1985 until 2005. In fact, gradualism was a central principle of monetary policy, with a clear preference for moving in small incremental steps, which in aggregate and over time produced the desired results. The exchange rate regime evolved continuously in response to changing economic conditions and to the need to resolve conflicts emerging from the pursuit of multiple objectives in an increasingly global environment. Although there was no deliberate overall plan at the beginning of the transition, the process was coherent, based on gradual steps that strengthened credibility while avoiding reversals, integration with supporting measures in other areas, and prompt and appropriate responses to emerging concerns before they could lead to severe pressures.

\section{Factors Motivating the Transition}

Israel's transition from a fixed peg-the nominal anchor in a heterodox disinflation plan-to increasing exchange rate flexibility was part of the move to an IT regime. Over 20 years, Israel moved from a monetary policy based on exchange rate targeting to one based on IT. Policy over that period was aimed at resolving the conflicts that arose from trying to achieve multiple and sometimes conflicting objectives. Details of the changes in the exchange rate regime and its parameters are presented in Table 7.

\section{From Fixed Peg to the U.S. Dollar to a Basket Peg}

The fixed peg to the U.S. dollar adopted as part of the Economic Stabilization Plan of 1985 helped stabilize the economy, but its limitations quickly became apparent. The single currency peg was meant to quickly restore nominal stability and achieve credibility in anti-inflationary policies, given the widespread direct and indirect impact of the exchange rate on the Israeli economy. Inflation fell immediately from 400 percent to 20 percent per annum, in part because of the visibility of exchange rates and their impact on expectations. Although the peg was advantageous in terms of transparency and public perception, it did result in exposure to changes in the international value of the dollar during a period when cross rates were especially volatile. In an effort to reduce this exposure, after one year the sheqel was pegged to a basket of currencies that reflected the composition of Israel's international trade.

In addition to reducing the impact of fluctuations in world exchange rates, the peg to a basket rather than a single currency brought additional benefits. It introduced an element of flexibility by allowing variation in the bilateral exchange rates (especially against the dollar) most visible to the public and encouraged more sophisticated risk management as market participants understood the need to hedge against changes in the basket. The composition of the currency basket was reviewed annually and changed, if deemed necessary, according to predetermined rules, without affecting the exchange rate prevailing at the time.

\section{From Basket Peg to Horizontal Band}

Although fixed exchange rates contributed to restoring credibility to economic policy and reducing inflation, their drawbacks became more apparent over time. With inflation higher in Israel than among its trading partners, the sheqel underwent considerable real appreciation and loss of competitiveness. The unsustainability of fixed exchange rates, given large and persistent inflation differentials, made the sheqel the target of speculative attacks, which led to periodic devaluations. In addition, the lack of flexibility in exchange rates led to a lack of balance in policy tools: All adjustments (for example, to external shocks) had to be made solely through changes in interest rates or foreign currency reserves, which led to wide swings in both. The desire to avoid such swings led to the adoption of horizontal bands in January 1989.

Horizontal bands introduced an element of flexibility in exchange rates while reducing volatility and maintaining confidence in the disinflationary process still under way. The exchange rate-in basket terms - could vary within predetermined limits around an announced central rate. The exchange rate against any single currency, including the dollar, was a function of international cross rates. The horizontal band system led to a significant decrease in the volatility of interest rates and more stability in the level of foreign currency reserves. However, the still-large inflation differentials between Israel and its trading partners, together with the discrete nature of changes in the central rate, continued to induce large capital movements and speculative pressure on the sheqel. As a result, the central rate was devalued four times in three years, by amounts ranging from 6 to 10 percent.

The width of the band was initially set at \pm 3 percent, and widened to \pm 5 percent after approximately one year. $\mathrm{A} \pm 3$ percent width was established to balance the need for sufficient flexibility to give substance to the band while avoiding excessive volatility in the exchange rate, which was still an important nominal anchor. Any narrower band was perceived as providing neither sufficient impetus for market development nor sufficient flexibility to relieve some of the strain on interest rates and FX reserves. On the other hand, moving too quickly to too wide a band might have introduced excessive volatility into the system without adequate time to adjust by, for example, introducing more sophisticated risk management practices. Once the market had adjusted smoothly to the \pm 3 percent band, widening it to \pm 5 percent was continuation of the policy of allowing greater flexibility. 
Table 7. Evolution of Israel's Exchange Rate Regimes, 1 985-2005

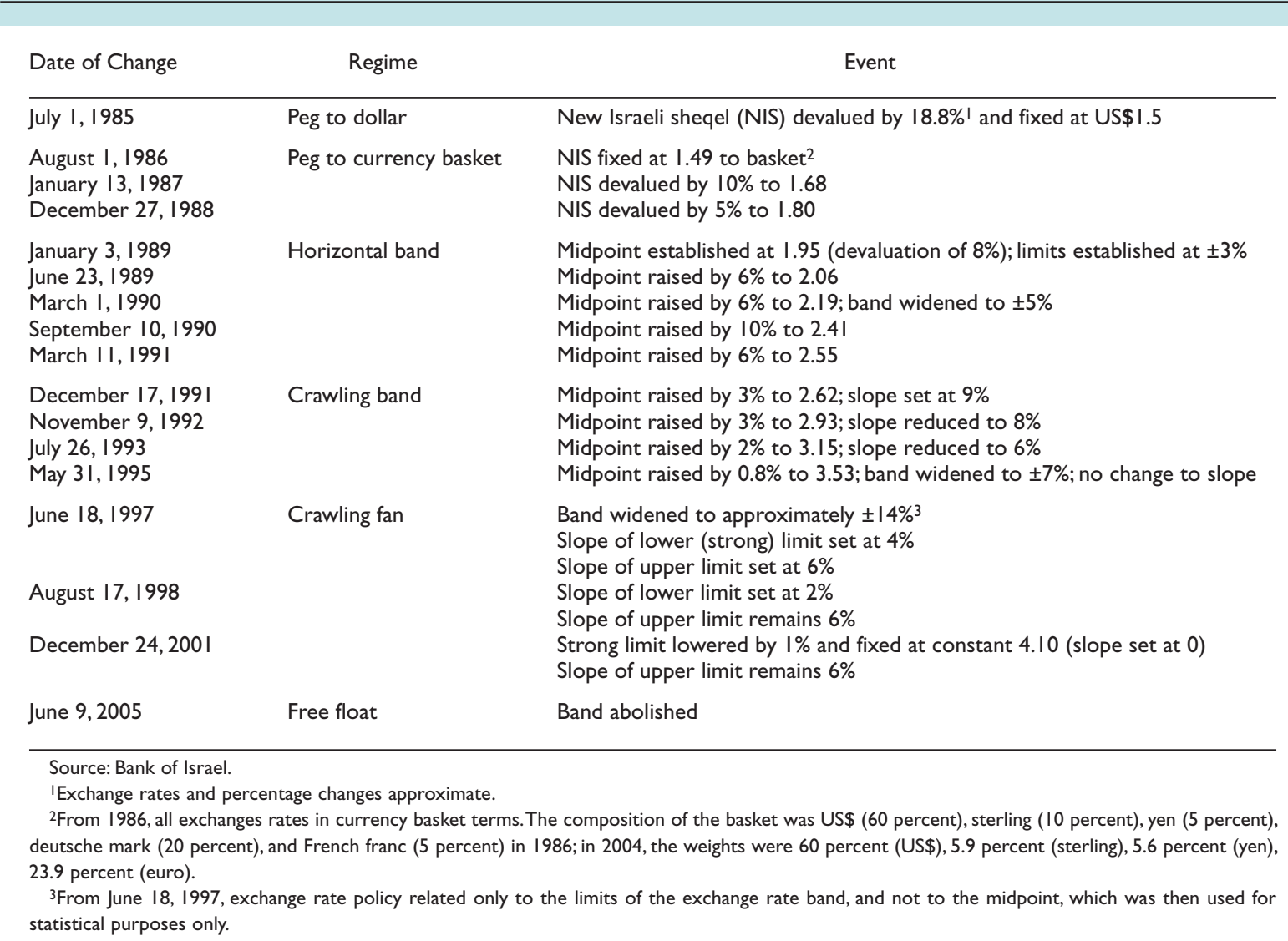

\section{From Horizontal to Crawling Bands}

In December 1991, the crawling band replaced the horizontal band; this change was made primarily to prevent periodic speculative cycles around realignments of the central rate. In the crawling band regime, the exchange rate could still vary around the central rate, defined in basket terms, but the central rate itself changed by a preannounced amount (the slope of the crawl) each day. The slope was the difference between the expected inflation rate in Israel and that of its partners; the crawl was one of the benefits of the new regime: The crawling band introduced de facto IT to Israel before it was officially introduced. The crawling band significantly reduced the frequency and magnitude of realignments, permitted smoother adjustment of the exchange rate, and lowered uncertainty regarding the real exchange rate.

\section{From Crawling Band to Crawling Fan}

Over time, pressures associated with increased capital mobility created a need for increased flexibility of the exchange rate. Although inflation was declining, this decline was a result of a disinflationary monetary policy requiring high nominal and real interest rates. Together with an improving geopolitical environment and strong economic growth, capital flows into Israel grew rapidly and exerted considerable upward pressure on the domestic currency. The level and width of the band (despite its widening in 1995) did not provide enough flexibility to avoid a clash between two conflicting goals: the rate of inflation and the exchange rate. The sheqel moved to the strong (lower) limit of the band, and the BoI was forced to defend the exchange rate band by buying foreign currency, in amounts and at a cost that threatened to become unsustainable. The ensuing costs of sterilization and desire to resolve conflicting goals led to the adoption of the crawling fan regime in June 1997.

The crawling fan was a response to the pressures generated by attempting to simultaneously target inflation and exchange rates by substantially increasing the actual and potential variability of the exchange rate. The slope of the lower (stronger domestic currency) limit of the band was reduced to 4 percent while the 
upper (depreciation) slope was left at 6 percent. Thus, the width of the band increased constantly over time, automatically increasing the flexibility of the regime. The central rate was abolished so as to remove any perceived target for the exchange rate. Most notably, the width of the band was increased asymmetrically to approximately \pm 14 percent: The weaker (upper) limit was raised and the stronger (lower) limit was left unchanged (although with a reduced slope).

This last step might seem counterintuitive, because the lower (more appreciated) limit of the band had been under attack yet the policy response was to shift the upper (more depreciated) limit. The motivation for this shift was twofold: First, it was felt that moving the lower limit under speculative pressure would severely damage the credibility of economic policy. Second, moving the upper band greatly increased the potential scope for depreciation. Taking advantage of high domestic interest rates was no longer a virtual one-way bet; the increased risk was expected to help restore equilibrium, which did indeed occur. With the adoption of the crawling fan, the BoI was able to stop its market intervention, a policy it maintained (with the exception of a few days later that year) until the formal abolishment of the band eight years later. The nonintervention policy was tested a number of times, and with each episode the credibility of the policy was strengthened.

\section{From Crawling Fan to Free Float}

The constantly increasing width of the band and further reductions in the slope of the appreciated sheqel limit rendered the band increasingly irrelevant, but it was only formally abolished in June 2005 , by which time the band had a width of about 62.5 percent around a theoretical midpoint. Several factors account for the de jure preservation of the band even after it had lost de facto significance. First was the difficulty in identifying in real time its loss of significance; even in retrospect, it is difficult to discern a specific time when it stopped being effective. Second, even when the band appeared to be ineffective regarding the actual exchange rate, there was a belief that its existence affected the behavior of the market, and that its abandonment could have been destabilizing. In addition, the de jure abolishment of the band was opposed in certain quarters because of the greater freedom of action it allowed the central bank, even if only in principle.

\section{Coordination of the Regime Transition with Supporting Elements}

In Israel, each stage of the transition to greater exchange rate flexibility was coordinated with steps in other areas to support a more flexible exchange rate regime. Important supporting elements included development of the FX market, intervention policy, capital account liberalization, ensuring financial system stability, and effective monetary policy and instruments.

\section{The Foreign Exchange Market}

The FX market in Israel developed in tandem with the evolution of the exchange rate regime, with considerable synergy generated between them. The development of the market was actively promoted by the BoI, because exchange rate flexibility would have been less effective without a mechanism by which the market could determine the rate.

Until May 1990, the BoI was the sole market maker and operated what was essentially an administrative fixing. At an appointed time each day, the commercial banks reported their net supply or demand for foreign currency; the central bank then set one rate, at which it bought or sold foreign currency against the banks. This method was very efficient from an operational point of view, and not incompatible in a regime of fixed or highly managed exchange rates. However, it precluded the development of the market and appropriate risk management.

In May 1990, shortly after the introduction of the horizontal band, the BoI introduced a new trading mechanism, based on an electronic trading platform, as a first step toward developing a more sophisticated market. During a single daily multilateral trading session, managed by the BoI, the aggregate net supply of or demand for foreign currency was offered to the market, which could then participate as the auction progressed until the market cleared. All transactions were conducted at the single final rate, which became that day's official exchange rate. Although this method increased transparency and allowed market forces to play a greater role in determining the exchange rate, the BoI was still dominant in the market.

In July 1994, the BoI began phasing out the multilateral trading system, abolishing it in April 1995, just before the further widening of the crawling band. In its place banks had to negotiate trades among themselves on a bilateral basis. This over-the-counter continuous trading was identical to the interbank markets that characterize FX trading in advanced economies. Trading volumes, though still relatively modest, grew steadily, as did the role of foreign investors and financial institutions. The market developed and expanded with the entry of interbank brokers, foreign financial institutions, electronic trading, and the addition of derivative products including swaps and options, spurred by the significant increase in the flexibility of the exchange rate regime from 1997. It is interesting to note that at the time of the development of interbank trading, its potential benefits had not been fully realized by the market or the authorities, thus illustrating the value of putting in place supporting measures even when the immediate need is not yet evident. 
The market for FX hedging instruments had been growing steadily before the de facto float in 1997, in part reflecting the active involvement of the BoI and in part the gradual increase in exchange rate flexibility. The market was stimulated by recognition of risks associated with a more flexible exchange rate as the authorities gradually widened the crawling band starting in the mid-1990s. Withdrawal of the BoI's intervention in the FX market in 1997 contributed significantly to risk recognition by the private sector, and thereby to the development of the hedging instruments. The BoI also played a direct role in developing hedging markets, by issuing financial instruments for the sole purpose of kick-starting financial markets in new instruments (such as FX futures and options) in 1989 (Appendix IV). Contributing to the development of the hedging markets was the gradual removal of restrictions on forward transactions, which facilitated a better management of FX exposures.

The authorities nevertheless recognized the risk that derivative transactions could facilitate speculation. There were fears that forward transactions could allow speculative attacks and were harder to control. Indeed, forward transactions played a major role in the speculative attacks on the sheqel. In most cases, however, the pressures were created when there were discrepancies between economic fundamentals and the policy regime, and the latter was adjusted to reduce these discrepancies. It was also recognized that maintaining restrictions on derivative transactions could lead to the development of derivatives markets offshore in an attempt to circumvent onshore restrictions.

When liberalizing derivative transactions, the authorities therefore established some safeguards to limit such risks. For example, documentation requirements were used for underlying transactions for a considerable period. Permitting forward transactions was done in stages by tenor (for example, first forward up to one month, then three months, then six months, and then one year, at which point all restrictions were lifted). Although the use of options was not considered an avenue for speculation and their market development was promoted actively, a documentation requirement to prove that options were used for hedging purposes was maintained. Banks' direct and indirect exposures to $\mathrm{FX}$ risks associated with derivative transactions were also incorporated in prudential systems (for example, forward exposures incorporated in open FX positions and capital requirements).

\section{FX Intervention Policy}

The BoI's intervention policies evolved parallel to the changes in the formal regime-gradually but steadily toward ever greater flexibility. Although the general trend was to try to reduce intervention as much as possible, intervention was often used as an ad hoc response to exchange rate developments. Tactics and methods responded to changes in the FX regime or to developments in the market, often on almost a trialand-error basis. It is likely that the lack of coherence in intervention policies was costly in terms of central bank credibility as well as financially.

During most of the period of horizontal and crawling bands, the exchange rate was much less variable than that permitted by the band. The BoI intervened regularly during this period, at times trying to influence the path of the exchange rate, at times keeping it within an informal "inner band." To a great extent, the informal band was an attempt at a compromise to allow flexibility in the exchange rate while avoiding negative consequences. Preventing too great a real appreciation and thus preserving the competitiveness of exports was a major motivation behind the attempt to steer the exchange rate while dampening excessive volatility. Therefore, preserving a nominal anchor role for the exchange rate was one of the reasons for maintaining a narrow inner band.

The distribution of the exchange rate was far from symmetrical, with the exchange rate most frequently in the lower (stronger) part of the band. The BoI usually resisted nominal depreciation of the sheqel much more strongly than it resisted appreciation, which could be attributed to the disinflationary process in Israel at that time. In light of a hyperinflationary past, structural rigidities, and the strong pass-through effect of the exchange rate on inflation, it was feared that depreciation could have a negative effect on the credibility of policies. As market participants gained confidence in the commitment and ability of the BoI to keep the exchange rate in a relatively narrow band, the attractiveness of exploiting the still-high interest rate differential in favor of the sheqel increased, stimulating capital inflows.

In mid-1995 the BoI reduced its market intervention in an effort to wean the market from its dependence on the central bank. It ceased intervention totally for some months in 1996. However, in August of that year intervention resumed, when capital inflows pushed the exchange rate to the lower edge of the band, and grew in intensity until June 1997, when intervention effectively stopped permanently with the move to the crawling fan. The commitment to a more flexible exchange rate underwent a severe test in the fall of 1998, when contagion from the Russian debt crisis and Long-Term Capital Management (LTCM) affair, together with local developments, precipitated a rapid and sizable depreciation of the sheqel. The willingness to tolerate large moves in the exchange rate without intervening in the market, while responding to inflationary pressures within the framework of monetary policy, played a decisive role in establishing the credibility of monetary policy, which has remained high ever since.

The means of intervention also varied as the FX market developed. Until 1990, when it operated through a 
fixing system, the BoI was the sole market maker and cleared the market, with intervention largely determined by the net demand and supply of the banks. During the multilateral trading period, there was greater flexibility in both the exchange rate and the trading system so the BoI could be more responsive to market developments and tailor intervention accordingly. After 1995, greater exchange rate flexibility and the introduction of continuous interbank trading made intervention more challenging. When inner bands were used, both the timing and amount of intervention were highly discretionary and attempted to gauge and respond to market moves. When policy was to intervene only at the limits of the band, timing and quantity issues were largely resolved; intervention occurred whenever the limits were reached, and in amounts needed to defend it. Whenever possible, efforts were made to reduce intervention, either to preserve the reserves or to reduce the cost of sterilization.

Policy became more transparent over time. Initially, the BoI's goals (other than the formal bands) were not made public, although they were usually quickly identified by the market. Intervention was unannounced, although in a market as circumscribed as Israel's, it was not difficult for the market to learn of the intervention. Eventually, a formal policy of nonintervention within the band was formally adopted as central bank policy, and, as described above, this policy gained considerable credibility; at the same time it helped the market learn to cope with exchange rate uncertainty and contributed to the development of FX hedging markets and instruments.

\section{Other Supporting Elements}

The gradualist approach was not limited to the exchange rate regime: The rest of the financial system underwent a similar gradual process of reform concurrent with the evolution of the FX regime. The government and the BoI greatly reduced their roles in the financial market and the banking system, even stopping their involvement in the allocation of credit or determination of interest rates on loans and deposits. Efforts were made to develop the capital markets, including the government bond market and nonbank financial intermediation. The government reduced the issuance of targeted nonmarketable securities to institutional investors, and increased the issuance of standardized marketable securities (including long-term nominal bonds), which greatly increased the liquidity and efficiency of the capital markets.

Capital account liberalization proceeded in a gradual manner, with the sequence of reforms complementing increased exchange rate flexibility. Because Israel had long faced a structural foreign exchange deficit, it was thought prudent to begin with the liberalization of inflows, which began in 1988; restrictions on outflows began to be lifted in 1992. Because long-term flows are generally less volatile than are short-term capital flows, restrictions on long-term flows were generally lifted two to three years before those on short-term flows.

There was also differentiation by sector, with restrictions generally lifted first for nonresidents, followed by the business sector, households, and, finally, institutional investors. Allowing nonresidents freedom of action attracted new participants with diverse views to the market, so that along with the usual benefits of foreign investment, a potentially stabilizing factor was added to the FX market. In many cases the foreign sector has in fact been a source of stabilizing speculation. Restrictions on households and institutions were the last to be lifted, because having been prohibited from investing abroad for many years, they were seen as having large pent-up demand for foreign exchange, which, if released too early or too rapidly, could destabilize the capital markets.

Monetary policy instruments were developed to support the transition to IT. Reserve requirements were drastically reduced, short-term central bank bills were introduced, and the policy interest rate became the primary channel of monetary policy. These steps were taken at a relatively early stage, before the crawling band was introduced, thereby facilitating implementation of monetary policy under a more flexible exchange rate.

Ensuring financial stability was a vital element in the successful transition to exchange rate flexibility. In particular, banks and supervisors had gained the necessary capabilities to monitor and manage FX risks by the time of the formal move to a free float. After the 1983 banking crisis, the prudential supervision of the banks was improved so that when the move to greater flexibility began, the banks' capital base had been strengthened and modern market risk management techniques were in place. In 1985, limits on open FX positions were enacted. By 1997, banks were required to adopt explicit policies regarding their management of direct and indirect FX exposures. Banks were also required to report their exposures both to the supervisor of banks and to the public. Stress testing was introduced in 1999. At times, specific prudential steps were taken, such as capital charges against FX exposures (in 1998, raised in 2004), requiring additional provisions against FX credit extended to borrowers with no FX income, or maintenance of required minimum levels of FX liquidity (in 2003). These efforts were supported by the crawling fan regime, which helped increase the perception of two-way risks, encouraging, in turn, hedging activities.

\section{Summary and Lessons from the Israeli Experience}

Israel chose a gradual approach to exchange rate flexibility, partly as a result of an unsuccessful attempt at a sudden exit at an earlier stage in 1977, and partly in keeping with a general philosophy of gradualism in economic reform in all spheres. The gradualist approach 
meant a protracted process, but progress, even if slow, was steady, and for the most part, crises and policy reversals were avoided. The costs of the gradualist approach, in terms of slower progress, are difficult to measure. Continued reform across the economy and financial system and coordination with the supporting elements of a flexible regime proved mutually reinforcing. Increased exchange rate flexibility accompanied the opening of the economy and greater integration in the international financial system.

The exchange rate regime evolved in response to changing economic conditions and the need to resolve conflicts arising from the pursuit of multiple objectives in an increasingly global environment. This approach likely limited the chances of severe market pressures and policy reversals. In the early stages, the move to greater flexibility was associated with efforts at macroeconomic stabilization, especially the disinflationary process. Eventually, the inherent conflict between exchange rate targeting and IT made the move to a floating regime necessary, especially with increasing integration into the global economy.

One of the advantages of a gradual transition was the ability to coordinate it with supporting steps in other areas: capital account liberalization, financial market development, and improvements in prudential regulation. Supporting steps, such as development of the FX market, and improved risk management, including hedging, played key roles. The minimization and eventual cessation of $\mathrm{BoI}$ intervention encouraged the emergence of stabilizing factors in the FX market. In fact, the experience shows that greater exchange rate flexibility need not lead to excessive volatility. A stable macroeconomic environment and effective monetary policy and operating tools were also essential and supported a smooth exit from the pegged regime.

The following lessons were learned:

- Although both exchange rate flexibility and capital account liberalization proceeded gradually, increased exchange rate flexibility generally preceded capital account liberalization. Flexibility of the exchange rate was needed in order to obtain the benefits of capital mobility while lessening its risks and allowing the economy to adjust to developments and maintain stability.

- Avoiding moral hazard was essential in making the transition successful. FX risk was made explicit and the responsibility to manage it was clearly imposed on those who incurred the risk, in both the banking and the nonfinancial business sector. The ability of the BoI to adopt and maintain a nonintervention policy provided strong incentives for the private sector to manage risk effectively.

- The availability of an alternative monetary anchor and the operating tools that were built over time were vital in making a smooth transition. Exchange rate flexibility without a credible and effective policy for maintaining price stability would have endangered hard-won progress on the path to macroeconomic stability.

\section{Poland $(1990-2000)^{12}$}

Poland's transition from a pegged to a floating exchange rate can be characterized as a gradual, step-bystep, and orderly process that lasted for about 10 years, from 1990 to 2000. Over this period, Poland moved from a monetary policy framework based on exchange rate targeting to a direct IT regime with a fully floating exchange rate, through an eclectic exchange rate and monetary targeting in the interim period. The steps toward flexibility were taken in response to a changing economic environment, aimed in general at moderating the conflicts that emerged in the pursuit of multiple objectives in an environment of increasing openness of the economy. The gradual move to flexibility was supported by structural reforms that strengthened the sustainability and credibility of the transition. Integration with supporting steps was vital for a coherent transition to a free float while avoiding policy reversals.

\section{Factors Motivating Each Stage in the Transition}

The authorities had no deliberate plans to switch to a floating regime at the beginning of the economic transition in 1990. However, the need to move to flexible rates became not only inevitable but also desirable in the latter part of the 1990s. The gradual step-by-step move toward a floating regime generally reflected the sometimes conflicting objectives of maintaining competitiveness, reducing inflation further, and integrating the domestic markets with the international markets; the last brought significant inflows of capital and complicated monetary policy implementation. The gradual evolution of the exchange rate regime was in fact largely in response to the increasing liberalization and restructuring of the economy; the introduction of market economy principles, privatization and restructuring of enterprises, development of the financial system, and increasing openness of the economy all resulted in growing challenges to exchange rate management.

The exchange rate regime evolved through five main stages: a fixed peg in the form of an administrative fix of the zloty (initially vis-à-vis the dollar from January 1990, then vis-à-vis a currency basket from May

\footnotetext{
${ }^{12}$ Prepared by Zbigniew Polański and Piotr Szpunar (both at the National Bank of Poland). The authors are grateful to R. Kokoszczyński for providing valuable information and comments.
} 
to October 1991); a preannounced crawling peg (from October 1991 to May 1995); a crawling band that was widened in several steps (from May 1995 to July 1998); a de facto float with a formal wide crawling band (from August 1998 to April 2000); and a free float (since April 2000). The details of the evolution are presented in Table 8.

\section{From Fixed Peg to the U.S. Dollar to a Basket Peg}

The fixed peg to the dollar was adopted in January 1990 as part of the economic stabilization program of late 1989, but soon had to be adjusted. The single currency peg was aimed at reducing inflation quickly by delivering credibility to anti-inflationary policies. The inflation rate was indeed reduced rapidly from four-digit levels at the beginning of 1990 to 249.3 percent by end-1990 and 60.4 percent by end-1991. The significant progress in disinflation was irreversible, in part owing to the visibility of a fixed exchange rate and its impact on expectations, but was slower than targeted (the targets were 95 percent and 32 percent, respectively) because of the factors inherited from the centrally planned economy (for example, the indexation mechanisms and low confidence in the stability of the zloty). With inflation much higher in Poland than in its main trading partners, the zloty underwent a significant real appreciation, resulting in a rapid loss of price competitiveness; the initial current account surplus in 1990 was reversed and the deficit widened at a fast pace in 1991.

The move from the dollar peg to the basket peg was hence motivated mainly by concerns over loss of competitiveness. The widening of the current account deficit and the beginning of the decline in the level of official reserves were considered a significant risk factor to the stability of the exchange rate regime and the whole economy. Although the single currency peg provided transparency and helped anchor inflation expectations, it also led to exposure to changes in the value of the dollar, given the rapidly growing importance of trade with Western Europe. To reduce this exposure and address the loss of competitiveness, the zloty was pegged to a basket of five currencies in May 1991, with the basket reflecting the composition of Poland's international trade, and the central parity was devalued against the dollar. The basket peg introduced some flexibility by allowing variations in the zloty's value that reflected cross exchange rate movements vis-à-vis the dollar.

\section{From Fixed Peg to Crawling Peg}

The move from the fixed peg to a crawling peg was again motivated by competitiveness concerns. After the first two years of transition, the authorities recognized that relatively high inflation would persist for some time and that inflation differentials combined with a fixed exchange rate would undermine external competitiveness. Maintaining competitiveness would call for further step devaluations that would result in uncertainty and distortion. The authorities also acknowledged, however, the need to maintain the peg to anchor inflation expectations. A preannounced crawling peg to a basket was introduced in October 1991, as a compromise between the goals of further disinflation and competitiveness. The basket was devalued according to a preannounced path at a constant pace on a daily basis. The rate of crawl was set at a level lower than the targeted inflation differential to support gradual disinflation and to smooth the path of real exchange rate appreciation; although the crawl rate was only gradually reduced from August 1993, two further step devaluations of the parity still proved necessary in 1992 and 1993 to address the loss of competitiveness.

\section{From Preannounced Crawling Peg to Crawling Band}

A large current account surplus and capital inflows with an increasingly open economy in the mid-1990s called for greater flexibility in the exchange rate. The zloty faced significant appreciation pressures from the current account surpluses in 1994-95, resulting mainly from a marked increase in net unclassified transactions associated with cross-border trade between Poland and its neighbors. At the same time, FDI inflows, persistently growing from the start of the transition, and nonresident portfolio investments from early 1995 added to the appreciation pressures. Portfolio inflows were attracted by the improving fundamentals of the Polish economy, as well as by a highly predictable exchange rate under the preannounced crawling peg that enabled foreign investors to easily estimate the forthcoming scale of zloty devaluation. The crawling peg therefore not only was unable to fully accommodate the appreciation pressure, but also added to it by attracting shortterm inflows. The increased flexibility permitted in March 1995 by widening the NBP's bid-ask spread (from \pm 0.5 percent to \pm 2.0 percent) was not sufficient to address these pressures.

In mid-May 1995, the crawling band system was put in place, again as a compromise solution between keeping the exchange rate as an anchor and allowing some flexibility to respond to the persistent appreciation pressures from the FX inflows. The anchor role of the exchange rate under the crawling band mechanism was maintained by limiting the zloty's fluctuations within a band and letting the band crawl at a rate less than inflation differentials. The regime change was carried out without a major shift in the monetary policy framework, in which the NBP formally followed a monetary targeting strategy while de facto implementing an eclectic policy, focusing on both interest 
Table 8. Evolution of Poland's Exchange Rate Regime since 1990

Date Event

I. Administratively fixed exchange rate regime-hard peg (January 1990-October I99I)

January I, $1990 \quad$ The zloty fixed to the U.S. dollar (PLN $0.95=$ US $\$$ I)

May 17, 1991 The zloty fixed to a basket of five currencies (US\$-45\%, DEM-35\%, GBP-10\%, FRF and CHF-5\%) and devalued against the U.S. dollar by $14.4 \%$

\section{Crawling peg regime (October I991-May 1995)}

October 14, 1991

The crawling peg introduced (monthly rate of crawl: $1.8 \%$ ) with a formal fluctuation band of $\pm 2.0 \%$ and the National Bank of Poland (NBP)'s margin of $\pm 0.5 \%$

February 26, 1992

The zloty devalued against the basket by $12.0 \%$

August 27, 1993

Monthly rate of crawl: $1.6 \%$; the zloty devalued against the basket by $8.0 \%$

September 13, 1994

Monthly rate of crawl: $1.5 \%$

November 30, 1994

Monthly rate of crawl: $1.4 \%$

February 16, 1995

Monthly rate of crawl: I.2\%

March 6, 1995

The NBP's margin increased to $(2.0 \%$

\section{Crawling band regime (May 1995-July 1998)}

May 16, 1995

Fluctuation band increased to $\pm 7.0 \%$; NBP intervenes in the foreign exchange (FX) market both directly' and indirectly²

December 22, 1995

Revaluation of the central parity rate by $6.0 \%$

January 8, 1996

Monthly rate of crawl: I.0\%

February 26, 1998

Monthly rate of crawl: $0.8 \%$; fluctuation band increased to $\pm 10.0 \%$ and reduction in the scale of direct FX interventions

July 17, 1998

Monthly rate of crawl: $0.65 \%$

July 3I, $1998 \quad$ Final abolition of direct interventions on the FX market

\section{De facto floating (August 1998-April 2000)}

September 10, 1998

October 13, 1998

Monthly rate of crawl: $0.5 \%$

October 29, 1998

Public commitment by the MPC to float the zloty at a future date (press conference at which the Medium-Term Strategy of Monetary Policy (1999-2003) was presented)

January I, 1999

Fluctuation band increased to $-12.5 \%$

March 25, 1999

New currency basket (EUR-55\%, US\$-45\%)

June 7, 1999

Monthly rate of crawl: $0.3 \%$; fluctuation band increased to $\pm 15.0 \%$

Abolition of fixing transactions (indirect interventions)

\section{Floating exchange rate regime (since April 2000)}

April 12, 2000

Formal introduction of the floating exchange rate regime

Source: Polański (2004, p. 14)

Note: DEM refers to the deutsche mark, GBP refers to the pound sterling, FRF refers to the French franc, and CHF refers to the Swiss franc

'Direct interventions were typical, market-based central bank interventions.

${ }^{2}$ Indirect interventions were $\mathrm{FX}$ transactions with commercial banks during fixing sessions.

rates and exchange rate control aimed at achieving a continued gradual disinflation.

Effectively, however, the crawling band system provided less flexibility than envisaged initially. Under this system, the central rate of the zloty continued to be devalued every business day by a certain amount. While the market rate was officially allowed to fluctuate within a band of \pm 7.0 percent, the NBP used a 
one-sided inner intervention band on the appreciation side. The NBP purchases of foreign exchange (both through market interventions and by fixing transactions) resulted in a massive increase in official reserves during 1995. In addition, in light of the high interest rate differential, intervention purchases led to high sterilization costs. The sustained appreciation pressure on the zloty induced the central bank to further revise its regime; in September 1995, the NBP moved its unofficial intervention level from about 5 percent to about 6 percent (on the strong side of the band) from the central rate, and in December 1995, it revalued the zloty against the basket by 6 percent.

Persistent appreciation pressure on the zloty and the widening current account deficit during 1996 led to a further increase in the flexibility of the exchange rate. Also mindful of the potential consequences for financial stability of growing capital mobility, the NBP abandoned its unofficial intervention level in May 1997 and allowed the volatility of the zloty to increase within the formal \pm 7.0 percent fluctuation band. As under the crawling peg system, the disinflation policy was intended to be supported by a reduction in the rate of crawl of the central parity.

\section{From Crawling Band to De Facto and De Jure Free Float}

The transition to greater exchange flexibility accelerated considerably from February 1998 as a consequence of a monetary policy regime change and the need for faster disinflation. As the new 1997 Polish constitution and the NBP Act gave the sole responsibility for the conduct of monetary policy to the central bank (goal independence included), the newly created Monetary Policy Council (MPC) decided to adopt the IT framework and committed itself to gradually float the zloty. IT combined with a floating exchange rate was considered to be the best framework to address the challenges facing Poland, that is, completing disinflation at the time of a growing current account deficit and increasing capital mobility.

In particular, with increasing capital mobility, competitiveness and disinflation objectives became increasingly incompatible under the eclectic monetary policy strategy, inducing the NBP to introduce further steps toward a floating exchange rate. By maintaining the exchange rate within preannounced limits and reducing exchange rate risk for financial investors, the crawling band system continued to attract large capital inflows. The inflows required interventions and a greater need for sterilization to neutralize their monetary impact. The interest rate policy aimed at restraining inflation resulted in significant sterilization costs, while attracting additional capital inflows and slowing down the disinflation process.

Given the unstable international environment and Poland's growing current account deficit, the NBP moved to a de facto floating regime during 1998-99. The fluctuation band was widened in several steps to \pm 15 percent in March 1999 and its crawl rate was reduced in several steps. The volume of FX interventions was also reduced (just before the Russian crisis, the NBP withdrew from direct FX interventions, letting the zloty absorb the contagion effects), and fixing transactions were eliminated in June 1999. The NBP has not intervened in the FX market since, although it continued to announce the central parity and the fluctuation band. In the final phase of the crawling band system, the zloty was hence fluctuating freely within a band of 30 percent, with no NBP intervention.

The considerable widening of the band width and further reductions in the pace of the central parity devaluation reduced the significance of the band. However, the existing band could still be considered as a potential commitment of the NBP to influence the FX market. After the required consultations with the government, ${ }^{13}$ the free float regime was adopted officially on April 12, 2000 — a step considered as the formal confirmation of a de facto switch to the floating system. Following this decision, the NBP ceased to announce the central parity and the fluctuation band, because the latter could constitute a target for speculation in an environment of large capital flows and a very high current account deficit. This action constituted the key step in the process of introducing a full-fledged IT regime, and there has been no NBP intervention in the FX market since then.

\section{Coordination of the Regime Transition with Supporting Elements}

The gradual move to flexibility was supported by structural reforms that strengthened sustainability and credibility of the transition. Integration with supporting steps was vital for a coherent transition process to a free float while avoiding policy reversals.

\section{Monetary Operations and Development of Financial Markets}

Financial markets have been developing since the beginning of the economic transition, particularly from the second half of the 1990s, helping to increase the efficiency of monetary operations and reducing the role of exchange rate policy in the disinflation process. The first market to develop was the interbank deposit market, which facilitated banks' management of their liquidity. The existence of a well-functioning deposit market was a precondition for the introduction of mod-

\footnotetext{
${ }^{13}$ According to the 1997 NBP Act, the change in the foreign exchange system (unlike its parameters, such as the rate of crawl and the width of the band) had to be agreed on by the government.
} 
ern market operations to implement monetary policy. The subsequent development of the treasury bill market enabled the government to fund budget deficits and provided securities that could be used for interbank and monetary operations. Effective monetary operations facilitated transmission of monetary policy to inflation through market interest rates. The introduction of partial convertibility of the zloty resulted in the emergence of the interbank FX market in the early 1990s. The Warsaw Stock Exchange, established in April 1991, developed simultaneously with the interbank markets.

The central bank contributed to the development of the financial markets mainly by creating infrastructure and institutions, setting standards, and creating incentives for market participants. The system of unified bank accounts in the NBP, which was crucial for the money market, was established in 1993-94, facilitating the introduction of averaging in the required reserve system at end-1994. The payment system was developed simultaneously. The NBP supported market development with the early introduction of repurchase operations in 1993. A book-entry system for treasury bills and NBP bills was introduced in 1995. The NBP (in cooperation with commercial banks) promoted the setting of market standards and encouraged banks to engage in market operations. In 1993, the money market dealers system was introduced. In 1994, the NBP started to reissue NBP money bills, which became the main tool for open market operations. ${ }^{14} \mathrm{~A}$ deep and liquid interbank deposit market developed following these measures. The reference WIBOR-WIBID rates became reliable market indicators, providing reference prices for settlement in derivative instruments.

The development of the domestic financial markets accelerated in the mid-1990s, with the rapid growth in the scale of transactions and turnover. The latter was stimulated by the presence of foreign investors attracted by improving economic fundamentals and a successful accord with the London Club. The domestic financial markets became increasingly liquid and offered a wide spectrum of instruments for financial management. The stimulus to the development of the bond market was also supported by declining inflation, which allowed the government to limit the issues of short-term bills and floaters and to increase the issues of fixed rate bonds; the maturity of the public debt was extended; and the first international placement was conducted in 1995. The development of the spot FX market accelerated with the crawling band from 1995. Since 1998, a vibrant market for FX swaps became the most liquid component of the domestic money market. The growing international integration of the domestic finan-

\footnotetext{
${ }^{14}$ Issuing money bills was considered to be a more effective way to absorb excess liquidity than, for example, deposit auctions, because a secondary market for these bills emerged, facilitating liquidity redistribution within the banking sector.
}

cial markets gave domestic entities access to derivative markets abroad, which offered hedging against price risk in the bond market.

\section{Foreign Exchange and Derivatives Markets}

In Poland, the FX market was developed in conjunction with the other financial markets and was supported by the scope for exchange rate volatility provided by greater exchange rate flexibility. The crawling peg system adopted at the end of 1991 permitted very limited exchange rate flexibility. Until 1995, the NBP acted as the sole market maker in the interbank FX market. The introduction of the crawling band in 1995 was a stimulus for development of the spot market, as well as for the rise of the forward FX market that in turn has facilitated hedging against FX risks. Whereas the spot FX market had already been well developed by 1998, when the NBP ceased its interventions, derivatives markets developed more gradually, with a significant pickup in the year before the float.

In developing hedging markets for foreign exchange, the authorities have faced the typical trade-off between the benefits and risks associated with the use of derivative instruments. Although acknowledging that increased availability of hedging instruments would help economic agents cope with increasing exchange rate risks, they also recognized the risk that derivative transactions could facilitate speculation. In fact, there were fears that forward transactions could allow speculative attacks and would be harder to control (use of derivatives indeed augmented the appreciation pressure on the zloty in 1998). The authorities hence considered it important to develop derivatives markets cautiously, with liberalization taking place only at later stages of the move to flexibility.

The authorities also recognized, however, that it would be difficult to stop the development of such markets as long as there were incentives and needs for such transactions. As in Israel, in most cases the pressures were created when discrepancies existed between economic fundamentals and the policy regime, and the latter was adjusted to reduce these discrepancies. It was recognized that it would be hard to stop the development of derivatives once the markets for underlying instruments (for example, treasury bills and treasury bonds) were liberalized. In fact, maintaining restrictions on derivative transactions was considered to be potentially counterproductive, leading to an even faster development of derivatives offshore in an attempt to circumvent onshore restrictions. A vibrant zloty NDF market indeed emerged in London, in part reflecting the restrictions on derivative transactions in the domestic market.

The authorities hence moved to liberalize FX swap markets, while also having some safeguards in place. In 1998, the Ministry of Finance issued a favorable 
interpretation of the Foreign Exchange Law of December 18, 1998, which made the Polish zloty externally convertible. According to the ministry's interpretation, FX swaps were not treated as derivatives and thus did not require a permit from the NBP; this facilitated the origin of FX swap transactions. ${ }^{15}$ The swap market has been developing dynamically since 1999 , after the introduction of the Foreign Exchange Law. A deep onshore FX swap market developed quickly and squeezed out the offshore NDF market, which practically ceased to exist in 1999; development of other segments of the FX market followed. ${ }^{16}$ Higher liquidity in the swap market was also supported by growing nonresident exposure in zloty-denominated treasury bonds. In liberalizing the transactions, the authorities used some prudential safeguards to limit the risks connected to banks' FX exposures associated with derivatives: To mitigate excessive risk taking, such exposures were included in limits on open FX positions and capital requirements.

\section{Foreign Exchange Intervention Policy}

Effective FX interventions were crucial in the conduct of monetary policy in Poland. In the first years of the transition, commercial banks were obliged to conduct FX operations with the NBP, and the NBP remained the sole market maker in the FX market until May 1995. Starting in 1995, the NBP conducted two types of FX interventions: "direct," performed by central bank dealers, and "indirect," in the form of the socalled fixing transactions.

Direct and indirect forms of interventions had different roles. During a typical day, the NBP used the direct interventions mainly to maintain an unofficial (inner) intervention range within the band, with clear guidelines from NBP management. Under the fixing, each domestic commercial bank could conduct one FX transaction with the NBP at the end of each working day. The rationale for introducing these latter operations was to help small banks to close open positions in the environment of a segmented FX market. In practice, however, large banks also used that facility. Initially, the indirect interventions were predominant, but over time the size of both types of operations became

\footnotetext{
${ }^{15}$ Foreign exchange swaps became useful for carry trade operations in an environment where the Foreign Exchange Law required a permit from the NBP (until September 2002) for the deposits made by nonresidents at domestic banks that were higher than 0.5 million zloty and with a maturity shorter than three months; these deposits were also subject to required reserves.

${ }^{16}$ At present, Polish commercial banks provide forwards, options, and other instruments in foreign exchange mostly for their customers or foreign banks (especially options), whereas they prefer to close their own foreign exchange positions using synthetic forward contracts traded in more liquid market segments (a combination of spot and swap transactions - these two segments remain the most liquid).
}

more balanced. ${ }^{17}$ Although it is hard to assess fully the role of fixing in the smoothing of exchange rate volatility, the fixing did provide a buffer that helped to absorb excess supply or demand at the end of the working day. On the other hand, it created a kind of last resort for commercial banks that could have induced adverse speculation in the market.

Changes in the FX regime or developments in the market influenced the extent of the interventions. Until mid-1997, the NBP limited the flexibility of the exchange rate within the informal inner limits on the appreciation side to resist strong appreciation pressures. The tolerance for a more depreciated exchange rate was much higher, as shown in July 1997, when the NBP reacted reluctantly to a sharp depreciation of the zloty (although the intervention was late and small-scale, it proved to be effective). The commitment to a more flexible exchange rate was tested in August 1998, when contagion from the Russian debt crisis caused a rapid fall of the zloty. In the absence of NBP reaction, the sharp zloty depreciation proved very short-lived.

Interventions have become scarce and more transparent over time. When the NBP maintained inner bands, the changes in the limits were discretionary and not published, although they were usually quickly recognized by the market. With the evolution to greater flexibility, the NBP ceased direct interventions. As the intervention policy of the NBP gained reasonable credibility, no direct intervention was needed to keep the exchange rate within the wide band during the de facto floating period. This was true even after the fixing arrangement was abolished in June 1999. After the official floating, the NBP retained the right to intervene in the FX market, should it prove necessary for the achievement of the inflation target, but so far has not done so.

\section{Current and Capital Account Liberalization}

Current account liberalization was faster than capital account liberalization, which was conducted very gradually. Poland's capital account liberalization was pragmatic and broadly adjusted to the process of transition to greater exchange rate flexibility. It was also based on a careful sequencing, linked to the fulfillment of certain macroeconomic prerequisites, in particular to declining inflation and interest rate differentials. The FDI inflows were liberalized first. After the significant reduction of interest rate differentials and increased exchange rate flexibility, long-term portfolio flows (first inflows, then outflows together with FDI outflows) and long-term credit flows were liberalized. Short-term capital movements (first inflows, then out-

\footnotetext{
${ }^{17}$ In 1995 their value was more than five times higher than that of direct transactions; in 1997 the volume of fixing transactions surpassed that of direct interventions by 65 percent.
} 
flows) and derivative transactions were liberalized only after introduction of the (initially de facto) floating exchange rate regime.

\section{The Role of Central Bank Communication}

One of the most important supporting elements of the transition to flexibility was proper communication and explanation of the measures being taken. The NBP's experience with the gradual move to a free float clearly showed that the general and strategic development of exchange rate arrangements should be accompanied by transparency. In some cases communication played a critical role. By announcing in advance the intention to change the system, the NBP allowed time for banks and real economic agents to prepare for the new regime and its possible impact on the volatility of the zloty. For example, because the switch from the preannounced crawling peg to the crawling band implied the beginning of FX interventions, it was necessary to put in place a proper infrastructure to conduct such operations and to allow time for banks to familiarize themselves with this type of transaction. Hence, the decision to move to the crawling band in May 1995 was announced in early April.

Transparency associated with the process of exiting from the crawling band to free float was much more complex. In early June 1998, the MPC for the first time announced its intention to introduce an IT framework that would imply increased flexibility in the exchange rate. Intentions for greater flexibility were also hinted to the public by comments made by some MPC members at around that time. However, the objective to move to the float was officially announced only in October when the MPC publicly presented the Medium-Term Strategy of Monetary Policy (1999-2003) (MPC, 1998), a document outlining the main characteristics of the new policy to be implemented and signaling the commitment to introduce a floating regime; this approach helped put the move to a flexible exchange rate regime in the context of a new monetary framework.

With respect to operational decisions (concerning the exact timing of their implementation and precise nature), the degree of transparency was much more limited, with a view to avoiding unnecessary speculative activities. Although the NBP was very open about its intentions, as manifested by the official announcements of its plans to change the exchange rate system well in advance (April 1995, October 1998), operational decisions were either made known only the day before their implementation (for example, as with the December 1995 revaluation of the zloty, all crawling rate reductions, and the widening of the fluctuation bands) or not announced at all (as with the introduction and change of the unofficial intervention level in 1995 or the withdrawal from direct FX interventions). Similarly, the official decision to adopt the floating system was communicated in the afternoon of the day before implementation, after the closing of the domestic FX market.

\section{Other Supporting Elements}

Ensuring financial stability was very important for the development of financial markets that facilitated a smooth transition to greater exchange rate flexibility. In the early 1990s, the banking sector was undercapitalized, poorly managed, and segmented. It was not long before the accumulation of bad loans became a serious threat to the stability of banks. In response, some exceptional measures aimed at capitalizing banks and restructuring bad loans were introduced. The supervision of the banking sector was strengthened and restrictive standards were introduced.

In particular, tight regulations were maintained over the whole period of transition to greater flexibility. Tight prudential regulation, strong offsite and onsite inspections, and privatization and foreign investment in the banking sector led to significant improvement in the quality of debts, increase in capital base, and introduction of modern market risk management techniques. One of the elements of restrictive prudential regulation was the tight limits on open FX positions..$^{18}$ In practice, banks made efforts to maintain balanced positions and made use of the limits only incidentally. In addition to protecting against FX exposures, those limits stimulated both the spot and derivatives markets development. Banks had to close their positions in the market, especially in the second half of the 1990s when the NBP was not always present in the market. Specific capital requirements on FX risk as well as close monitoring of direct and indirect FX risks were adopted only after the float, through the EU harmonization directives adopted in 2001.

Coordination between the NBP and the Ministry of Finance played a significant role in the conduct of exchange rate policy. The coordination was institutionalized in the creation of the Public Debt Management Committee. The committee, which was an important platform for information exchange, was helpful in analyzing and coordinating measures to reduce market volatility that could result from some large-scale operations connected with public debt management or privatizations.

\section{Lessons from the Polish Experience}

Since 1990 Poland has adopted nearly all possible forms of exchange rate regimes, moving smoothly from a fixed peg to a pure float. In the process, it avoided any

\footnotetext{
${ }^{18}$ According to the Ordinance of the President of the NBP of March 19, 1993, the net open position of a bank in individual currency was limited to 15 percent of its capital.
} 
serious market turbulence. The following lessons can be drawn from the experience:

- The zloty's float helped reduce the vulnerability of the economy to currency risk. The gradual approach to a floating regime helped domestic economic agents cope with higher volatility of the exchange rate.

- The transition to flexibility was facilitated by its coordination with, and the support of, the development of financial markets and institutions, stability and strength of the financial system, and monetary policy strategy. The evolution of the exchange rate regime was also associated with a cautious capital account liberalization.
- The gradual transition to greater exchange rate flexibility should be accompanied by a proper communication strategy. In Poland, regime changes were communicated in advance, whereas operational decisions were conveyed to the public the day before or were not announced at all, thus helping avoid speculative activities.

- The transition from peg to float required tough and consistent decision making and coordination between the central bank and the government. Once decisions were made, they were never revoked. Policy reversals would have been damaging to the credibility of the central bank with large costs to the economy. 


\section{Disorderly Transitions}

\section{Brazil (1999)।}

In Brazil, the transition to a floating exchange rate regime involved a crisis exit. After four years in place, the collapse of the crawling peg system in January 1999 marked the outbreak of an economic crisis during which the floating exchange rate system was adopted, accompanied by a sharp depreciation of the domestic currency. The adoption of IT and the change in the fiscal stance in 1999 were fundamental to overcoming the instability associated with the crisis. A new macroeconomic policy framework was put in place, with a view to preventing the return of high inflation and promoting disinflation in the ensuing years.

\section{Factors Triggering the Move to a Floating Exchange Rate System}

Brazil's transition to a floating exchange rate regime can be considered against the background of an inconsistent mix of exchange rate, fiscal, and monetary policies. These policies resulted in growing imbalances in the domestic economy that undermined the sustainability of the peg, compounded by the crises in other emerging market countries.

The exchange rate played a crucial role in the transition from a high- to a low-inflation regime. Under the Real Stabilization Plan put in place in July 1994, the currency was allowed to float initially, though with an upper limit of R\$1/US\$1. The float, coupled with abundant net capital inflows, resulted quickly in an appreciation of the nominal exchange rate, contributing to a sharp reduction in inflation. The Central Bank of Brazil resumed its interventions in the market a few months later and, in March 1995, adopted a system of horizontal exchange rate bands that were shifted five times until 1999. Through FX auctions, the CBB

${ }^{1}$ Prepared by André Minella (Central Bank of Brazil). The author thanks Carlos Hamilton Araújo, Afonso Bevilaqua, and Pedro Fachada for comments on an earlier version of the paper. The paper also benefited from the knowledge of specialists in the CBB-Daso Coimbra, Eduardo Fernandes, Rogers Gomide, Clarence Hillerman Jr., Alan Mendes, Fernando N. de Oliveira, Cornélio Pimentel, Gustavo Souza, and Gilneu Vivan-whose contribution is greatly acknowledged. established significantly narrower inner bands (usually lower than 1 percent), which were adjusted frequently, resulting, in practice, in a steady devaluation of the real-around 0.6 percent per month. In light of the steady devaluation path and the size of the inner bands, the band system acted de facto like a crawling peg, with the exchange rate providing an anchor for inflation.

The path followed by the nominal exchange rate under the Real Plan resulted in a considerable appreciation of the real effective exchange rate and contributed to a deterioration of macroeconomic fundamentals. The initial significant appreciation of the nominal rate, combined with the high inflation differential between Brazil and its main trading partners in the first years of stabilization, led to a further real appreciation. As this differential faded away, the steady devaluations of the nominal exchange rate led to some, though not significant, reduction in the appreciation of the real exchange rate. Coupled with the boost in demand that accompanied the stabilization, the appreciation of the domestic currency resulted in a significant widening of current account deficits financed by large capital inflows that were attracted by the large interest rate differential, the privatization program during the period, and the liberalization of the capital account.

Contributing to a deterioration of the macroeconomic situation was the lack of a sound fiscal policy. The weak fiscal results during the period-consolidated public sector primary surplus around zero-accompanied by the recognition of hidden contingent liabilities and substantial domestic interest rates resulted in an increasing consolidated net public debt (from 30 percent of GDP at end-1994 to 42 percent at end1998), with average short maturities. The loose fiscal policy also added to aggregate demand and deterioration of the trade and current account balances. Against this background, monetary policy took on most of the burden through high interest rates, which were also pressured by the external crises. In the context of deteriorating domestic imbalances, market comparisons of Brazil's macroeconomic indicators with those of the countries facing similar crises added to market concerns about vulnerability of the economy, and contributed to a greater distrust in the peg. 


\section{Nature and Pace of the Exit}

Although the macroeconomic imbalances had been building gradually, the transition to the float took place very quickly, with the collapse of the peg and the outbreak of economic turmoil. After having reached a historical maximum in April 1998, international reserves were almost halved by the speculative attacks, with the loss of confidence compounded by the default of a state government on its foreign agreements. The significant loss of reserves led to an attempt to adjust the exchange rate bands and introduce the so-called endogenous diagonal band. Under the new system, the inner exchange rate bands were abandoned, and the new bands were adjusted every three working days according to the behavior of the exchange rate over the previous three days. With the exchange rate rapidly moving to the upper limit of the new band and a continued loss of reserves, the new system was abandoned in two days: on January 15, 1999, the CBB announced that it would not intervene in the market, and on the subsequent working day it introduced the floating exchange rate system.

The switch to a float was accompanied by a short period of sharp depreciation of the currency and great macroeconomic uncertainty. The sharp depreciation of the currency in less than three weeks caused significant market panic, given the relatively recent history of high inflation in Brazil. The crisis, however, was not accompanied by generalized and severe financial distress in the private sector. In contrast to similar crises in other countries in the period, the turmoil did not result in a banking crisis or widespread bankruptcy in the nonfinancial sector, owing to the limited exposure of the private sector to exchange rate depreciation. Putting together an alternative monetary policy framework relatively quickly helped limit market and monetary instability.

\section{Coordinating the Transition with Supporting Elements of Flexibility}

There was no advance coordination with other elements to support the transition to a floating system, but the switch took place rapidly and with a relatively short period of instability. Although many observers characterized Brazil's exit as a "preannounced crisis," no exit strategy had been developed in advance with deliberate attempts to put in place the elements to facilitate the transition. Nevertheless, some advances made in the preceding years-although not meant to prepare for a transition to a floating exchange rate-were important for a softer landing. In particular, improvements in monetary, financial, and fiscal sectors prevented a deeper crisis and eased the transition to the new regime.

The Real Plan had generated, for the first time in decades, a low-inflation environment. Considering its historical pattern, the Brazilian economy had enjoyed a relatively long period of stabilization (four years), which had somehow changed agents' behavior. For instance, the pervasive indexation system had been undermined. Had the depreciation occurred closer to the start of the stabilization, the fears of the return of high inflation would perhaps have been more well founded.

The FX market was relatively well developed, though with a dual market structure until recently. The spot FX market traded substantial volumes with high liquidity. The futures market was developed as well, but other derivatives contracts (options, swaps, and forwards) were traded at low volumes. Higher exchange rate uncertainty resulting from the float helped stimulate the derivatives markets. In the context of the first steps toward capital account liberalization, the authorities introduced at end-1988 a floating exchange rate market, alongside the commercial or free exchange rate market. Although most transactions were carried out in the other official market when the real was floated, the new market acted as an important reference point in the process of capital account liberalization, with the goal of bringing FX operations in the parallel market into a regulated market. In fact, the regulation increasingly broadened the operations that could go through the new market. As a result, the parallel market lost its economic significance, with a significant fall in the exchange rate spread over the official market. The two official markets were unified shortly after the float (formally unified only in 2005).

The pattern of direct intervention in the FX market has changed with the new exchange rate regime. During the crawling peg, the CBB intervened within inner bands through spread auctions, alongside the usual sale and purchase auctions. The spread auctions were the main instrument used to set the pace of devaluations and were usually held at regular intervals. The magnitude of balance of payments net flows led the $\mathrm{CBB}$ to intervene in the market quite frequently and on both sides. The size of the inner bands was marginally increased during 1998, and the adjustment pace of the bands also rose slightly. When the real was floated, the CBB announced that interventions would be occasional and limited, aiming to curb disorderly exchange rate movements. In fact, the interventions became less frequent and were not meant to achieve any specific target. However, during the second semesters of 2001 and 2002 (periods of pronounced market pressures), the interventions were more frequent and systematic. ${ }^{2}$ In 2004, the CBB announced a policy of replenishing international reserves, taking advantage of favorable market conditions and attempting neither to add undue

\footnotetext{
2In mid-2001, the CBB announced a daily sale of US $\$ 50$ million in the foreign exchange market that lasted until December. In March 2002 , the CBB began to conduct exchange swap operations.
} 
volatility to the market nor to impede the fluctuation of the real. No commitment was made to a precise rule as to amounts and timing of intervention, or to a predefined reserve target.

Nevertheless, indirect mechanisms of FX market intervention played a key role in both regimes. The government issued U.S.-dollar-linked debt to ease demand pressures on the exchange rate market, providing also a hedge to the private sector. The share of dollar-linked debt in the federal domestic debt rose significantly, from 5.3 percent in 1995 to 20.9 percent in 1998 , causing the government to incur a predominant part of the financial cost of the depreciation. The CBB also engaged in transactions in the futures market during the peg system. In the 1999 agreement with the IMF, however, the government committed to refrain from using futures market operations. Under the new regime, it issued securities with an exchange swap transaction during the period of market pressures in 2002. Coupled with the exchange rate depreciation of the period, these operations led the dollar-linked debt to reach a maximum share of 41 percent of federal domestic debt that year. With the recovery of confidence and the policy to reduce such debt-including the conduct of reverse exchange swap operations-its share fell to 1.2 percent at end-2005.

The financial system was in reasonably good condition at the time of the float, after having undergone a large adjustment in previous years to adapt to the lowinflation environment. As a consequence of the stabilization, financial institutions had to adjust considerably, with some of the financial institutions, including large banks, facing significant difficulties. However, under the Program of Incentives to the Restructuring and Strengthening of the National Financial System launched in 1995, the private financial system was restructured through mergers and acquisitions by foreign banks and some liquidations. By the time the peg system collapsed, private financial institutions had already completed the adjustment. At that time, the state-owned bank segment was also undergoing a process of restructuring through the Program for Reducing the Presence of the State Public Sector in Banking Activity.

Moreover, the financial system was not dollarized, reflecting mainly a number of FX regulations that limited a pronounced exposure to FX risks. ${ }^{3}$ Banking deposits or payments in foreign currency were not permitted. External loans, in turn, were on-lent with obligatory dollar-indexed clauses, avoiding problems of mismatching between assets and liabilities. Hence, the depreciation of the domestic currency during the crisis exit did not produce significant losses. In fact, the financial system was not exposed to risks associated with an exchange rate depreciation; many finan-

\footnotetext{
${ }^{3}$ During the high-inflation period, a widespread and sophisticated indexation system avoided financial disintermediation and the dollarization of the economy.
}

cial institutions were trading against the sustainability of the bands through derivatives contracts so that they were exposed to risks associated with an appreciation of the domestic currency.

Prudential regulations against FX risks that require financial institutions to hold capital against that risk were not in place at the time of the float. There were limits on the amounts of foreign currency purchased and sold in the spot market, but no limit on the global exchange rate risk exposure of financial institutions. ${ }^{4}$ Positions in the derivatives market were not considered. Given a long history with pegged exchange rates and the steady adjustment of the exchange rate in previous years, market participants were not accustomed to assessing, as a matter of routine, the exchange rate risks posed by regular market volatility. A few months after the crisis, the monetary authorities set forth specific regulations limiting the exposure of financial institutions to exchange rate risks.

The nonfinancial private sector was, nevertheless, not exposed to unhedged exchange rate risks, whereas the public sector was vulnerable to depreciation of the real. Although the nonfinancial private sector had increased its external debt, it benefited from hedging mechanisms, such as foreign currency proceeds in the case of exporters, large remittance of flows abroad prior to the collapse of the peg system, the issuance of domestic dollar-linked public debt, and the derivative transactions. In fact, private agents benefited from those hedging mechanisms with the depreciation. Some private agents were exposed to exchange risks through dollarlinked leasing contracts, but those operations were not significant in the system. In contrast, the public sector was financially vulnerable to a depreciation because of the issuance of external debt, domestic dollar-indexed securities, and derivative transactions. As a result, the government incurred most of the financial distress.

The monetary policy institutional framework had advanced in the period before the float, and additional improvements were made following the adoption of IT as the alternative monetary policy framework. The CBB had created the Monetary Policy Committee (Copom) in June 1996, and the minutes of its meetings began being published in March 1998. However, there was a need for greater transparency and further progress in ensuring the CBB's operational independence. Significant progress was achieved with the adoption of IT. In particular, the level of transparency has increased, and the CBB has gained greater credibility. Although price

\footnotetext{
${ }^{4}$ There was a specific limit on long positions (amounts exceeding those limits should be deposited in the CBB) and a limit contingent on banks' adjusted net worth for short positions, both in the spot market. The limits on the short position in the spot market were abolished in October 1999 and on the long position at the end of 2005. For the prudential regulation on the foreign exchange market in Brazil, see Loyola (2005).
} 
stability appears among other central bank objectives in the legislation enacted in 1965, in practice it became its primary commitment over time. De jure central bank independence has not been adopted, although the CBB has been de facto independent in conducting monetary policy.

Monetary policy instruments and the capacity to affect interest rates were well developed before the float and were further improved in the transition. The government securities market was already well developed at the time, with substantial trading volumes and high liquidity supporting monetary operations. During the peg system, Copom set targets for two interest rates on discount loans, which, by arbitrage, led to the formation of the Selic overnight interest rate-the benchmark rate (the rate on overnight repurchase (repo) operations between banks, with government securities as collateral). Greater use was made of open market operations in conducting monetary policy during 1998. The CBB suspended both rates following the float. In March 1999, it began setting targets for the Selic rate, determined by its interventions instead of banks' arbitrage operations. The Selic rate has worked as the main reference for the other interest rates in the economy.

The transition to the floating exchange rate system took place in the context of a fairly open capital account. Brazil had gradually liberalized its capital account during the 1990s. The abundance of capital inflows led to the adoption of some restrictive measures on inflows from 1993 through 1996, but the authorities started relaxing these measures in 1997. In addition, further measures were adopted in those years to liberalize outflows, with a view to reducing net inflows without affecting the trend toward greater integration with financial markets. After the float, further liberalizing measures were introduced. ${ }^{5}$ Brazil accepted the obligations of IMF Article of Agreement VIII in November 1999.

\section{Challenges during the Transition}

The main challenges the monetary authorities faced during the transition were to curb market panic, restore foreign investors' confidence, and prevent the return of high inflation. The authorities considered it important

\footnotetext{
${ }^{5}$ These measures included, for instance, reduction and subsequent elimination of the minimum maturity requirements for external loans and reduction to zero percent of the financial transaction tax on foreign investment in fixed-income funds and on external loans with an average maturity above 90 days in 1999; regulation of investment in the financial and capital markets (nonresidents were allowed to invest in the same instruments as were residents); consolidation of the regulation on external loans and debt securities in 2000 (ending the CBB prior approval requirement); permission for prepayment of external debt and regulation of the issuance of real-denominated external debt in 2004; and more direct procedures and clearer rules for the conversion of domestic currency into foreign currency in 2005 (for more details, see Goldfajn and Minella, 2005).
}

to limit the period of high uncertainty and attain a return of capital inflows to reverse the overshooting of the exchange rate and resume external financing and foreign investment in the economy. The exchange rate depreciation, the absence of an anchor for inflation expectations, and memories of the high-inflation period fueled fears of a return to high inflation. Analysts predicted a double-digit inflation rate for that year, with some forecasts reaching as high as 80 percent, with considerable uncertainty about the pass-through of the exchange rate to prices.

The adoption of IT that shortly followed the float contributed significantly to limiting the period of uncertainty and to preventing the return of high inflation following the depreciation. In a joint statement with the IMF in February 1999, the authorities declared that they intended to put in place an IT system. In March, the government announced that the goal would be to bring inflation down to a single-digit annualized rate by the last quarter of 1999, and that the IT regime would be adopted by the end of June. In fact, IT was implemented as scheduled within a period of six months. The targets were set for 1999, 2000, and 2001.

At the time of the float, IT was considered to be the best alternative to play a key role in anchoring inflation expectations and reducing uncertainties in the economy. Keeping the peg system with a simple change in the exchange rate value would not be appropriate, because the peg system had lost market trust. It would also be hard to gauge the appropriate level for the exchange rate peg because of the imbalances and uncertainties surrounding the economy. On the other hand, excessive devaluation would have brought about unnecessary inflationary pressures. A fully discretionary policy without an explicit anchor would not be suitable in the context of high uncertainties, a history of high inflation, and weaknesses in monetary institutions.

The government also had to put in place a new fiscal policy regime aimed at stabilizing the economy and preventing a return to high inflation. The economic slowdown and some fiscal tightening that had started in 1998 had already contributed to restraining the magnitude of the exchange rate pass-through to inflation. In addition to the end-1998 measures, new restrictive fiscal measures were introduced in 1999 as part of a new policy mix with three pillars (IT, a floating exchange rate, and a sound fiscal policy), signaling a major shift in the fiscal regime. The fiscal adjustment also had to cope with the fiscal effects of the currency depreciation. In fact, the economic turmoil, which exposed the fiscal fragility of the economy, created better political conditions for a turnaround in fiscal policy. As a result, the primary surplus rose by 3.3 percentage points of GDP during 1999. The primary fiscal surplus has reached record highs recently-a continuation of the policy initiated during the transition period. 
These efforts were also supported by a tightening of monetary policy, external financial support, and government efforts to normalize relations with investors. The CBB raised the base interest rate substantially after the depreciation. As the macroeconomic situation improved, the interest rate hikes were reversed and monetary policy gradually became less restrictive. The revised IMF-supported program in November 1999 pioneered the use of inflation targets as part of the program conditionalities. On the external side, the financial package from the IMF played a key role, also by helping to restore capital flows. The government's active relations with international banks and investors also helped in major international banks' maintaining trade and interbank lines in the country. The government also gave the reassurance that the capital account liberalization trend would not be reversed. Capital flows resumed as the panic was reversed and macro conditions improved. ${ }^{6}$

The implementation of IT nevertheless encountered several challenges. First, the system was adopted in a period of great uncertainty and sharp exchange rate depreciation. Second, its goal was not simply to maintain the inflation rate at low levels, but to bring it down. Third, the new framework was part of a process of building the credibility of the monetary authority and developing monetary institutions. Fourth, it was necessary, in a short period, to build a technical capacity, including forecasting models. The monetary transmission mechanisms were not well understood and estimated. Brazil had enjoyed less than five years of stabilization, so only a short sample size was available to accurately estimate inflation dynamics, particularly given the structural shifts in the macroeconomic policy regime. Coherent conduct of monetary policy under the IT regime, intensive communication efforts (publication of a quarterly Inflation Report and timely release of Copom minutes), and investing in research and modeling at the CBB helped in addressing the challenges.

\section{Lessons from the Brazilian Experience}

Although Brazil's transition to a floating regime took place in the context of an economic crisis, as a whole, the policy response to the crisis was successful. The following lessons can be drawn from the Brazilian experience:

- A pegged exchange rate system that generates increasing external imbalances and is coupled with an unsound fiscal policy would not be sustainable.

\footnotetext{
${ }^{6}$ The combination of tighter fiscal and monetary policies, adoption of IT, and external financial support was crucial to reverse inflation expectations and bring inflation down (in early 2000, inflation expectations fell below 7 percent). After peaking in early 1999 , the inflation rate fell and the real was stabilized. In mid-1999, the panic was reversed (Fraga, 2000). These improvements allowed interest rate cuts from April 1999.
}

- A transition to a floating exchange rate system should be planned to avoid the risk of being caught unprepared, and should be accompanied by the announcement and possibly implementation of the new regime to replace the exchange rate anchor.

- A transition to a floating system in a situation of fiscal and external imbalances leads to a high degree of uncertainty, calling for tight fiscal and monetary policy.

- A financial system with low exposure to exchange rate risks, coupled with prudential regulation that deals with such risk, contributes to a softer landing after a crisis exit.

- The adoption of IT could be essential to establishing a new credible monetary regime that preserves stabilization gains previously achieved, in particular in the context of uncertainty and developing monetary institutions.

- Although more advanced planning for the implementation of IT could have resulted in a smoother transition, it was possible to implement the new framework rapidly and successfully, owing to both the determination of the CBB to put in place the essential elements that comprise a full-fledged IT regime and the supportive fiscal policy.

\section{Czech Republic (1996-97)}

The Czech Republic abandoned its horizontal band regime in June 1997 without an exit strategy and after a mini currency crisis that came as a reaction to a number of macroeconomic and structural policy-related factors. The mix of an expansionary fiscal and contractionary monetary policy, along with the slow progress in structural reforms, became inconsistent with the pegged regime in an open economy with a largely liberalized capital account. The authorities managed a soft landing after the crisis, which provided an opportunity to change the overall macroeconomic management. In the short period that followed the exit, IT was chosen as the only available option for the new nominal anchor. Although incomplete preparedness for IT contributed to the challenges faced in the early stages, its introduction in a reasonably short period helped limit prolonged market instability and lessened the severity of the disorderly exit. IT has also proved successful in achieving price stability and anchoring inflation under a floating regime.

\footnotetext{
${ }^{7}$ Prepared by David Vávra (Czech National Bank). The author thanks Miroslav Hrncir, Tomas Kvapil, Vera Masindova, Ivana Matalikova, and Rudolf Olsovsky for insightful comments and discussions.
} 


\section{Factors Triggering the Exit}

The exchange rate peg, in effect from the beginning of the transition process, provided a useful nominal anchor in the early periods of transition, but became increasingly difficult to sustain as integration with international markets continued. The basket peg within a \pm 0.5 percent band helped stabilize inflation after price liberalization while providing for a competitiveness cushion through an initially depreciated parity. Inflation quickly fell and the economy soon began recovering from a slowdown associated with the transition process. Monetary policy was able to retain independence under monetary targeting (M2). As the transition progressed, however, the exchange system was liberalized at a fast pace, with gradual relaxation of surrender requirements, easing of administrative procedures for capital account transactions, and full current account convertibility in 1995 . With the Czech Republic becoming the first former socialist OECD member in 1996, deadlines were established for phasing out the remaining capital controls.

The opening of the economy brought large capital inflows, with a significant volatile short-term component, exposing monetary policy to the "impossible trinity" dilemma. These flows began putting appreciation pressure on the exchange rate in the 1993-95 period, prompting the monetary authorities to resort to largescale sterilization policies, in an attempt to maintain simultaneously the exchange rate and monetary targets. Yet, money targets were repeatedly missed and progress in disinflation slowed.

As a partial response to these developments, the exchange rate band was widened (to \pm 7.5 percent) in February 1996, but this provided only a temporary relief in the absence of a needed change in the policy mix. Greater exchange rate flexibility helped in reversing short-term flows in 1996, by introducing more uncertainty into short-term speculative investments, and provided monetary policy with more room for maneuvering. In the absence of a countercyclical policy reaction, however, the macroeconomic situation became unsustainable: With the slow progress in economic restructuring and corporate governance, the economy started overheating, disinflation slowed down, and the external balance deteriorated. ${ }^{8}$ In the absence of a sufficiently tight fiscal policy to contain domestic and external imbalances, monetary policy was tightened

\footnotetext{
${ }^{8}$ See, for example, Begg (1998) and Christensen (2004). Although domestic demand expansion, not the low level of competitiveness (exports continued to grow at high rates in that period), was the primary contributor to the worsening of the current account, the rapid deterioration of the various competitiveness indicators undermined the sustainability of the economic fundamentals. Falling corporate profitability also put in doubt the stability of the largely state-controlled banking system, which tended to support specific industries.
}

from 1996, attracting additional short-term inflows that put further pressure on the exchange rate. With deteriorating economic fundamentals and the lack of steady long-term capital inflows, the sustainability of the peg became hostage to a potential reversal of short-term capital inflows.

\section{The Nature of the Exit}

The Czech Republic's switch from the exchange rate band could be characterized as a mini-crisis exit following a temporary capital flight. With the exchange rate being at the appreciating limit of the band, that the koruna would depreciate effectively became a one-way bet, because it was considered unlikely that the strong edge of the band would be relaxed, given the large current account deficits (Begg, 1998). Rising political instability, combined with contagion from the Asian crisis, induced investors to abandon the region, including the Czech Republic, which had been receiving significant amounts of short-term capital inflows.

Despite the circumstances, the crisis was not severe and was well managed. Exchange rate overshooting was avoided (the koruna depreciated by a mere 13 percent), reserves loss was minimal (only about 20 percent of reserves was used to defend the peg and was soon replenished), and interest rates started to ease shortly (having more than doubled previously). Crucially, there was no spillover to the banking and financial sector. Moreover, the peg regime was not defended at all costs. The decision to float was announced rather quickly at a relatively calm moment during the crisis and was followed by an announcement of the intention to focus on long-term price stability. The authorities also announced temporary indicative bands for the exchange rate under an officially declared managed float. The market calmed down after these announcements.

Although not planned in advance, the exit was reasonably smooth. The authorities subsequently took important measures to improve the macroeconomic management, including by reducing fiscal imbalances, addressing labor market imbalances, launching a program for attracting FDI, and speeding up structural reforms, including privatization of the banking sector (Hrncir, 1998). Adoption of the inflation target as the new nominal anchor and implementation of IT as the new monetary policy framework played an important role in limiting the severity of the crisis following the exit.

\section{Coordination with Supporting Elements of a Flexible Exchange Rate Regime}

Being an abrupt exit in the context of a currency crisis, the switch out of the peg was not associated with any particular strategy to prepare the economy 
for flexible exchange rates. Although the sustainability of the peg had been in doubt for some time (at least since the monetary tightening in late 1996), no specific exit plan, in particular an alternative monetary policy framework to replace the peg, had been put in place. Some exchange rate flexibility had been introduced through a widening of the horizontal band before the crisis, but the move was under market pressure and not part of a deliberate process of establishing the supporting elements of a new monetary policy regime.

After a short period of heavily managed floating with Czech National Bank interventions on both sides of the indicative band, and rising inflation, IT was adopted as the new monetary policy regime. With various forms of pegged exchange rate regimes largely discredited and monetary targeting operationally difficult with a poor track record, IT was viewed to be the only feasible option. Because there were no deliberate plans to move to targeting inflation, only some, though key, conditions for successful IT implementation were in place at the time of its adoption (central bank operational independence, effective implementation of monetary policy, availability of a key policy rate, reasonably developed financial markets, and no fiscal dominance). Some of the other important conditions were absent (for example, price stability mandate, political and/or public support, a strong state-owned banking system, adequate capacity for forecasting inflation, accountability, and transparency), which in turn contributed to the challenges in regaining credibility in the early stages of the new regime.

One of the key elements in place to support the implementation of both IT and a floating exchange rate regime was reasonably well developed financial markets. At the time of the float, there were active spot and derivatives markets in foreign exchange. Interbank money markets and secondary markets for securities were sufficiently developed by mid-1994, so that the CNB could abandon its market-maker role, conduct repo operations through the open market, and modify its operative target from monetary base to banking reserves. By late 1995, the markets (though somewhat undermined by banking sector segmentation and other problems) were functioning sufficiently well to permit monetary transmission by targeting money market interest rates.

The CNB contributed significantly to the development of the financial markets. A major boom in FX market development took place in 1996, supported in part by the widening of the horizontal band and relaxation of impediments on bank-client and forward transactions. Market participants learned to work with FX risks, because small exchange rate fluctuations had been allowed early on, and especially following the significant widening of the band in 1996. The CNB actively promoted money market liquidity in the early 1990s by issuing its own bills, with the liquidity of the treasury- bill market largely constrained by near-balanced budgets during this period. It also coordinated issues of the bills of other government agencies, as well as encouraged market development by initially playing a market-maker role. A number of technical measures were taken to improve the market infrastructure, such as setting up a system of quoting interbank offered rates, establishing an online clearing center, and defining the legal basis for repo contracts.

The capacity to implement monetary policy was relatively advanced at the time of the exit, facilitating the operation of the new monetary framework with a floating exchange rate. The central bank had established reasonable capacity to affect short-term interest rates, one of the key supporting conditions for IT. The CNB adopted a gradual approach to changing its operational target from the monetary base to banking reserves, and subsequently to money market rates, following closely the development of the markets and instruments. With relatively well developed money and financial markets, the CNB began using short-term market interest rates as the operational variable in early $1996 .{ }^{9}$ The CNB had a large variety of instruments for both active and passive operations. ${ }^{10}$ The elements of an interest rate corridor emerged in 1997, but it was finalized only in 2001 (with a two-week repo rate supported by a standby deposit and lending facility). The importance of the role of required reserves fell rapidly given the reduced need for sterilization under the float. Many of the other existing instruments were abolished or consolidated to ensure compatibility with the new system. ${ }^{11}$

The financial system was also reasonably stable, with adequate capacity to manage FX risks. This stability likely helped avoid a spillover of the currency market pressures into the banking system, notwithstanding the presence of some vulnerabilities in the banking sector (Box 2). The agents had capacity and tools to manage FX risks, because the authorities had actively promoted market development for some time, including during the

\footnotetext{
${ }^{9}$ Banking reserves replaced the monetary base as the operational target in the second half of 1994, when the CNB stopped playing the role of market maker. This was designed as an intermediate stage before interest rate targeting could be implemented, in particular to facilitate daily liquidity management without jeopardizing the stability of the underdeveloped money market. During 1995, the reserve-based system was complemented with conditions on the limits of market interest rate increases, and from late 1995 with an indicative corridor.

${ }^{10}$ Market-based instruments played a dominant role from early 1993, but repo operations fully replaced refinancing credit auctions only after the secondary short-term bill market was reasonably developed in mid-1994.

${ }^{11}$ Operations at the three-month maturity were abandoned in 2001 , because the demand was small and markets were unclear about the CNB's price-taking behavior at this longer maturity. Refinancing operations at the discount rate were also abolished in 1996, with the CNB considering such operations as nonsystematic, supporting liquidity of problematic banks at below-market rates, or supporting certain (export) industries.
} 


\section{Box 2. Czech Republic: The Condition of the Financial System}

The Czech financial system came through the foreign exchange (FX) crisis largely unscathed, notwithstanding some ongoing vulnerabilities in the banking sector. The main reason for the good performance of the banking system during the crisis was its good capacity to manage FX risks, acquired in the preceding period. The banks reacted promptly to the changing situation using their standard information and decision-making systems to limit losses by engaging in more active liquidity management, closing FX positions daily, imposing credit restrictions, and more frequently changing deposit and FX conversion rates for their clients; in fact, FX transactions during the crisis had a positive impact on profits in a vast majority of banks, and the sector had been very profitable in 1997 overall, also thanks to the performance during the crisis period. There was no worsening of the loan quality associated with the crisis, because the exposure through FX-denominated loans was either covered by foreign currency proceeds (that is, with positions naturally hedged) or through hedging instruments, or such loans were provided only to firstrate clients (usually of foreign banking institutions). The situation was also helped by a relatively smooth management of the crisis and the limited depreciation of the exchange rate.

Although insulated from the FX crisis contagion, the banking system was in a state of flux in the mid-1990s, mostly owing to solvency problems in the small banks segment and to slow progress in major bank privatizations. As a whole, the banking system was inefficient and noncompetitive; the levels of intermediation and maturity transformation were very low, with large spreads. Credit markets were highly segmented and uncompetitive at the time of the exit; as late as in 2000, private sector credit to GDP was well below the relevant market economy benchmark and the quality of the legal environment lagged significantly behind that of neighboring countries (OECD, 1996; Buiter and Taci, 2003; Christensen, 2004; and Arvai, 2005). As in other transition countries, the absence of long-term instruments contributed much to the large volumes of direct foreign borrowing and other capital inflows. Because the banking system development was relationship-based, with banks as the main financiers of the economic recovery, the slow privatization progress of banks also contributed to inefficient corporate control in the economy as a whole. The stagnation of structural reforms impacted the quality of the bank's loan portfolio.

The strengthening of the prudential and regulatory framework was gradual throughout the 1990s, and in general not directly associated with greater flexibility of the exchange rate. Although the FX risk exposure was regulated by the limits established on banks' open positions from the early 1990s and later was complemented by limits on short positions (to limit inflows of speculative capital), both measures were considered as monetary rather than prudential. The strengthening of the framework began in late 1993, involving tougher licensing and asset classification conditions, adaptation of international and European Union (EU)-compatible accounting standards, restrictions on investment in certain sectors, and the requirement to make capital provisions on anticipated portfolio losses. Although the Czech National Bank had kept limits on banks' open FX positions from the early 1990s, other FX-risk-related prudential regulations, including a regulation that established capital adequacy rules for foreign exchange risks, came into effect only in 2000.

In addition to exogenous factors, such as the Basel Accords and EU harmonization requirements, the prudential and supervisory measures evolved according to the situation in the banking system. The stability of the banking system suffered from relatively loose and liberal conditions in the early 1990s. Following the forced administration of a major bank in 1994 and the collapse of others in 1995, a consolidation program was put in place to improve the condition of mostly small, weak, and undercapitalized banks, following largely unsuccessful earlier attempts on an individual bank basis. The program involved tougher supervision based on individual rescue plans and led to the discontinuation of the activities of many banks. Despite the central bank's extensive deposit guarantees (in addition to the deposit insurance scheme, mandatory since 1994), the public's trust in the banking system was shaken.

The government adopted a stabilization program for small banks in 1996 to improve banking system credibility. A state company purchased the nonperforming loans of the banks in the program at their face value, against the banks' obligation to write them off within seven years. The banks involved were subjected to a number of performance criteria in addition to general prudential rules. The program continued with varying success until 1999 , leading to a consolidation of the small banking sector. The privatization program of major banks was put in place after 1997, improving the effectiveness and stability of the system.

Most of the bank failures in the process of banking system consolidation were attributed to fraud, credit risk, and bad management (corporate governance), and not to exposure to exchange rate risk. The limited link between exchange rate exposure and bank failures was mostly because banks with a significant FX exposure belonged to the better tier of institutions and foreign banks were very active in this market, having been allowed to operate either as subsidiaries or, more important, as branches of foreign institutions from the start. Permitting branches of foreign banks to operate in the domestic market also proved an important stabilizing element for the banking system, as well as during the FX crisis. pegged regime period. The FX risk management was also helped by a gradual strengthening of prudential regulation and supervision during the 1990s, and by the active involvement of foreign institutions and their branches. However, this gradual strengthening of the prudential and regulatory framework was not directly 
associated with the increased flexibility of the exchange rate. Although the CNB had kept limits on the open FX positions of banks from the early 1990s, other FXrisk-related prudential regulations came into effect only in 2000 in the context of EU harmonization rules that established capital adequacy rules for FX risks.

The FX market intervention strategy developed gradually in tandem with the exchange rate regime and alongside FX market development. Having been first used after the widening of the band in early 1996, interventions have become a standard policy tool since the exchange rate was floated in 1997. Interventions were used as a standard, though infrequent, tool to stabilize market fluctuations, including in response to large capital flows that could threaten the inflation target. Interventions have been based on limits and goals set by the Board, and implemented through major market players by operative decisions of the staff without a predetermined system of allocation or bank rotation lists. The volumes of interventions have been published with a two-month lag since 1998, but no procedural rules exist as to whether the interventions are announced immediately; both practices have been used with varying success (Holub, 2005).

\section{Challenges Faced during the Transition}

One of the major challenges the authorities faced in exiting from the pegged regime was the difficulty in introducing an alternative monetary policy framework under near-crisis conditions. These conditions made it even more difficult to replace the exchange rate anchor with monetary targeting, while the conditions for a successful IT were not fully in place at the outset. With so little preparation time (six months), the authorities were caught unprepared for the challenges of the new framework under a floating exchange rate. The following were the main challenges:

- Public support and awareness: Owing to the lack of a communication strategy, there was very little public awareness about the new regime. This lack of awareness naturally had an adverse effect on the level of public support. Since late 1998, the CNB has been very active in communicating its strategy to the public and specific interest groups, which has proven to be beneficial in terms of gaining their support for the new regime (Jonas and Mishkin, 2003).

- The role of the government: The government was not involved in defining the new goal of price stability and setting inflation targets. The new regime essentially required a brand new interpretation of the law that until 2002 referred to currency stability. Given the lack of agreement with the government, the CNB chose CPI net of administered prices to target inflation, which raised communication and statistical problems in the subsequent period. Since
2000 , the government has been involved in quantifying inflation targets and has assumed responsibility for supporting the IT regime.

- The CNB's internal processes: The CNB's internal processes were not adequately equipped for the information and technical requirements of monetary policymaking under IT. It had very little capacity to forecast inflation with reasonable precision and analyze other macroeconomic developments. The staff responsible for forecasting inflation focused their attention on information collection, rather than on their role of undertaking analyses for monetary policy decision making. The elements of a proper forecasting and policy analysis were put in place only by 2000 (Čapek and others, 2003b).

- The credibility of the new regime: The lack of some of these supporting elements of the IT framework indeed proved costly in terms of establishing the credibility of the new regime. The undershooting of the targets in the early years was associated with a protracted recession with rising unemployment, which endangered the independence of the CNB (see Jonas and Mishkin, 2003; and Čapek and others, 2003a). ${ }^{12}$ Although the CNB's independence was preserved, these pressures underpinned the importance of achieving the consent of the key parties (the government and the public in particular) in setting the inflation trajectory.

\section{Lessons from the Czech Experience}

The following lessons can be derived from the Czech experience:

- The Czech experience underscores the importance of maintaining consistency between the peg regime and the mix of macroeconomic policies under relatively open capital accounts in avoiding disorderly exits from a pegged exchange rate regime. When policies are not in line with the peg, attempts to adjust the regime toward flexibility provide only a temporary relief and postpone an eventual adjustment.

- The authorities' efforts to strengthen the condition of the banking system and put in place reasonably well developed financial markets and instruments for risk management helped limit the severity of the disorderly exit and facilitated implementation of the new exchange rate regime and policy framework.

- The experience also underscores the importance of adequate preparation for IT, public and government

\footnotetext{
${ }^{12}$ Whether or not high real interest rates were kept unduly long was not clear ex ante, particularly because there was a need to preserve credibility in the face of rising inflation. With the benefit of hindsight, a proper forecasting system could perhaps have allowed an earlier relaxation of the policy (Capek and others, 2003a).
} 
consent, effective communication, and necessary technical and organizational changes to improve support of the new framework.

- Although the conditions for a successful implementation of the IT regime were not fully in place, the presence of a few key elements helped introduce the IT framework in a reasonably short period, thereby helping limit prolonged market instability.

\section{Uruguay (2002) ${ }^{13}$}

Uruguay moved from a crawling band regime to a free float in June 2002 in one step, in the context of a full-blown financial crisis, followed by a sharp depreciation of the peso and insolvency of firms, banks, and the government. The band was abandoned without the supporting elements that would deal with greater flexibility and establish an alternative monetary framework. The experience of Uruguay shows how the absence of these elements and the misperception of FX risks in the context of high dollarization of the public and private sectors and fiscal weakness may increase the severity and challenges of a disorderly exit to a floating regime, requiring in turn substantial efforts for credibility building and capacity building in the post-crisis period.

\section{Factors Motivating the Exit}

The crawling band to the U.S. dollar was adopted in September 1990 as part of a stabilization plan aimed at reducing inflation that had reached three-digit levels that year. The rate of crawl was set on a forward-looking basis in order to anchor inflationary expectations, and the band width was set at 7 percent to allow greater flexibility of the exchange rate. The crawling band regime was coupled with a fiscal adjustment plan and the renegotiation of the public external debt under the Brady Plan in 1991. The stabilization plan indeed led to a significant reduction of the inflation rate, to single-digit levels by 1998. With accompanying strong economic growth in 1990-98 (fostered by large capital inflows and favorable external conditions), fiscal improvement, and a reduction of the external debt burden, Uruguay reached investment-grade status in 1997.

The domestic economy became highly susceptible to a sudden change in market sentiment triggered by external shocks in the presence of growing domestic financial vulnerabilities. In particular, the substantial increase in the degree of dollarization of the economy, in part reflecting the highly predictable nature of the exchange rate regime, exposed the domestic economy

\footnotetext{
${ }^{13}$ Prepared by Fernando Barrán (the Central Bank of Uruguay, BCU). The author thanks Carolina Gervaz and Umberto Della Mea.
}

to FX risks. Almost 100 percent of public debt and more than 90 percent of total deposits and banking loans were in foreign currencies. The presence of excessive dollarization constituted the seed for public and private sector insolvency that followed the collapse of the exchange rate.

\section{Coping with Adverse Real Shocks: Increasing Flexibility within the Band}

The authorities initially responded to the deterioration of the external conditions in 1998 by increasing the flexibility of the exchange rate under the existing crawling band regime. First, the preannounced reduction in the monthly rate of crawl was abandoned, and the rate of crawl was left unchanged to allow for a greater exchange rate adjustment in coping with the adverse shocks (for example, the substantial deterioration of the terms of trade and real appreciation of the peso following the devaluation of the Brazilian real in January 1999). However, despite initial turmoil in the FX market, the exchange rate remained at the lower (strong) end of the band. Additional shocks (for example, a drought, followed by a flood, an outbreak of foot-and-mouth disease, and the devaluation of the Argentine peso) led to a significant fall in real GDP and a jump in the fiscal deficit and government debt. Further attempts to adjust the real exchange rate were made in June 2001 and January 2002, when the monthly rate of crawl and the band width were doubled (Table 9).

This piecemeal approach to exchange rate flexibility was done without coordination with other supporting elements. Annual inflation targets have been announced and achieved since 1998. However, no measures were taken to prepare the economy for an exit. Moreover, greater flexibility of the exchange rate came from changes in the slope of the band and not from the increase in the band width, because the authorities limited the flexibility of the exchange rate by heavily supporting the stronger limit of the band; as a result of these interventions, the exchange rate regime looked like a de facto crawling peg. Measures taken in the FX market were also used to limit exchange rate volatility (for example, government FX purchases through the BCU, off the market).

\section{The Move from Crawling Band to Free Float}

The eventual move to a floating regime took place in the context of a massive outflow of capital and plummeting international reserves during the first semester of 2002. The outflows were triggered by contagion from the Argentine 2001-02 crisis, ${ }^{14}$ the loss of con-

\footnotetext{
${ }^{14}$ The measures adopted by Argentina included a freeze of all deposits and the immediate conversion of foreign currency deposits into Argentine pesos.
} 
Table 9. Evolution of Uruguay's Exchange Rate Regime, 1990-2005

\begin{tabular}{|c|c|c|}
\hline Date of change & Regime & Event \\
\hline September 1990 & Crawling band & Slope set at $3 \%$ (monthly rate); band width set at $2 \%$ \\
\hline October 1990 & Crawling band & Slope increased at $6.5 \%$ \\
\hline January 1991 & Crawling band & Slope reduced at $4 \%$ \\
\hline November I991 & Crawling band & Band widened to $\pm 4 \%$ \\
\hline January 1992 & Crawling band & Band widened to $\pm 6 \%$ \\
\hline June 1992 & Crawling band & $\begin{array}{l}\text { Public announcement of the crawling band; slope } \\
\text { reduced at } 2.5 \% \text {; band widened to } \pm 7 \%\end{array}$ \\
\hline October 1992 & Crawling band & Slope reduced at $2 \%$ \\
\hline April 1996 & Crawling band & Slope reduced at $1.8 \%$ \\
\hline September 1996 & Crawling band & Slope reduced at $1.4 \%$ \\
\hline May 1997 & Crawling band & Slope reduced at $1.2 \%$ \\
\hline August 1997 & Crawling band & Slope reduced at I\% \\
\hline November 1997 & Crawling band & Slope reduced at $0.8 \%$ \\
\hline April 1998 & Crawling band & Slope reduced at $0.6 \%$; band narrowed to $\pm 3 \%$ \\
\hline June 200I & Crawling band & Slope increased at $1.2 \%$; band widened to $\pm 6 \%$ \\
\hline January 2002 & Crawling band & Slope increased at $2.4 \%$; band widened to $\pm 12 \%$ \\
\hline June 2002 & Free float & \\
\hline
\end{tabular}

fidence in the domestic banking system, and the fiscal weakness of the Uruguayan government, which led to a downgrading of Uruguay's investment grade by international rating agencies in February 2002. Banks faced a massive withdrawal of deposits from nonresidents and residents. By the end of the first semester, depositsmostly foreign currency denominated-dropped by 50 percent. ${ }^{15}$ On June 20, 2002, the government announced that it had abandoned the crawling band and adopted a floating exchange rate system. Monetary base targeting was adopted as the nominal anchor and the government committed itself to a high degree of exchange rate flexibility, with only limited FX intervention aimed at ensuring orderly market conditions. However, the program included a floor on the net international reserves of the BCU and a ceiling on its net domestic assets that limited BCU's FX sales.

The regime shift was associated with a substantial depreciation of the currency and a subsequent worsening

\footnotetext{
${ }^{15}$ The pattern of the 2002 crisis followed very closely that of the 1982 crisis. As stated in Campanero and Leone (1991), "The devaluation of the Argentine Peso in 1981 (78 percent in March) caused a massive outflow of capital in Uruguay, owing to the lack of confidence in the sustainability of the Uruguayan crawling band once Argentina had abandoned its own." The collapse of the crawling band and the accompanying devaluation triggered the financial crisis and made many institutions technically insolvent by inducing loan defaults.
}

of macroeconomic and financial fundamentals in the absence of supporting measures prior to the adoption of the free float system. With the currency depreciating more than 80 percent by September 2002, the annualized inflation rate soared to an annualized 71.5 percent in the third quarter of 2002, compared with 6.5 percent in May. The debt-to-GDP ratio rose from 54 percent in 2001 to 92 percent in 2002, and the country risk premium skyrocketed from 216 basis points at end-2001 to 1,702 basis points at end-2002. In an effort to stabilize the markets, a bank holiday was introduced, followed by the closure of insolvent private banks which represented one-third of the banking system. ${ }^{16}$ With the financial support of multilateral agencies, a bank resolution strategy was designed to address the crisis, complemented by tight monetary policy and a public debt reprofiling in May 2003.

\section{Challenges and Supports in the Switch to Free Float}

The absence of prior measures to support a more flexible exchange rate regime made the process of moving

\footnotetext{
${ }^{16}$ At the time of the move to float, the authorities intervened in two large private banks and removed their management. Concerns about banks and the government's solvency also led to the removal of some key officials.
} 
to a floating regime very challenging. The most important challenges faced were (1) the absence of an alternative nominal anchor and hence the need to redesign the monetary policy framework around a new anchor, (2) the need to create an institutional framework to foster the establishment of an efficient FX market and to help the private sector better manage its FX risks under the flexible regime, and (3) the lack of domestic-currencydenominated instruments and a reference yield curve over which to perform monetary policy operations.

The task of regaining monetary and financial control and stability therefore required substantial efforts for capacity and credibility building. These efforts included establishing the necessary elements of an alternative monetary policy framework (that is, IT); major changes in the development and functioning of, and intervention policy in, the FX market; development of effective monetary policy instruments; introduction of an indexed unit of account to provide an alternative to the dollar; design of a communication strategy; and review of the financial safety net. The authorities accelerated their efforts to set up these capacities following the exit, while facing significant challenges under a highly uncertain and volatile crisis environment.

\section{Alternative Monetary Policy Framework}

The need to redesign an alternative monetary policy framework under crisis conditions was one of the main challenges in the post-transition period. Attaining inflation and monetary control was the most urgent task of monetary policy, with uncertainty over the level and volatility of the exchange rate having destabilized inflation expectations and exposed market participants to FX risks. To regain monetary control, the authorities chose monetary targeting as the alternative framework, although the effectiveness of the targets was undermined by the weak relationship between monetary aggregates and inflation with a high degree of currency substitution. ${ }^{17}$

IT was not viewed as a feasible option at the time of the exit, given the lack of credibility of the BCU, the high degree of dollarization, and the lack of knowledge and experience with monetary instruments. Estimates of money demand were useful to make consistent projections of the nominal monetary aggregates (given current and past values of prices), but not to forecast inflation, given the unstable market conditions. The BCU decided to adopt IT gradually in several stages aimed at creating IT-conducive conditions. It tightened monetary policy and signalled a strong commitment to price stability.

${ }^{17} \mathrm{FX}$-denominated sight deposits and current accounts represented more than 50 percent of sight deposits and current accounts in 2005. Almost 40 percent of local payments were made through dollar-denominated checks.

\section{Keeping inflation under control}

The first stage of this strategy, implemented in the second quarter of 2002, was aimed at keeping inflation under control and stabilizing the level and volatility of the exchange rate. The BCU pursued a tight monetary policy through open market operations and, for a short period, maintained higher reserve requirements for peso deposits. Because there was no market for pesodenominated instruments prior to the abandonment of the band, the authorities sought to develop a market for short-term treasury bills. They also made efforts to place inflation-indexed notes to increase maturity of market instruments. Monetary tightening helped curb the rise in inflation and after an initial overshooting, the peso appreciated significantly. Interest rates for the treasury bills more than halved by year's end. Efforts were also devoted to designing information systems, building capacity to forecast inflation and produce monetary actions consistent with maintaining price stability, and developing a communication strategy. These measures helped achieve monetary and financial stability, but the economic and social costs of the crisis were significant (a sharp drop in GDP and a steep rise in unemployment).

\section{Restoring credibility: Control of monetary aggregates and higher transparency}

In 2003, the second phase of the implementation of the new monetary policy framework was launched, aimed at restoring monetary policy credibility, with positive results. Because inflation forecasts were not accurate, efforts were made to achieve a monetary target. After the success in curbing inflation, the BCU announced a monetary growth target for 2003. At the end of each quarter, and according to the performance of the inflation rate, the goals were revised and a new quarter added to complete a one-year horizon target. Higher-than-expected output growth, fostered by gains in the competitiveness of the export sector, and the successful public debt swap led to a lower-than-expected depreciation of the peso and a lower-than-expected inflation outcome, given the high degree of exchange rate pass-through and the absence of significant pressures on wages and nontradable good prices. Interest rates in peso also plummeted to levels below 20 percent (from 60 percent earlier).

\section{Toward an IT framework}

Building on the credibility obtained after the first year of the new monetary regime, the BCU relaxed its commitment to monetary targets in 2004, announcing a range of values and shifting emphasis to achieving an inflation target. At the end of each quarter, the BCU announced the inflation target for the following year, revising, if needed, the monetary targets announced at 
the end of the previous quarter. Quarterly press releases communicating the decisions adopted by the Monetary Policy Committee were issued. Greater transparency, credibility building, and a better understanding of the BCU's reaction function have in turn reduced the discrepancy between the inflation targets and inflation expectations obtained through survey. By the end of 2004 , inflation fell to single digits, well inside the \pm 1 percent band around a target of 8 percent. The BCU's inflation-indexed notes (up to 10 years) and short-term bills became the main instruments of monetary policy, with a significant fall in short-term bill rates and a rise in average maturity (up to five months).

The monetary authorities continued the strategy toward adopting a formal IT regime after a new government took office in March 2005. The inflation targets for 2005 were reduced further. The new reputation gained by the $\mathrm{BCU}$ through its actions began to allow a more flexible use of the instruments and auctions in the FX market. Consequently, the announcements of treasury bill issues at the beginning of the day were abandoned. Moreover, the BCU stopped announcing a range of values for base money at the end of 2005 and started to announce indicative point estimates for M1, while continuing its efforts to introduce IT. The switch from an operational target (base money) to an intermediate target (M1) reinforced the commitment to inflation because the latter monetary aggregate has a closer link to prices. A law aimed at increasing the BCU's independence and strengthening its financial situation was submitted to the congress.

Although the monetary framework has been significantly improved, further efforts are needed to complete the transition to a full-fledged IT framework. These include, for example, the need to further enhance transparency and the communication strategy for monetary and exchange rate policy; further progress in technical areas, including in modeling and forecasting inflation; and further development of the financial markets and capacity to conduct monetary policy, particularly in the context of a highly dollarized environment that hinders transmission of monetary policy.

\section{Monetary Policy Instruments}

Because there had been no significant attempts to design peso-denominated instruments before the abolishment of the crawling band, the authorities needed to develop effective monetary policy instruments after the float. Developing these instruments was important initially to sustain the monetary targeting regime and subsequently to support the move to IT. The authorities accelerated efforts to develop a peso market for short-term treasury bills and extended its maturity over time from the initial maturity of less than a month to five months, including through placement of inflationindexed notes. They also conducted secondary market operations (through repo and reverse repo operations). By 2003, the BCU's inflation-indexed notes (up to 10 years) and short-term bills became the main instruments in conducting monetary policy.

\section{The Foreign Exchange Market}

At the time of the shift to a floating regime, Uruguay had a relatively well developed spot FX market but an underdeveloped FX derivatives market. The spot FX market had been well developed since the early 1970s, when all restrictions on the capital account and FX trading were lifted. However, the de facto narrower crawling band regime had limited the development of FX derivatives, with the government providing an implicit and costless FX guarantee. No explicit measures had been undertaken to develop such a market because doing so would have been perceived as undermining the credibility of the crawling band.

In particular, until June 2002, the BCU established on a daily basis the lower and upper limits of the band, and financial institutions traded between those limits on a bilateral basis. Trading volumes remained modest during the band period, in part because the public sectorcentral government and public enterprises-did not participate in the FX market. Public sector purchases of foreign currency, which accounted for more than 50 percent of total trading, were carried out directly with the BCU, in order to reduce the volatility of the exchange rate and to ensure that the exchange rate would remain close to the lower (stronger) limit of the band. Since 2003, the government's FX transactions were carried out in the market through a state bank with significant powers in the money and FX markets, rather than with the BCU, allowing greater exchange rate variability. Efforts have also been made to develop the FX derivative markets mainly with direct participation of the BCU, although this market remains underdeveloped.

\section{Foreign Exchange Intervention Policy}

During the crawling band regime, the exchange rate remained mostly at the lower (stronger) part of the band through interventions of the central bank. Contractionary monetary policies generally kept the exchange rate in the stronger part of the band. Although the crawling band in theory allowed greater flexibility of the exchange rate, the system looked like a crawling peg, with the BCU interventions limited to support the stronger limit of the band. The crawling-peg-like system allowed a steady reduction in inflation, given the strong pass-through effect of the exchange rate on inflation, while maintaining scope for greater flexibility without changing the regime. Pursuing this system was important in terms of the credibility of the program because the failed 1978 Stabilization Plan had been based on a crawling peg regime. 
The BCU adopted a new intervention strategy with the move to the floating regime and considerably increased the transparency of its FX operations immediately after the crisis. At the beginning of the free float period, interventions in the FX market were limited to fulfilling the $\mathrm{BCU}$ needs, established in advance. The objectives, amounts, and procedures of all BCU interventions were made explicit. Starting in November 2003, BCU purchases of foreign currency were performed through auctions announced at the beginning of the day. Transparency of the government's FX transactions did not increase, however, with the latter channelled in the market through the state bank.

Since 2005 , monetary policy has become more transparent and interventions in the FX market have been carried out and perceived as an instrument to achieve monetary and inflationary goals. Indeed, the reputation gained by the $\mathrm{BCU}$ through its actions began to allow for a more flexible use of the instruments and auctions in the exchange market. Since September 2005, the BCU interventions have not been announced in advance, although they are reported ex post on the BCU's website.

\section{Communication Strategies}

High levels of transparency and communication of the monetary policy framework were also major goals of the monetary authorities after the move to a free float regime. In 2003, Monetary Policy Reports were issued quarterly and regular meetings with economic analysts helped explain the monetary authorities' assessment of inflationary trends, policy actions, and achievement of the monetary targets. Since January 2004, the monetary authorities have conducted surveys of inflation expectations and the results have been made publicly available. The objectives, amounts, and procedures of all BCU interventions in the FX market were made explicit until October 2005, to allow market participants to develop credible views on the exchange rate and future monetary policy. Since the BCU gained a strong reputation, interventions in the FX market have no longer been explicit.

\section{The Financial Safety Net}

A number of measures had been taken to strengthen the banking system in the late 1990s prior to the float, but they were not adequate to improve the capacity to assess and manage FX risks. In September 1998, the $\mathrm{BCU}$ increased the minimum capital adequacy requirements from 8 percent to 10 percent of risk-weighted assets to strengthen the resilience of the banking sector. However, because this increase was not currency specific, FX risk was not internalized and hence the regulatory framework and bank behavior continued to undervalue FX risk. Moreover, reserve requirements in foreign currency held at the BCU were remunerated at above-market interest rates. The movement to a free float in a context of a high level of dollarization had raised concerns about banks' and the government's solvency, leading to an increase in the bank run.

After the movement to a free float regime, important changes in prudential regulation on FX risk have been adopted to strengthen the capacity to manage FX risks (2002-05): Liquidity requirements on foreign currency deposits have been raised, and reserve requirements in foreign currency started to be remunerated at belowmarket rates. Exposure to unhedged FX risk has been incorporated in loan classification and provisioning purposes (stress tests for large loans have been requested), and more information has been required for foreigncurrency-denominated loans (including business plans and audited financial statements). Capital requirements have been made currency specific: risk weights on dollar loans to the nonfinancial private sector were set at 125 percent, and they have also been increased for foreign currency loans to the public sector. Moreover, capital requirements against market risk have been established. Finally, foreign currency deposits have been assigned a lower coverage and a higher risk premium has been charged by the Deposit Insurance Agency.

\section{Lessons from the Uruguayan Experience}

The following lessons can be drawn from the experience of Uruguay:

- The absence of the supporting elements to deal with greater flexibility and the misperception of FX risks in the context of high financial dollarization and fiscal weakness make an abrupt exit from a pegged regime very challenging. The challenges faced in stabilizing the economy during the crisis highlight the importance of early preparations in achieving a smooth transition to greater flexibility.

- In particular, the absence of a strong and sound financial system with appropriate prudential rules to manage exposure to FX flexibility, and the lack of markets and instruments to hedge FX risks, magnify the challenges of a crisis exit. Moreover, the absence of domestic monetary instruments robust to changes in the monetary regime limits the ability of the authorities to support an alternative monetary framework.

- Intensifying efforts to put in place the supporting elements of a flexible exchange rate regime can help minimize the period of uncertainty, thereby helping market participants cope with flexible rates. In particular, prompt establishment of an alternative monetary framework and the development of the capacity to implement it are essential in restoring monetary credibility under floating exchange rates. 
- The adoption of consistent macroeconomic monetary policies, including on the fiscal side, also supports the steps taken to gradually increase monetary credibility and inflation control within a flexible exchange rate regime.
- The experience also emphasizes the importance of transparent and explicit communication of monetary, exchange rate, and intervention policies in rebuilding credibility following a sudden and disorderly exit. 


\section{Appendix I From Fixed to Float: \\ Operational Ingredients of Durable Exits to Flexible Exchange Rates}

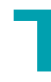
his appendix summarizes the main points of the IMF's operational framework for moving toward flexibility for those countries that have decided to move to a more market-determined exchange rate. ${ }^{1}$ This framework provides hands-on guidance on the institutional, operational, and technical aspects of moving toward exchange rate flexibility, drawing on the experience of countries that have managed the transition.

\section{Operational Ingredients of Durable Exits from Fixed to Floating Regimes}

Although the timing and priority accorded to each of these areas may vary from country to country depending on initial conditions and economic structure, the successful ingredients for floating include: ${ }^{2}$

- Developing a deep and liquid foreign exchange (FX) market;

- Formulating intervention policies consistent with the new exchange rate regime;

- Establishing an alternative nominal anchor in the context of a new monetary policy framework and developing supportive markets; and

- Reviewing exchange rate exposures and building the capacity of market participants, including the public sector, to manage exchange rate risks and of the supervisory authorities to regulate and monitor them.

\section{Developing a Deep and Liquid FX Market}

Operating a flexible exchange rate regime works well only when there is a sufficiently liquid and efficient

\footnotetext{
${ }^{1}$ This summary, prepared by Neil Saker, draws on IMF (2004a and 2004b), which in turn draws heavily on Duttagupta, Fernandez, and Karacadag (2004).

${ }^{2}$ These are in addition to the role of sound macroeconomic and structural policies-including fiscal discipline, monetary policy credibility, and a sound financial sector-which are essential to maintaining any type of regime, fixed or floating.
}

FX market for price discovery. ${ }^{3}$ A well-functioning FX market allows the exchange rate to respond to market forces and helps to minimize instances and durations of disruptive day-to-day fluctuations in the exchange rate and longer-term deviations from equilibrium. Fixing the exchange rate itself is often a key factor in limiting FX market liquidity. A central bank operating a fixed exchange rate regime is usually active in the market by necessity, which reduces the need for market participants to trade and keeps them from gaining experience in price formation or exchange rate risk management. In the extreme, the central bank may dominate the interbank FX market and act as the primary FX intermediary.

Allowing some exchange rate flexibility is a key step that can help improve the depth and efficiency of the FX market and stimulate better risk management. Such flexibility, in turn, could limit what is, to some extent, an unavoidable chicken-and-egg problem: Exchange rate flexibility requires a deep market and better risk management, but a deep market and prudent risk management require flexibility. Fluctuations in the exchange rate, even if small, quickly create incentives for market participants to gather information, form views, price foreign exchange, and manage exchange rate risks. Creating a sense of two-way risk in the exchange rate is also essential in establishing a deep market and capacity to manage risks. Market perceptions that the exchange rate can either appreciate or depreciate help reduce the risk of one-way bets against the central bank, minimize

\footnotetext{
${ }^{3}$ The FX market in general consists of a wholesale interbank market, in which authorized dealers (usually banks and other financial institutions) trade among themselves, and a retail market, in which authorized dealers transact with final customers (usually households and firms). The interbank market is where price discovery occurs through a decentralized allocation of FX by market participants on their own behalf as well as on behalf of their customers. A liquid market is characterized by (1) relatively narrow bid-offer spreads to lower transaction costs (tightness); (2) high turnover in volume as well as an abundance of orders to minimize the price impact of individual trades (depth and breadth); (3) efficient trading, clearing, and settlement systems to facilitate the swift execution of orders (immediacy); and (4) a wide range of active market participants to ensure that new orders flow quickly to correct order imbalances and misalignments (resiliency) (see Sarr and Lybek, 2002).
} 
destabilizing trading strategies, and help foster better risk management expertise.

There are four key aspects of deepening the market and enhancing price discovery: (1) reducing the central bank's market-making role, including its quotation of buying and selling rates, and requiring market makers to provide two-way price quotations; (2) increasing market information and transparency on the sources and uses of foreign exchange, detailed economic data, and a coherent policy framework as a basis for market participants to develop accurate views on monetary and exchange rate policy and efficiently price foreign exchange; (3) eliminating (or phasing out) regulations that stifle market activity; ${ }^{4}$ and (4) improving the market's microstructure, including by reducing market segmentation, improving the effectiveness of market intermediaries, and securing reliable and efficient settlement systems.

\section{A Coherent FX Intervention Strategy}

FX market intervention becomes discretionary under a flexible exchange rate regime, making it essential to establish well-specified intervention principles to enhance credibility of the new regime. The authorities face some difficult dilemmas and need to consider a number of important issues in this process:

- Potential disconnect between the exchange rate and macroeconomic fundamentals can create a role for intervention under floating exchange rates, even in well-functioning FX markets. But misalignments are difficult to detect and the typical indicators may not always allow policymakers to identify the degree of misalignment precisely enough to pinpoint appropriate intervention amounts and timing. 5

- Volatility reflecting market illiquidity may warrant intervention, because the latter stifles trading and, if it persists, can have serious adverse effects. Intervention can jump-start the market or tip a perverse price trend in the other direction. However, short-term volatility may not always warrant intervention, especially when it occurs in an orderly

\footnotetext{
4These regulations include, for example, (1) abolishing surrender requirements for FX receipts to the central bank, taxes and surcharges on FX transactions, restrictions on interbank trading (for example, outright bans on interbank trading or a requirement that all spot and forward market trades with customers have an underlying commercial transaction), and limits on price ranges quoted by dealers; (2) unifying segmented FX markets; and (3) relaxing current and, to some extent, capital account restrictions to bolster the sources and uses of foreign exchange in the market.

${ }^{5}$ These indicators include, for example, the nominal and real effective exchange rates, productivity and other competitiveness measures, the terms of trade, the current external account and balance of payments outlook, interest rate differentials, and parallel market exchange rates.
}

(liquid) market. Volatility often reflects the process of price discovery and provides useful signals to policymakers and the market. Efforts to smooth such volatility often end up suppressing useful signals and reduce incentives to learn how to manage FX risks.

- Exercising restraint in intervention during the transition to a flexible regime can help signal the official commitment to a market-determined exchange rate. Interventions that target an exchange rate level or a path can undermine the credibility of the new regime. By entering the market infrequently, central banks can maximize the element of surprise and the chances of intervention effectiveness and can build market confidence in the commitment to flexibility. As confidence grows, policy pronouncements and the capacity to intervene may suffice in most instances to achieve the desired change in the price trend, without an actual intervention operation.

- Even in fully flexible exchange rate regimes, central banks cannot completely avoid regular interventions (for example, to have a regular FX supply from purchases of the foreign currency revenue of public sector companies or export boards, or to target an appropriate level of reserves). Such interventions can be regular, preannounced, and rule-based (for example, through auctions) to support the information flow to the market, reduce noise, and enhance the signaling of surprise interventions.

The transition to flexible exchange rates hence creates the need to develop a coherent intervention strategy that specifies the policies on objectives, timing, and amounts of intervention. Whether the objective of intervention is to correct misalignments, calm disorderly market conditions, accumulate reserves, or supply publicly acquired foreign exchange to the market, care needs to be taken to signal the commitment to a market-determined rate and avoid excessive smoothing of short-term fluctuations. The latter is necessary to avoid suppressing the nascent markets and the useful market signals, as well as to avoid sending confusing messages about policy intentions. Intervention policy transparency is important in building confidence in the new regime, especially following forced exits. A public commitment to both the objectives of intervention and the criteria applied in its conduct enables market scrutiny and accountability for the central bank's FX operations.

\section{Developing an Alternative Nominal Anchor under a New Monetary Policy Framework}

Moving away from a fixed exchange rate creates the need to replace it with another credible nominal anchor and to redesign the monetary policy framework around the new anchor. The two tasks, in turn, require a substan- 
tial amount of capacity building and credibility building, and thus planning ahead for the transition is critical to achieving an orderly exit. The viability of maintaining a flexible regime without a nominal anchor depends on the authorities' credibility to sustain a responsible monetary policy without an anchor. Such credibility is generally difficult to build quickly, especially if a country had relied on a rigid exchange rate until the exit. Many countries moving to flexibility in recent years have favored IT frameworks over money-targeting ones (IMF, 2000a; and Khan, 2003). Although the latter can serve as a nominal anchor after floating, the weak relationship between monetary aggregates and inflation limits the effectiveness of such targets.

However, a credible alternative such as IT requires extensive preparation. A lengthy transition period reflects, in part, the time required to fulfill the necessary institutional requirements and macroeconomic conditions including (1) a central bank mandate to pursue an explicit, publicly announced inflation target as the overriding objective of monetary policy; (2) central bank operational independence; (3) transparency and accountability in the conduct and evaluation of monetary policy actions; (4) a reliable methodology for forecasting inflation and its link with other macroeconomic aggregates; (5) a forward-looking operating procedure that systematically incorporates forecasts into policy actions and responds to deviations from targets; (6) lack of fiscal dominance; and (7) a wellregulated and supervised financial sector (see Carare and others, 2002; Eichengreen and others, 1999; Fraga, Goldfajn, and Minella, 2003; IMF, 2000a and 2000b; and Mishkin, 2000).

The difficulty of developing a credible alternative nominal anchor to the exchange rate has also caused many countries to relinquish its anchor role only gradually or follow various versions of the monetary-targeting approach. Especially in the case of disorderly exits, some countries adopted monetary targets (namely, targeting base money, broad monetary aggregates, or bank reserves) in an effort to quickly establish a new nominal anchor and restore policy credibility until the preconditions of IT were established. Some countries used crawling bands as an intermediate regime for transitioning to another nominal anchor over a long period. The band usually has been set symmetrically around a crawling central parity and gradually widened over time as the tension between the exchange rate and the inflation rate objectives was eventually resolved in favor of the latter.

\section{Capacity to Assess and Manage FX Risks}

Private sector FX risk exposures can have an important bearing on the pace of exit, the type of flexible exchange rate regime adopted, and official intervention policies. Floating the exchange rate moves exchange rate exposure from the public to private sector balance sheets, as central banks no longer stand ready to intervene at fixed rates (Allen and others, 2002). ${ }^{6}$ Determining the scale and scope of FX risk exposures in the financial and nonfinancial sectors is therefore a key area for countries planning an orderly exit from pegs. Early analysis of, and improvements in, the management of FX risk are particularly important in economies where dollarization and currency mismatches are high. Even when these risks are modest early on, market participants need to develop the capacity to measure and monitor them to avoid building up exposures over time.

Evaluating exchange rate risk exposures involves detailed balance sheet analysis-focusing on the currency composition of balance sheets and the maturity, liquidity, and quality of foreign currency assets and liabilities. Unhedged FX borrowing by the corporate sector can translate into massive losses for banks and a surge in demand for foreign currency. Banks often closely control foreign currency liabilities and assets, but even when these are matched, the use of short-term foreign currency funds to finance long-term FX loans to unhedged borrowers causes their FX risks to translate into sizable credit and liquidity risks for banks (indirect FX risks). Two related risks also require close attention: (1) maturity mismatches in banks' foreign currency books that expose them to foreign currency liquidity risks and (2) corporate and banking sector exposure to interest rate risk that can limit the extent to which the central bank can use interest rates instead of interventions in the FX market. Corporations in developing countries have particular difficulty off-loading interest rate risk, particularly because they may not be able to obtain long-term fixed rates for their liabilities to fund assets.

An orderly exit from a pegged regime hence requires close scrutiny of the private sector's capacity to manage FX risk. Market participants need to develop information systems monitoring the FX risks, analytical systems for risk measurement, and internal risk and prudential procedures. Adequate prudential and supervisory arrangements need to complement internal risk management systems. Prudential measures may include limits on net open positions (as a percentage of capital), foreign currency lending (as a percentage of foreign currency liabilities), and overseas borrowing and bond issuance (as a percentage of capital); limits on the range of FX operations banks are allowed to perform; capital requirements against FX lending or risk; ${ }^{7}$ and the

\footnotetext{
${ }^{6}$ The public sector remains exposed to risks relating to its foreigncurrency-denominated public debt.

${ }^{7}$ The Basel Committee recommends a capital charge of 8 percent on the open position based on the shorthand method and recommends that the net open position does not exceed 2 percent of capital, although countries with greater risk exposures may need to adopt more conservative limits (Basel Committee on Banking Supervision, 1996). All open position calculations should include net spot and forward positions, guarantees, and net future income and expenses not yet accrued, but already fully hedged.
} 
Figure A I. Preparing for an Orderly Exit from a Peg

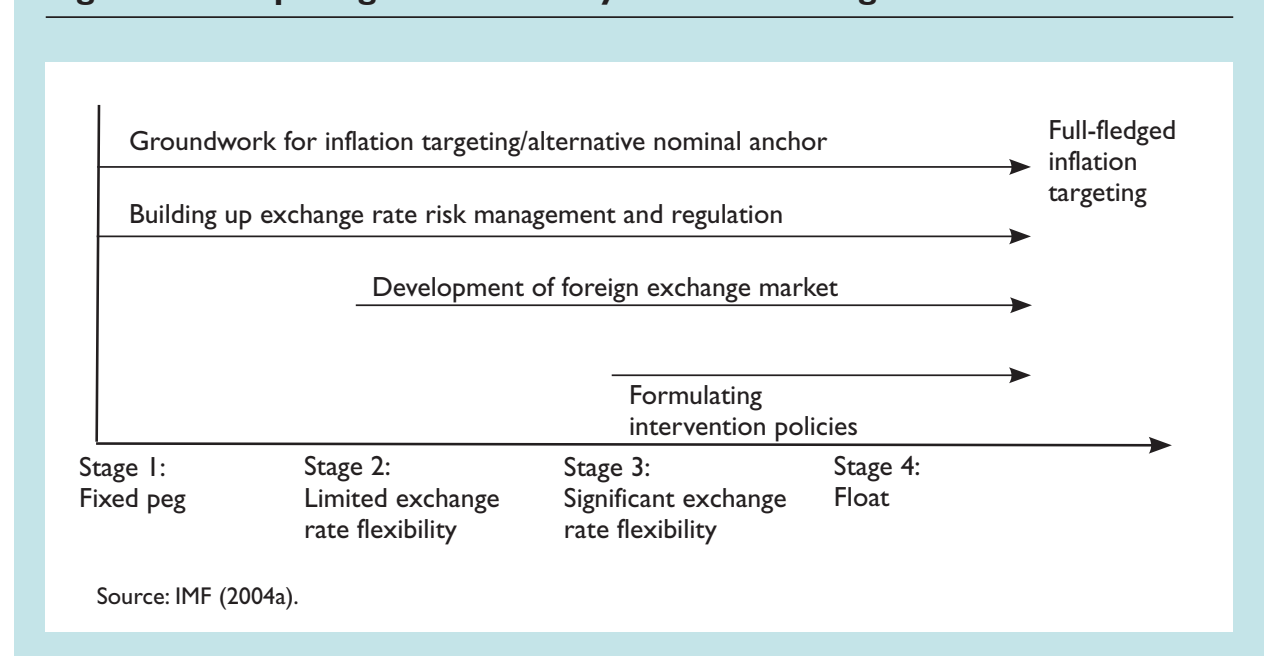

issuance of regulations or guidelines on the design of banks' internal control systems. Improving the capacity to enforce regulations can help ensure that regulations are complied with and are effective. Developing a risk-based supervisory system can help ensure that the internal control systems are adequate and properly enforced.

Although early investment into these elements is typically beneficial on its own, it can also help in mitigating the risk of disorderly exits during market turbulences. For instance, providing for a two-way risk when developing FX markets reduces the scope for destabilizing risk strategies. Similarly, having an effective FX-risk-related supervisory and prudential framework can prevent contagion of financial crises.

Carefully developed derivatives markets for foreign exchange are an essential element in building capacity to manage FX risks. However, facilitating the development of risk-hedging instruments by lifting controls on forward market activity can be a double-edged sword. While improving risk management capacity and supporting FX market development, liberalization of forward transactions could also facilitate speculative activity where there are incentives to do so. Several considerations can help guide the safe use of derivatives. Such instruments require financial institutions (and corporations) that have achieved a certain level of sophistication in risk management and supervisory authorities capable of conducting risk-based supervision. Close monitoring of the use of the instruments is important to prevent their being used to push a normally sustainable situation over the edge by sizable leveraged bets. Also critical are the standardization of derivative products traded among banks and the presence of accounting standards for fair valuation and a reliable legal system for contract enforcement. The central bank should promote market transparency and, with other regulators, promote high reporting standards.

\section{Pace and Sequencing of Exit to Exchange Rate Flexibility}

There are important policy questions regarding the pace of exit and sequencing of moves toward exchange rate flexibility with other policies, including capital account liberalization. These questions involve difficult trade-offs and considerations that are often countryspecific, including the degree of preparedness for floating rates, the openness of the capital account, the macroeconomic situation, and the condition in the domestic and international markets. Some broad conclusions are as follows:

- If taken from a position of macroeconomic strength, a faster pace of exit has benefits in that it signals purpose and determination, thereby enhancing the credibility of monetary policy. It also has a greater chance of exploiting what may turn out to be a narrow window of tranquility, provided also that the institutional underpinnings for operating a floating exchange rate are in place.

- In practice, the pace at which relevant institutions (for example, an alternative nominal anchor and the capacity to manage risks) can be built is a main determinant of the pace at which an orderly exit can proceed. Many countries have opted for a gradual approach, which in principle may reduce the risk of excessive exchange rate volatility and its potentially adverse effects on inflationary expectations. It also 
allows the FX market to deepen through the mutually reinforcing relationship between FX activity and exchange rate flexibility and provides time to build the remaining institutional blocks.

- Early preparation for an exchange rate float can bolster the chances of success of the exit strategygradual or rapid. Many of the operational areas require substantial information on the exposures to and capacity to manage FX risk, and increasing data on balance of payments developments. These steps can be undertaken early on, even before a peg is exited. The second stage may involve allowing some exchange rate flexibility to stimulate FX market activity and continuing to develop other operational areas. Intervention policies can be addressed at a relatively later stage, once greater exchange rate flexibility is embraced (see Appendix Figure A1 for a suggestive illustration of the various stages taken toward moving to full flexibility).

- The absence of a full-fledged IT framework as an alternative nominal anchor should not preclude a rapid exit strategy, provided that there is a robust commitment to price stability. The building blocks of IT-such as fiscal discipline, operational independence of the monetary authorities to pursue low inflation, and transparency and accountability - are necessary for the success of any monetary policy regime regardless of a formal adoption of IT.

- The pace of exit also needs to take into account the openness of the capital account. For example, it may be difficult to pursue a gradual exit strategy under conditions characterized by large and volatile capital flows. By contrast, a less open capital account would make it easier to operate variants of pegs or manage the exchange rate within a band. Clear trade-offs are involved in the sequencing of exchange rate flexibility and capital account liberalization. ${ }^{8}$

- There are risks to opening the capital account before adopting a flexible exchange rate; many countries were forced off pegs after sudden reversals of capital flows, whereas others faced heavy inflows and appreciation pressures and had to allow flexibility to avoid overheating. On the other hand, liberalizing the capital account can help offset transitory current account shocks, expand the instruments for risk management, and deepen the FX market, which is important for operating a flexible exchange rate.

- The transition to flexibility can be facilitated by removing or strengthening existing asymmetries in the openness of the capital account to support an orderly correction of misalignments (for example, by liberalizing outflows to reduce pressures from inflows, and liberalizing long-term inflows before short-term ones). Remaining controls can be removed following a successful move to floating.

${ }^{8}$ The successful liberalization of the capital account itself depends on a wide range of issues related to the economy, financial sector stability and reform, and sequencing issues (see Ishii and others, 2002). 


\section{Appendix II Experiences with Short-Lived Exits to Greater Flexibility'}

\begin{abstract}
T he experiences of the countries presented below highlight a number of factors relating to macro conditions, commitment to reform, and operational aspects that have contributed to reversals in the attempts to establish greater exchange rate flexibility. In particular, they highlight the roles of (1) an underdeveloped and illiquid FX market (Uzbekistan), (2) a limited capacity to manage exchange rate risk with ensuing fear of floating (all three cases), (3) a lack of an appropriate (for example, rules-based) intervention policy (Uzbekistan and Pakistan), (4) a limited institutional and technical capacity to adopt a credible alternative nominal anchor (Uzbekistan and Pakistan), (5) a limited degree of monetary policy independence (Ecuador and Uzbekistan), (6) adverse economic conditions and poor macroeconomic policy (Ecuador), and (7) a lack of commitment to free (exchange) markets (Pakistan and Uzbekistan).
\end{abstract}

\section{Ecuador}

In February 1999, the Ecuadorian authorities abandoned the exchange rate band and moved to a floating exchange rate regime after repeated episodes of exchange market pressures. The Ecuadorian economy plunged into a major economic crisis in 1999: Real GDP declined by about 7.5 percent; inflation accelerated to 61 percent; the fiscal deficit exceeded 5 percent of GDP; public debt grew to over 100 percent of GDP and was in default; unemployment almost doubled to 17 percent; FX reserves fell by 64 percent; and volatility of the sucre continued well after the floating, depreciating by 200 percent in 1999 .

Simultaneously Ecuador was hit by a major crisis in the banking sector. The crisis originated in persistent institutional weaknesses in banking supervision and regulation that allowed excessive accumulation of credit risk from connected and foreign currency lending to unhedged borrowers. The weaknesses in the banking system were exacerbated by a tradition of bailing out troubled banks. Lack of effective supervi-

${ }^{1}$ Prepared by Jahanara Zaman. sion of offshore subsidiaries of banks provided an easy way to circumvent regulations and controls and ultimately contributed substantially to the losses of failed banks.

The banking crisis further weakened monetary and exchange rate policy, which resulted in renewed exchange market pressure at the end of 1999. With shattered monetary policy credibility, looming hyperinflation, and no access to international financial markets after the sovereign default on the Brady bonds in the fall of 1999, the authorities moved to a full-blown dollarization in January 2000.

\section{Pakistan}

Pakistan made two attempts to introduce greater exchange rate flexibility from a de facto peg to the U.S. dollar. The first move took place during 1998, when a number of liberalization measures were undertaken (based on the recommendations of an IMF mission in 1997) to allow greater scope for market determination of the exchange rate. The process was interrupted in May and June 1998 with the introduction of exchange controls and a dual exchange system. In May 1999 the exchange rate system was unified and an initial attempt was made at liberalizing the exchange rate by allowing authorized dealers to quote their own buying and selling rates.

However, the authorities reversed some of the liberalization measures. Only a month later, they imposed a narrow exchange rate band. In May 2000, they made a new attempt at liberalizing the exchange rate and invited an IMF mission to advise on a framework for money and FX market operations. However, the authorities continued their strong preference for maintaining nominal exchange rate stability through (1) direct and indirect interventions on the official and parallel markets, (2) exertion of moral suasion on market participants, (3) close monitoring of bank's activity, (4) imposition of restrictions on authorized dealers' FX operations, and (5) other indirect forms of intervention (for example, managing import demand). All these restrictive measures hampered the interplay of demand and supply in the FX market and did not allow an 
exchange rate adjustment as warranted by the underlying macroeconomic conditions.

Pakistan's slow progress toward greater flexibility suggests a lack of operational preparedness. The FX market is not sufficiently liquid; the intervention policy has not been developed to yield consistent and transparent outcomes; formal adoption of IT is still in process; and the institutional capacity to manage exchange rate risk is not fully developed.

\section{Uzbekistan}

In July 2001, the authorities took steps toward greater exchange rate flexibility motivated primarily by a consideration to implement economic reforms. An overthe-counter market was created for buying and selling foreign exchange to allow the exchange rate to float freely in accordance with demand and supply, but the market remained shallow. Progress toward a market economy was slowing because of excessive government control, including (1) restrictions on domestic and external trade, (2) numerous barriers to the normal functioning of the financial markets, and (3) exchange restrictions and controls (including surrender requirements and restrictions on interbank sales of foreign exchange).

The financial sector remained weak with substantial vulnerabilities related to FX risk. Uzbekistan's banking system was characterized by extensive government controls and limited confidence in financial intermediation. In addition, banks had large exposures to FX risk. Uzbek banks were heavily dependent on foreign financing, and a reduction in the flows of such financing would jeopardize their ability to continue to finance the domestic economy.

A fear of floating led to frequent intervention in the FX market and to a reversal to a more tightly managed exchange rate regime. The fear of floating stemmed from a number of factors, including a strong passthrough from the exchange rate to inflation, the potential impact of the high level of liability dollarization on private sector balance sheets, potential output costs of variable exchange rates, and concerns about the implications for the heavy dependence of Uzbek banks on external borrowing. 


\section{Appendix III Ukraine: An Example of Ongoing Cautious Steps toward Greater Exchange Rate Flexibility'}

U kraine's move toward exchange rate flexibility is motivated by the difficulties in maintaining a fixed exchange rate with an increasingly more open capital account and a surge in foreign exchange receipts from the large current account surplus. Since 1999 the authorities have maintained a de facto peg to the U.S. dollar, but over time the balance of payments situation has changed from being at the brink of default to a sizable current account surplus (though more recently, the current account balance switched from a large surplus to a deficit). Short-term capital inflows attracted by the perception of exchange rate undervaluation added to the pressure on the hryvnia in 2005 and complicated the control over monetary aggregates and inflation.

In response to these developments, the authorities took a number of actions in 2005. They increased sterilization operations and prohibited nonresident purchases of short-term treasury bills. They have also taken some initial steps to increase exchange rate flexibility by allowing a step appreciation of the hryvnia and introducing an indicative narrow band of HRV1/US\$5.0-\$5.2; the official exchange rate has been left unchanged at HRV1/ US\$5.05, however, and the interbank market rate has mostly moved in a narrower band of HRV1/US\$5.00$\$ 5.06$. Furthermore, since late 2004 the authorities have been focusing on preparations for the introduction of an IT regime as an alternative nominal anchor.

The authorities' approach to moving toward greater exchange rate flexibility has been very cautious, reflecting a number of challenges typically associated with fear of floating: concerns about losing a transparent nominal anchor and policy credibility, potential exchange rate losses associated with currency mismatches in corporate balance sheets, weaknesses in banks' risk management practices and lack of hedging markets and instruments to cover against exchange rate risks, underdeveloped financial markets, and fears of worsening of external competitiveness should the currency appreciate.

${ }^{1}$ Prepared by Inci Ötker-Robe and David Vávra.
Some progress has been made in most of the areas identified in the fixed-to-float framework and technical assistance (TA) reviews, but further efforts are needed. ${ }^{2}$ First, with a view to establishing the elements of an inflation-targeting framework, the National Bank of Ukraine (NBU) has started improving its modeling and forecasting capacity over the past two years, communicating more on the introduction of IT, and improving monetary policy transparency. Further efforts are needed to firmly establish NBU's operational independence, clarify the primacy of price stability as the main monetary policy objective, continue efforts to strengthen the communication strategy, and deepen financial markets and instruments. The efforts to accelerate the preparations have been undermined by an uncertain political environment.

Second, the spot and forward foreign exchange markets remain substantially underdeveloped and illiquid. A high degree of regulation and dominant central bank presence in the market have been key obstacles to market development. To address these issues, the NBU undertook measures in 2005 to relax restrictions on forward transactions, on open foreign exchange positions, and on banks' two-way trading and to make foreign exchange trading more flexible and transparent. These measures have not yet become productive, reflecting in part the existence of a fee on foreign exchange transactions and the absence of liquid interbank and government securities markets to facilitate price formation in the forward market.

Third, banks and borrowers continue to remain vulnerable to foreign exchange and related risks. Existing limits on short positions seem to be binding, but in practice the banks tend to balance their foreign exchange liabilities with foreign exchange credits, extending them even to

${ }^{2}$ To support the transition, the authorities have received extensive technical assistance from the IMF since late 2004 in the areas of moving to greater exchange rate flexibility; monetary operations; monetary policy communication; bank supervision, regulation, and resolution; development of the government securities market; and establishing the remaining conditions conducive to adopting an IT regime that could replace the exchange rate anchor. 
clients with no foreign currency earnings; foreign-currency-denominated lending has been about 40 percent of total loans since 2001 and has edged up recently to over 40 percent. The NBU tightened supervision and regulation of banks, and introduced higher provisioning requirements for foreign exchange lending to unhedged borrowers to address indirect foreign exchange risks. However, banks also face maturity risks, with maturities of bank funding not having kept up with the increase in loan maturities. A potential funding risk for banks also emerged, because the rising dollarization of loans has required banks to borrow foreign funds, making banks vulnerable to rollover and liquidity risks.

Finally, lack of adequate capacity to affect market interest rates hinders the introduction of IT as well as the capacity to implement a flexible exchange rate regime. Although the central bank has several instruments to steer market liquidity, it lacks a transparent policy rate to influence short-term interest rates. The discount rate, the NBU's policy rate, has no influence on interest rates, and the refinancing rate has lost its signaling function. Reserve requirements have played an increasingly large role in steering liquidity, not least because of lower fiscal costs compared with other sterilization instruments, but have caused significant interest rate volatility, raised spreads between borrowing and lending rates, and led to concerns about their implications for financial intermediation. The NBU has recently increased its focus in this area to improve the functioning of its monetary instruments. 


\section{Appendix IV Foreign Exchange Hedging, Complementary Markets, and the Role of the Central Bank'}

\begin{abstract}
$F_{\text {o }}^{\circ}$ oreign exchange risk is present in any modern economy. The risks may not be recognized or transparent, they might be ignored or implicitly transferred or assumed by official entities, or they may be measured and managed. Financial theory as well as extensive experience strongly suggests that failure to explicitly measure and manage risk by the entities that create that risk is potentially destabilizing, at both the institutional and systemic levels. Moreover, FX markets are only one of many financial system components, which are becoming increasingly integrated in developed economies. For reasons of appropriate risk management as well as efficient functioning of the financial system, development of the FX markets requires welldeveloped hedging and complementary markets.
\end{abstract}

\section{Hedging}

Open or unhedged FX exposures pose significant risks and can cause significant losses or even insolvency. The losses can often spread beyond those directly affected to their creditors, especially financial intermediaries, including commercial banks. If severe and widespread, the losses can pose systemic risks to the financial system.

Hedging FX exposures obviously reduces risk to the individual institution, but also has several other important benefits. It makes risks explicit, which allows them to be better measured, priced, and managed. It also allows the trading and transfer of risk, presumably to those better able to manage it. This improved allocation of risk in the economy should improve overall stability and yield important welfare benefits.

The central bank can play a key role in stimulating FX hedging. It can make clear the need for hedging; it can help assure that the means of hedging are available; and it can promote the effectiveness of hedging and reduce its cost. The central bank should ensure that the

${ }^{1}$ Prepared by Barry Topf. environment and conditions permit and are supportive of hedging; it can also assume an active role in promoting the development of hedging.

Establishing the need for hedging is best done by making FX risks transparent and making it clear who bears them. Every effort should be made to avoid the creation or appearance of a moral hazard issue, whereby the creators of risk assume that the cost will be borne by others. Specifically, the central bank should eliminate explicit or implicit guarantees, multiple exchange rates, and subsidies. Suppressing volatility of the exchange rate, smoothing operations, or providing a predetermined path of the exchange rate all inhibit management of FX risk, especially when combined with interest rate differentials that are not consistent with the predetermined level or range of the exchange rate. Increased variability of the exchange rate will provide an incentive for hedging practices. The central bank should promote the use of market exchange rates for all transactions, transfer commercial transactions to the market, and reduce the factors that create segmentation among market participants.

Prudential regulations and supervision should recognize the benefits of financial hedging. Business plans should explicitly address FX exposures, and lenders and financial intermediaries should examine their client's risk management policies and procedures. Where appropriate, specific regulation might be called for, including higher provisioning requirements on FX loans to borrowers with no FX income, or higher capital requirements against unhedged FX exposures.

The central bank has an important role in making available the means to hedge FX risks: It should eliminate unnecessary regulatory obstacles that stifle market development. These include surrender requirements, restrictions on instruments such as forwards and options, and restrictions on market participants. For example, restrictions on types of transactions (for example, short selling), or parties to certain transactions (for example, nonresidents prevented from engaging in certain transactions), hinder the development of the market and can introduce serious distortions. The legal framework 
should be modernized and adapted for modern financial markets, tax issues that increase the cost of hedging should be addressed, and tax discrimination should be eliminated. Accounting standards should provide for appropriate treatment of hedging transactions.

The central bank can undertake efforts to increase awareness and hedging skills in the relevant sectors of the public, including users as well as third parties, such as accountants and auditors. It can support professional groups $(\mathrm{ACI})^{2}$ and the setting of standards (CFA), ${ }^{3}$ as well as market codes of conduct; it can also support the adoption of master agreements and standard documentation of transactions (ISDA ${ }^{4}$ ). It could also consider providing support to the market by making available objective benchmarks and pricing mechanisms, such as FX and interest rate fixings. In this case the central bank should play a statistical role only, leaving the market to actually determine the rates.

Foreign entities can often bring valuable experience and skills in risk management and should be allowed to play a constructive role. Other financial intermediaries, such as nonbank market makers and brokers, can also contribute to market development.

The effectiveness of hedging depends primarily on the efficiency of the markets and instruments, and the skills of those employing it. Nevertheless, the central bank can also play a useful role. An efficient infrastructure is vital, and payment and clearing systems should meet accepted standards. Safe and efficient payment versus payment and delivery versus payment are essential to a well-functioning financial system, as is the availability of reliable financial data and information. Even where the central bank is not the regulatory authority, a degree of market surveillance can be extremely helpful, especially in the early stages of market development.

\section{Complementary Financial Markets}

The FX market cannot develop independently of other financial markets. In a modern financial system, markets are highly integrated, information and capital flow quickly, and segmentation is costly and difficult to maintain. Lack of development in one market can retard the development of other markets, introduce inefficiencies and distortions, and hold back positive developments in the economy. Well-developed markets, on the other hand, reinforce one another, promote effi-

\footnotetext{
${ }^{2} \mathrm{ACI}$, the Financial Markets Association, has branches in many countries; it undertakes training activities and promotes best market practices.

${ }^{3}$ The CFA (Certified Financial Analyst) charter is granted by the Certified Financial Analyst Institute.

${ }^{4}$ The International Swap Dealers Association promotes standard documentation for financial transactions.
}

ciency, and spur continued development. FX markets are especially dependent on other markets, because FX transactions rarely stand alone: They are often derived from or connected to the need to transact or manage risk in other markets.

Short-term money markets have the closest link to FX markets because the most basic FX transactions are no more than transfers of bank balances. FX and money market transactions often complement one another, and in some cases can be substitutes. Furthermore, the interest rates established in the money market are vital for developing the FX market, especially that for forward and swap transactions, important hedging tools. A liquid and efficient interbank market in loans and deposits is essential to allow interest rate parity to function.

Within the FX market itself, foreign exchange versus foreign exchange transactions are important risk management tools (in addition to the FX versus domestic currency transactions that local players will naturally concentrate on). Derivative markets are important adjuncts to the FX market. Forward and swap transactions usually develop in close conjunction with the (spot) FX market and money market, whereas longdated swaps, futures, and options usually come later.

Fixed-income markets, especially the government bond market, also play key roles. A liquid government bond market, in addition to its important role in government finance and monetary operations, provides a benchmark to other markets. Absence of a well-developed liquid securities market undermines the market's ability to price swaps, forwards, and other hedging instruments. A developed capital market complements banking markets, broadens the universe of available assets, diversifies financing channels, and improves operational efficiency.

The role of the central bank in promoting the development of complementary markets is analogous to its role in developing the hedging market. It can eliminate unnecessary obstacles, such as restrictions on instruments or techniques (such as short sales), and reduce excessive licensing, reporting, or regulatory burdens that stifle market development. It should help establish a strong bank supervisory capability-usually involving coordination with other authorities, including capital market regulators, securities regulators, and organized exchanges - and supervisory authorities of nonbank financial institutions.

Although it may not be its direct responsibility, the central bank can assist in establishing a conducive environment for market development. The bank can do this by reducing or eliminating institutional segmentation (by product or by customer), clarifying and rationalizing legal issues (such as treatment of collateral and repurchase (repo) transactions), promoting an efficient and transparent tax regime, and eliminating tax discrimination. Clear and modern accounting and reporting standards are also essential. The central bank could also play a supporting role in establishing efficient mar- 


\section{Box AI. The Bank of Israel's Role in Developing Foreign Exchange and Complementary Markets}

The Bank of Israel (BoI) has twice played a direct role in developing markets by issuing derivative financial instruments for the sole purpose of kick-starting financial markets in new instruments. The outcomes were very different, but both illustrate important points.

The first attempt involved the use of foreign exchange options. All sectors of the economy had extensive experience - not always successful —in dealing with foreign exchange risk. As a result, the use of swaps and forwards, but not options, developed on its own. Moreover, although hedging was widespread in dealing with foreign exchange and foreign exchange exposures, hedging was not widely practiced in dealing with fluctuations of the domestic currency (the new Israeli sheqel-NIS). In part, lack of this sort of hedging stemmed from a long history of managed exchange rates. Managed exchange rates led to a perception that exchange rate risk was a matter for the authorities - the central bank and government-rather than market participants. Available hedging instruments were lacking, and there were indications that this situation stemmed more from lack of supply than lack of demand. Early in 1989, Israel adopted a horizontal band, allowing limited foreign exchange rate flexibility ( \pm 3 percent), which replaced the previous regime of a fixed peg with periodic - and not infrequent-devaluations (see Section III).

In 1989 the BoI began selling call options on the U.S. dollar by means of auctions to the commercial banks. (Because of legal restrictions, the central bank could not deal directly with the public or business sector, and the restriction of operating exclusively through commercial banks was itself seen as a considerable disadvantage.) The BoI wanted its involvement in call options to serve as a catalyst to developing the market, and therefore carefully limited its role so as to avoid substituting for private sector activity. The amount issued was set at \$24 million per week, and never increased. Although the total amount issued was capped at \$24 million per week, changes were made in issuance policy: put options and six-month maturities, in addition to the original three-month contracts, were added.

The market developed steadily thereafter. An over-thecounter (OTC) market began in 1990, and in 1994 the Tel Aviv Stock Exchange began trading options contracts (in 2002 it added NIS/euro contracts). In 1996, volume in both the OTC and the Stock Exchange began increasing rapidly. Because the amounts issued by the BoI remained the same, their share in the market shrank steadily: By 2004, BoI options accounted for less than 3 percent of outstanding options and less than 0.5 percent of turnover. In 2005, the
BoI ceased issuing three-month foreign exchange options, but continued issuing six-month contracts. By that time, the market was well established and stopping the issuance of these products had no noticeable effect on options trading.

The active role played by the BoI undoubtedly acted as a catalyst, at least partially, in developing the foreign exchange options market. Although the claim can be made-quite rightly - that such a market would have developed on its own, the initiative of the central bank certainly accelerated its appearance, and quite probably made the process more efficient. In addition, the BoI options provided an important source of data and information on exchange rate developments and expectations.

The BoI had less success in promoting the use of interest rate hedging instruments. Interest rate exposure was less recognized and hardly managed at all. This situation was the result of a history of high inflation, widespread indexation of financial assets and liabilities, a fragmented market, and extensive government interference. By 1990, the focus of the BoI's monetary policy shifted to interest rates. In that year, the BoI began to auction three-month future contacts based on 3- and 12-month treasury bills, in an effort to spur the practice of interest rate hedging.

Interest rate risk hedging markets developed much more slowly than did those for foreign exchange risk, and have remained fairly small and illiquid. OTC trading of interest rate forwards developed sporadically, and exchange traded contracts were introduced only in 2000 , and discontinued shortly thereafter owing to low trading volumes. In 2004, total outstanding OTC interest rate derivatives reached NIS 4 billion, compared with NIS 160 billion for foreign exchange derivatives. This ratio differs substantially from international experience, where interest rate derivatives comprise 80 percent of outstanding derivatives positions, far greater than the 14 percent share of foreign exchange derivatives.

The lack of development of interest rate hedging remains a puzzle, but a number of factors can be cited. Historically, risk was managed through consumer price indexation and real interest rate denominated contracts, rather than nominal interest rate instruments. There has been a shorter history of interest rate volatility, and government debt issuance policy has not always been helpful. The underlying market is illiquid, fragmented, and incomplete and there are still administrative obstacles-no short selling or security lending and no market makers (although there are plans for government bond market makers to begin operations in 2006). The lack of clear enforceability of netting and collateral arrangements has also been an obstacle. kets, either organized or over the counter, including brokers and other intermediaries.

A number of technical issues in the design and function of instruments and markets should also be addressed, because a lack of standards can often constitute a considerable obstacle to the development and acceptance of new instruments and markets. These issues include daycount, computation, and payment methods for money and fixed income markets; information systems; and the availability of indices and reliable benchmarks. Wherever possible, these should be compatible with international standards and accepted market practices. 


\section{A Direct Role for the Central Bank}

The central bank can consider taking a proactive role in developing hedging or complementary markets. Its role might include providing incentives or institutional support to products or markets. Central bank policy and operations will often play a role in spurring the development of markets. For example, monetary policy using open market operations will provide a powerful incentive to traded securities markets and the development of repurchase transactions.

The central bank could also initiate the development of instruments and markets by actually issuing or making a market in instruments such as forwards and options (for example, see Israel's experience in Appendix Box A1). The case for an explicit central bank role is not clear-cut. Arguments supporting an active role include the possibility of market failure (in the sense of multiple equilibrium, inertia, collusion, or coordination failures); relative advantage of the central bank; or the existence of a development cycle, where there is a natural role for the central bank as a catalyst. Moreover, the argument can be made that risks and costs already exist and in many cases are borne by the central bank; the use of tradable instruments simply makes the role of the central bank more transparent and explicit.

However, there are also weighty arguments against the central bank taking a direct role in developing financial markets. It is not a core central bank role, and could be counterproductive in the long term if it displaces or crowds out the private sector or introduces distortions and inefficiencies. There is a risk of failure, with implications for the reputation and credibility of the bank. This direct role adds financial risk and operational risks that require the managing of scarce resources; if they are not managed correctly, failures could be costly.

Given the risks and uncertainties, any direct role for the central bank should be carefully considered and well prepared. If the central bank does decide to play a proactive role, goals should be carefully defined and limited, and the role of the central bank should be delineated and circumscribed from the outset. Milestones should be established so that the central bank role does not become self-perpetuating, and periodic evaluations of market development and the costs and/or profitability of the central bank should be rigorously examined. If safety nets are extended to the private sector, they should be limited in both extent and duration. Costs and incentives should be made explicit, and any incentives should be tied to obligations. Finally, an exit strategy for the central bank should be prepared and strictly adhered to.

\section{Summary}

The main points of this appendix can be summarized as follows:

- FX risk hedging should be encouraged to improve the pricing and managing of risk, increase stability at all levels, and improve welfare. For these goals to be achieved, FX variability should be allowed to increase, regulatory and other obstacles to hedging should be removed, and an appropriate environment should be provided.

- The development of complementary financial markets is essential to the development of the FX market and brings additional benefits to the financial system, including greater efficiency, completeness, improved monetary policy transmission, competition, diversification, and operational efficiency.

- The central bank can promote the appropriate environment, assist in establishing the necessary conditions and infrastructure, and take a number of initiatives to help develop FX hedging and complementary markets. In certain cases a direct role for the central bank might be beneficial, but the costs and risks should be carefully considered. 


\section{Bibliography}

Ahumada, L.A., F. Alarcón, J. Selaive, and J.M. Villena, 2006, "The Development of the Currency Derivatives Market in Chile," Central Bank of Chile Financial Stability Report (first half), pp. 69-77.

Allen, Mark, C. Rosenberg, C. Keller, B. Setser, and N. Roubini, 2002, "A Balance Sheet Approach to Financial Crisis," IMF Working Paper 02/210 (Washington: International Monetary Fund).

Ariyoshi, A., K. Habermeier, B. Laurens, I. Ötker-Robe, J. Canales Kriljenko, and A. Kirilenko, 2000, Capital Controls: Country Experiences with Their Use and Liberalization, IMF Occasional Paper No. 190 (Washington: International Monetary Fund).

Arvai, Z., 2005, "Capital Account Liberalization, Capital Flow Patterns, and Policy Responses in the EU's New Member States," IMF Working Paper 05/213 (Washington: International Monetary Fund).

Bank for International Settlements (BIS), 2004, "Triennial Central Bank Survey of Foreign Exchange and Derivatives Market Activity in April 2004" (Basel: Monetary and Economic Department). Available via the Internet: www.bis.org/publ/rpfx04/pdf.

Bank of Israel, Annual Report (Jerusalem, various issues). Available via the Internet: http://www.bankisrael.gov. il/publeng/publeslf.php?misg_id=12.

Bank of Israel Foreign Currency Department, Annual Report (Jerusalem, various issues). Available via the Internet: http://www.bankisrael.gov.il/publeng/publeslf. php?misg_id=27\& toptitlela=Regular\%20Publications.

Basel Committee on Banking Supervision, 1996, Amendment to the Capital Accord to Incorporate Market Risks (Basel: Bank for International Settlements). Available via the Internet: http://www.bis.org/publ/bcbs24.pdf.

Barrán, F., 2002a, "Política cambiaria y objetivos de inflación en Uruguay" (Exchange Rate Policy and Objectives of Inflation in Uruguay), Banco Central de Bolivia Revista de Análisis, Vol. 5 (June). Available via the Internet: http://www.bcb.gov.bo/pdffiles/iniciales/revistas/ junio2002/Capitulo3final.pdf.

___ 2002b, "Uruguayan 2002 Financial Crisis Resolution at a Glance," paper presented at the FSAP Seminar on Financial Stability and Development, Washington, June 18.

Begg, D., 1998, "Pegging Out: Lessons from the Czech Exchange Rate Crisis," Journal of Comparative Economics, Vol. 26 (December), pp. 669-90.

Ben-Bassat, A., 1995, "The Inflation Target in Israel: Policy and Development" in Targeting Inflation, ed. by A. Haldane (London: Bank of England).
Bruno, M., 1997, "Growth, Inflation and Economic Stabilization" (Hebrew) (Jerusalem: Bank of Israel). - and L. Meridor, 1991, "The Costly Transition from Stabilization to Sustainable Growth: Israel's Case," in Lesson of Economic Stabilization and Its Aftermath, ed. by Bruno and others (Cambridge, Massachusetts: MIT Press).

Bruno, M., and S. Piterman, 1988, "Israel's Stabilization: A Two Year Review," in Inflation Stabilization: The Experience of Israel, Argentina, Brazil, Bolivia and Mexico, ed. by Bruno and others (Cambridge, Massachusetts: MIT Press).

Buiter, W., and A. Taci, 2003, "Capital Account Liberalization and Financial Sector Development in Transition Countries," in Capital Liberalization in Transition Countries: Lessons from the Past and for the Future, ed. by A. Bakker and B. Chapple (Northampton, Massachusetts: Edward Elgar), pp. 105-41.

Campanero, J., and A. Leone, 1991, "Liberalization and Financial Crisis in Uruguay, 1974-87," in Banking Crises: Cases and Issues, ed. by V. Sundararajan and T. Baliño (Washington: International Monetary Fund).

C̆apek, A., T. Hlédik, V. Kotlán, S. Polák, and D. Vávra, 2003a, "Developing Consistent Scenarios with the Forecasting and Policy Analysis System," in The Czech National Bank's Forecasting and Policy Analysis System, ed. by W. Coats, D. Laxton, and D. Rose (Prague: Czech National Bank).

, 2003b, "Historical Perspective on the Development of the Forecasting and Policy Analysis System," in The Czech National Bank's Forecasting and Policy Analysis System, ed. by W. Coats, D. Laxton, and D. Rose (Prague: Czech National Bank).

Carare, A., A. Schaechter, M.R. Stone, and M. Zelmer, 2002, "Establishing Initial Conditions in Support of Inflation Targeting," IMF Working Paper 02/102 (Washington: International Monetary Fund).

Central Bank of Chile, Annual Report (Santiago, various issues). Available via the Internet: http://www.bcentral. cl/eng/funorg/annualreport/.

Céspedes, L.F., and C. Soto, 2005, "Credibility and Inflation Targeting in an Emerging Market: Lessons from the Chilean Experience," International Finance, Vol. 8 (Winter), pp. 545-75.

Chan-Lau, J.A., 2005, "Hedging Foreign Exchange Risk in Chile: Markets and Instruments," IMF Working Paper 05/37 (Washington: International Monetary Fund).

Christensen, J., 2004, "Capital Inflows, Sterilization, and Commercial Bank Speculation: The Case of the Czech 
Republic in the Mid-1990s," IMF Working Paper 04/218 (Washington: International Monetary Fund).

Cowan, K., and J. De Gregorio, 2005, "International Borrowing, Capital Controls and the Exchange Rate: Lessons from Chile," Working Paper No. 322 (Santiago: Central Bank of Chile). Available via the Internet: http://www. bcentral.cl/eng/stdpub/studies/workingpaper/htm/322. htm.

De Brun, J., and G. Licandro, 2006, "To Hell and Back: Crisis Management in a Dollarized Economy: The Case of Uruguay," in Financial Dollarization: The Policy Agenda, ed. by A. Armas, A. Ize, and E. Levy-Yeyati (London: Palgrave MacMillan).

De Gregorio, J., 2001, "La Política Cambiaria," Economic Policy Paper No. 2 (Santiago: Central Bank of Chile).

___ and A. Tokman, 2004, "Overcoming Fear of Floating: Exchange Rate Policies in Chile," Working Paper No. 302 (Santiago: Central Bank of Chile). Available via the Internet: http://www.bcentral.cl/eng/stdpub/ studies/workingpaper/htm/302.htm.

Dominguez, K.M.E., and L. Tesar, 2001, "Exchange Rate Exposure," NBER Working Paper No. 8453 (Cambridge, Massachusetts: National Bureau of Economic Research).

Dominioni, D., 2004, "Uruguay: Two Years of Monetary Policy in Adverse Conditions" (unpublished).

Durjasz, P., and R. Kokoszczyński, 1998, "Financial Inflows to Poland, 1990-96," Empirica, Vol. 25, No. 2, pp. 217-42.

Duttagupta, R., G. Fernandez, and C. Karacadag, 2004, "From Fixed to Float: Operational Aspects of Moving Towards Greater Exchange Rate Flexibility," IMF Working Paper 04/126 (Washington: International Monetary Fund).

Eichengreen, B., and others, 1998, Exit Strategies: Policy Options for Countries Seeking Greater Exchange Rate Flexibility, IMF Occasional Paper No. 168 (Washington: International Monetary Fund).

Eichengreen, Barry, Paul Masson, Miguel Savastano, and Sunil Sharma, 1999, "Transition Strategies and Nominal Anchors on the Road to Greater Exchange-Rate Flexibility," Essays in International Finance No. 213 (Princeton, New Jersey: Princeton University).

Fischer, S., 2001, "Exchange Rate Regimes: Is the Bipolar View Correct?" Distinguished Lecture on Economics in Government, Journal of Economic Perspectives, Vol. 15 (Spring), pp. 3-24.

Fraga, A., 2000, "Monetary Policy During the Transition to a Floating Exchange Rate: Brazil's Recent Experience," Finance \& Development, Vol. 37 (March).

___ Ilan Goldfajn, and André Minella, 2003, "Inflation Targeting in Emerging Market Economies," NBER Macroeconomics Annual 2003 (Cambridge, Massachusetts: MIT Press), pp. 365-99.

Goldfajn, I., and A. Minella, 2005, "Capital Flows and Controls in Brazil: What Have We Learned?" NBER Working Paper No. 11640 (Cambridge, Massachusetts: National Bureau of Economic Research). Forthcoming in Sebastian Edwards, ed., 2007, Capital Flows and Capital Controls in Emerging Economies: Policies, Practices and Consequences, NBER Conference Report (Chicago: University of Chicago Press).

Gottlieb, D., and M. Blejer, 2002, "Liberalization in the Capital Account of the Balance of Payments," in The Israeli
Economy, 1985-1988: From Government Intervention to Market Economics, ed. by A. Ben-Bassat (Cambridge, Massachusetts: MIT Press).

Hersko, S., 2005, "Principle Stages in the Liberalization of Control on Foreign Exchange in Israel 1987January 2003" (Hebrew) (unpublished; Jerusalem: Bank of Israel, Foreign Exchange Activity Department, July).

Holub, T., 2005, "Forex Interventions: The Czech Experience," in "Foreign Exchange Market Intervention in Emerging Markets: Motives, Techniques and Implications," BIS Papers No. 24 (Basel: Bank for International Settlements). Available via the Internet: http://www.bis. org/publ/bppdf/bispap24l.pdf.

Hrncir, M., 1998, "Transition Stages and Monetary Policy Strategy: Some Lessons from the Czech Case," paper presented at the Fourth Dubrovnik Conference on Transition Economies, Dubrovnik, Croatia.

__ _ 2001, "Impact of Capital Inflows into the Czech Republic and Policy Responses," in Central Europe Towards Monetary Union: Macroeconomic Underpinnings and Financial Reputation, ed. by R. MacDonald and R. Cross (Norwell, Massachusetts: Kluwer Academic Publishers).

International Monetary Fund (IMF), 2000a, Practical Issues in the Adoption of Inflation Targeting by Emerging Market Countries, SM/00/199 (Washington).

___ 2000b, "Summing Up by the Acting Chairman, Inflation Targeting-Implications for IMF Conditionality" (Washington). Available via the Internet: http:// www.imf.org/external/np/pp/eng/1999/121499.pdf.

, 2004a, From Fixed to Float: Operational Aspects of Moving Toward Exchange Rate Flexibility (Washington). Available via the Internet: http://www.imf.org/ external/NP/mfd/2004/eng/111904.htm.

-, 2004b, "IMF Executive Board Discusses 'Fixed to Float: Operational Aspects of Moving Toward Exchange Rate Flexibility"' (Washington). Available via the Internet: http://www.imf.org/external/np/sec/pn/2004/ pn04141.htm.

Ishii, S., and others, 2002, Capital Account Liberalization and Financial Sector Stability, IMF Occasional Paper No. 211 (Washington: International Monetary Fund).

Jonas, J., and F.S. Mishkin, 2003, "Inflation Targeting in Transition Countries: Experience and Prospects," NBER Working Paper No. 9667 (Cambridge, Massachusetts: National Bureau of Economic Research).

Khan, M., 2003, "Current Issues in the Design and Conduct of Monetary Policy,” IMF Working Paper 03/56 (Washington: International Monetary Fund).

LeFort-Varela, G., 2005, "Capital Account Liberalization and the Real Exchange Rate in Chile," IMF Working Paper 05/132 (Washington: International Monetary Fund).

Leiderman, L., 1999, Inflation and Disinflation in Israel (Hebrew) (Jerusalem: Bank of Israel).

, and G. Bufman, 1996, "Searching for Nominal Anchors in Shock-Prone Economies in the 1990s: Inflation Targets and Exchange Rate Bands," Working Paper No. 15-96 (Tel Aviv: Tel-Aviv University).

Loyola, G., 2005, "Regulação Prudencial e Mercado de Câmbio," in Aprimorando o Mercado de Câmbio Brasileiro, ed. by Daniel L. Gleizer (São Paulo: Bolsa de Mercadorias \& Futuros). 
Massad, C., 1998, "Monetary Policy in Chile," Economía Chilena, Vol. 1 (August).

Michaeli, M., 2004, "Liberalization of the Foreign Exchange Market in Israel 1950-2002," in Volume II of Bank of Israel: 50 Years of Striving for Monetary Control (Jerusalem: Bank of Israel). English edition forthcoming: Haim Barkai (ed. by Nissan Liviatan), 2007, The Bank of Israel (Oxford: Oxford University Press).

Mishkin, F., 2000, "Inflation Targeting in Emerging Market Countries," NBER Working Paper No. 7618 (Cambridge, Massachusetts: National Bureau of Economic Research).

Monetary Policy Council (MPC), 1998, "Medium-Term Strategy of Monetary Policy (1999-2003)" (Warsaw: National Bank of Poland, September). Available via the Internet: http://www.nbp.pl/en/publikacje/o_polityce_ pienieznej/strategia.pdf.

Morandé, F., 1999, "La Nueva Política Cambiaria," speech presented at the Entrepreneurial Forum ICARE, September 22. Available via the Internet: http://www. bcentral.cl/esp/politicas/exposiciones/ejecutivos/ pdf/1999/morandeseptiembre221999.pdf.

___ 2001, "Exchange Rate Policy in Chile: Recent Experience," paper presented at an IMF High-Level Seminar on "Exchange Rate Regimes: Hard Peg or Free Floating?" Washington, March 19-20.

, and K. Schmidt-Hebbel, 2000, "Chile's Peso: Better Than (Just) Living with the Dollar?" Working Paper No. 68 (Santiago: Central Bank of Chile). Available via the Internet: http://www.bcentral.cl/eng/stdpub/studies/ workingpaper/htm/068.htm.

Morandé, F., and M. Tapia, 2002, "Exchange Rate Policy in Chile: From the Band to Floating and Beyond," Working Paper No. 152 (Santiago: Central Bank of Chile). Available via the Internet: http://www.bcentral.cl/eng/ stdpub/studies/workingpaper/htm/152.htm.

Mussa, M., P. Masson, A.K. Swoboda, E. Jadresic, P. Mauro, and A. Berg, 2000, Exchange Rate Regimes in an Increasingly Integrated World Economy, IMF Occasional Paper No. 193 (Washington: International Monetary Fund).

National Bank of Poland, 2002, "Financial Market in Poland 1998-2001," Financial System Development Report (Warsaw).
OECD, 1996, "Czech Republic_Economic DevelopmentDevelopments in Individual OECD Countries," OECD Economic Outlook (June).

Ozer, B., S. Reiss, and Y. Soffer, 2005, "Israel's Financial Account Liberalization" (Jerusalem: Bank of Israel, Foreign Exchange Activity Department, August). Available via the Internet: http://www.boi.gov.il/deptdata/ neumim/neum190e.pdf.

Piterman, S., and B. Topf, 1996/7, "Exchange Rate Policy," Central Banking, Vol. VII, No. 3 (Winter), pp. 67-74.

Polański, Z., 2004, "Poland and the European Union: The Monetary Policy Dimension. Monetary Policy Before Poland's Accession to the European Union," Bank i Kre$d y t$, No. 5 (May), pp. 4-18. Available via the Internet: http://www.nbp.pl/publikacje/bank_i_kredyt/2004_05/ polanski.pdf.

Pruski J., and P. Szpunar, 2005, "Exchange Rate Policy and Foreign Exchange Interventions in Poland," in "Foreign Exchange Market Intervention in Emerging Markets: Motives, Techniques and Implications," BIS Papers No. 24 (Basel: Bank for International Settlements), pp. 26170. Available via the Internet: http://www.bis.org/publ/ bppdf/bispap24u.pdf.

Sadowska-Cieślak E., 2003, "Capital Account Liberalization in Poland," in Capital Liberalization in Transition Countries: Lessons from the Past and for the Future, ed. by A.F.P. Bakker and B. Chapple (Northampton, Massachusetts: Edward Elgar), pp. 225-43.

Sarr, A., and T. Lybek, 2002, "Measuring Liquidity in Financial Markets," IMF Working Paper 02/232 (Washington: International Monetary Fund).

Schmidt-Hebbel, K., and Alejandro Werner, 2002, "Inflation Targeting in Brazil, Chile, and Mexico: Performance, Credibility, and the Exchange Rate," Working Paper No. 171 (August) (Santiago: Central Bank of Chile).

Tapia, M., and A. Tokman, 2004, "Effects of Foreign Exchange Intervention Under Public Information: The Chilean Case," Working Paper No. 255 (Santiago: Central Bank of Chile). Available via the Internet: http:// www.bcentral.cl/eng/stdpub/studies/workingpaper/ htm/255.htm.

Williamson, J., 1996, The Crawling Band as an Exchange Rate Regime, Lessons from Chile, Colombia, and Israel (Washington: Institute for International Economics). 


\section{Recent Occasional Papers of the International Monetary Fund}

256. Moving to Greater Exchange Rate Flexibility: Operational Aspects Based on Lessons from Detailed Country Experiences, by Inci Ötker-Robe and David Vávra, and a team of IMF economists. 2007

255. Sovereign Debt Restructuring and Debt Sustainability: An Analysis of Recent Cross-Country Experience, by Harald Finger and Mauro Mecagni. 2007.

254. Country Insurance: The Role of Domestic Policies, by Törbjörn Becker, Olivier Jeanne, Paolo Mauro, Jonathan D. Ostry, and Romain Rancière. 2007.

253. The Macroeconomics of Scaling Up Aid: Lessons from Recent Experience, by Andrew Berg, Shekhar Aiyar, Mumtaz Hussain, Shaun Roache, Tokhir Mirzoev, and Amber Mahone. 2007.

252. Growth in the Central and Eastern European Countries of the European Union, by Susan Schadler, Ashoka Mody, Abdul Abiad, and Daniel Leigh. 2006.

251. The Design and Implementation of Deposit Insurance Systems, by David S. Hoelscher, Michael Taylor, and Ulrich H. Klueh. 2006.

250. Designing Monetary and Fiscal Policy in Low-Income Countries, by Abebe Aemro Selassie, Benedict Clements, Shamsuddin Tareq, Jan Kees Martijn, and Gabriel Di Bella. 2006.

249. Official Foreign Exchange Intervention, by Shogo Ishi, Jorge Iván Canales-Kriljenko, Roberto Guimarães, and Cem Karacadag. 2006.

248. Labor Market Performance in Transition: The Experience of Central and Eastern European Countries, by Jerald Schiff, Philippe Egoumé-Bossogo, Miho Ihara, Tetsuya Konuki, and Kornélia Krajnyák. 2006.

247. Rebuilding Fiscal Institutions in Post-Conflict Countries, by Sanjeev Gupta, Shamsuddin Tareq, Benedict Clements, Alex Segura-Ubiergo, Rina Bhattacharya, and Todd Mattina. 2005.

246. Experience with Large Fiscal Adjustments, by George C. Tsibouris, Mark A. Horton, Mark J. Flanagan, and Wojciech S. Maliszewski. 2005.

245. Budget System Reform in Emerging Economies: The Challenges and the Reform Agenda, by Jack Diamond. 2005.

244. Monetary Policy Implementation at Different Stages of Market Development, by a staff team led by Bernard J. Laurens. 2005.

243. Central America: Global Integration and Regional Cooperation, edited by Markus Rodlauer and Alfred Schipke. 2005.

242. Turkey at the Crossroads: From Crisis Resolution to EU Accession, by a staff team led by Reza Moghadam. 2005.

241. The Design of IMF-Supported Programs, by Atish Ghosh, Charis Christofides, Jun Kim, Laura Papi, Uma Ramakrishnan, Alun Thomas, and Juan Zalduendo. 2005.

240. Debt-Related Vulnerabilities and Financial Crises: An Application of the Balance Sheet Approach to Emerging Market Countries, by Christoph Rosenberg, Ioannis Halikias, Brett House, Christian Keller, Jens Nystedt, Alexander Pitt, and Brad Setser. 2005.

239. GEM: A New International Macroeconomic Model, by Tamim Bayoumi, with assistance from Douglas Laxton, Hamid Faruqee, Benjamin Hunt, Philippe Karam, Jaewoo Lee, Alessandro Rebucci, and Ivan Tchakarov. 2004.

238. Stabilization and Reforms in Latin America: A Macroeconomic Perspective on the Experience Since the Early 1990s, by Anoop Singh, Agnès Belaisch, Charles Collyns, Paula De Masi, Reva Krieger, Guy Meredith, and Robert Rennhack. 2005.

237. Sovereign Debt Structure for Crisis Prevention, by Eduardo Borensztein, Marcos Chamon, Olivier Jeanne, Paolo Mauro, and Jeromin Zettelmeyer. 2004.

236. Lessons from the Crisis in Argentina, by Christina Daseking, Atish R. Ghosh, Alun Thomas, and Timothy Lane. 2004.

235. A New Look at Exchange Rate Volatility and Trade Flows, by Peter B. Clark, Natalia Tamirisa, and Shang-Jin Wei, with Azim Sadikov and Li Zeng. 2004.

234. Adopting the Euro in Central Europe: Challenges of the Next Step in European Integration, by Susan M. Schadler, Paulo F. Drummond, Louis Kuijs, Zuzana Murgasova, and Rachel N. van Elkan. 2004. 
233. Germany's Three-Pillar Banking System: Cross-Country Perspectives in Europe, by Allan Brunner, Jörg Decressin, Daniel Hardy, and Beata Kudela. 2004.

232. China's Growth and Integration into the World Economy: Prospects and Challenges, edited by Eswar Prasad. 2004.

231. Chile: Policies and Institutions Underpinning Stability and Growth, by Eliot Kalter, Steven Phillips, Marco A. Espinosa-Vega, Rodolfo Luzio, Mauricio Villafuerte, and Manmohan Singh. 2004.

230. Financial Stability in Dollarized Countries, by Anne-Marie Gulde, David Hoelscher, Alain Ize, David Marston, and Gianni De Nicoló. 2004.

229. Evolution and Performance of Exchange Rate Regimes, by Kenneth S. Rogoff, Aasim M. Husain, Ashoka Mody, Robin Brooks, and Nienke Oomes. 2004.

228. Capital Markets and Financial Intermediation in The Baltics, by Alfred Schipke, Christian Beddies, Susan M. George, and Niamh Sheridan. 2004.

227. U.S. Fiscal Policies and Priorities for Long-Run Sustainability, edited by Martin Mühleisen and Christopher Towe. 2004.

226. Hong Kong SAR: Meeting the Challenges of Integration with the Mainland, edited by Eswar Prasad, with contributions from Jorge Chan-Lau, Dora Iakova, William Lee, Hong Liang, Ida Liu, Papa N'Diaye, and Tao Wang. 2004.

225. Rules-Based Fiscal Policy in France, Germany, Italy, and Spain, by Teresa Dában, Enrica Detragiache, Gabriel di Bella, Gian Maria Milesi-Ferretti, and Steven Symansky. 2003.

224. Managing Systemic Banking Crises, by a staff team led by David S. Hoelscher and Marc Quintyn. 2003.

223. Monetary Union Among Member Countries of the Gulf Cooperation Council, by a staff team led by Ugo Fasano. 2003.

222. Informal Funds Transfer Systems: An Analysis of the Informal Hawala System, by Mohammed El Qorchi, Samuel Munzele Maimbo, and John F. Wilson. 2003.

221. Deflation: Determinants, Risks, and Policy Options, by Manmohan S. Kumar. 2003.

220. Effects of Financial Globalization on Developing Countries: Some Empirical Evidence, by Eswar S. Prasad, Kenneth Rogoff, Shang-Jin Wei, and Ayhan Kose. 2003.

219. Economic Policy in a Highly Dollarized Economy: The Case of Cambodia, by Mario de Zamaroczy and Sopanha Sa. 2003.

218. Fiscal Vulnerability and Financial Crises in Emerging Market Economies, by Richard Hemming, Michael Kell, and Axel Schimmelpfennig. 2003.

217. Managing Financial Crises: Recent Experience and Lessons for Latin America, edited by Charles Collyns and G. Russell Kincaid. 2003.

216. Is the PRGF Living Up to Expectations? An Assessment of Program Design, by Sanjeev Gupta, Mark Plant, Benedict Clements, Thomas Dorsey, Emanuele Baldacci, Gabriela Inchauste, Shamsuddin Tareq, and Nita Thacker. 2002.

215. Improving Large Taxpayers' Compliance: A Review of Country Experience, by Katherine Baer. 2002.

214. Advanced Country Experiences with Capital Account Liberalization, by Age Bakker and Bryan Chapple. 2002.

213. The Baltic Countries: Medium-Term Fiscal Issues Related to EU and NATO Accession, by Johannes Mueller, Christian Beddies, Robert Burgess, Vitali Kramarenko, and Joannes Mongardini. 2002.

212. Financial Soundness Indicators: Analytical Aspects and Country Practices, by V. Sundararajan, Charles Enoch, Armida San José, Paul Hilbers, Russell Krueger, Marina Moretti, and Graham Slack. 2002.

211. Capital Account Liberalization and Financial Sector Stability, by a staff team led by Shogo Ishii and Karl Habermeier. 2002.

210. IMF-Supported Programs in Capital Account Crises, by Atish Ghosh, Timothy Lane, Marianne SchulzeGhattas, Aleš Bulír Javier Hamann, and Alex Mourmouras. 2002.

209. Methodology for Current Account and Exchange Rate Assessments, by Peter Isard, Hamid Faruqee, G. Russell Kincaid, and Martin Fetherston. 2001.

Note: For information on the titles and availability of Occasional Papers not listed, please consult the IMF's Publications Catalog or contact IMF Publication Services. 
